\title{
Biomarkers in disease and health
}

\author{
F. Branca ${ }^{1}$, A. B. Hanley ${ }^{2}$, B Pool-Zobel ${ }^{3}$ and H. Verhagen ${ }^{4} \dagger$ \\ ${ }^{1}$ Istituto Nazionale di Ricerca per gli Alimenti e la Nutrizione, Via Ardeatina, 54600178 Rome \\ ${ }^{2}$ Central Science Laboratory, Sand Hutton, York YO41 1LZ, UK \\ ${ }^{3}$ Friedrich-Schiller-University-Jena, Faculty for Biology and Pharmacy, Dept of Nutritional \& Environmental Toxicology, \\ Institute for Nutrition \& Environment, Dornburger Str. 25, D-07743 Jena, Germany \\ ${ }^{4}$ TNO Nutrition and Food Research Institute, Utrechtseweg 48, PO Box 360, 3700 AJ Zeist, The Netherlands
}

\section{Contents}

1. Introduction (B. Hanley) $\quad$ S56

1.1. Types of biomarkers $\quad S 56$

1.2. Diet and health $\quad$ S57

2. Cancer (B. Pool-Zobel \& B. Hanley) $\quad$ S57

2.1. Introduction $\quad$ S57

$\begin{array}{ll}\text { 2.1.1. } \text { Cancer background } & \text { S57 }\end{array}$

$\begin{array}{ll}\text { 2.1.2. Cancer and diet } & \text { S58 }\end{array}$

$\begin{array}{lr}\text { 2.1.3. Biomarkers and cancer } & \text { S58 }\end{array}$

$\begin{array}{lr}\text { 2.2. Diet and cancer } & \text { S58 }\end{array}$

$\begin{array}{lr}\text { 2.3. Biomarkers and cancer } & \text { S59 }\end{array}$

$\begin{array}{lr}\text { 2.3.1. Directly predetermined susceptibility biomarkers } & \text { S60 }\end{array}$

$\begin{array}{lr}\text { 2.3.2. Susceptibility biomarkers - predisposing alteration } & \text { S60 }\end{array}$

$\begin{array}{lr}\text { 2.3.3. Biomarkers of early effect } & \text { S60 }\end{array}$

2.3.4. Biomarkers of exposure (risk and protective factors)

2.4. Cancers of specific organs $r$

$\begin{array}{lr}\text { 2.4.1. Stomach cancer } & \text { S64 }\end{array}$

2.4.2. Colon/rectal cancer $r$

$\begin{array}{lr}\text { 2.4.3. Breast cancer } & \text { S66 }\end{array}$

2.4.4. Conclusions $\quad$ S68

3. Coronary heart disease (B. Hanley \& H. Verhagen) $r$ S69

$\begin{array}{lr}\text { 3.1. Introduction } & \text { S69 }\end{array}$

$\begin{array}{lr}\text { 3.2. Causative and protective factors } & \text { S70 }\end{array}$

$\begin{array}{lr}\text { 3.2.1. Environmental factors } & \text { S70 }\end{array}$

$\begin{array}{lr}\text { 3.2.2. } \text { Genetic predisposition } & \text { S70 }\end{array}$

$\begin{array}{ll}\text { 3.3. Preventative action possible } & \text { S71 }\end{array}$

3.3.1. Primary markers $\quad$ S71

$\begin{array}{lr}\text { 3.3.2. Secondary effects } & \text { S73 }\end{array}$

$\begin{array}{lr}\text { 3.3.3. Maintenance } & \text { S73 }\end{array}$

$\begin{array}{lr}\text { 3.3.4. Other factors } & \text { S73 }\end{array}$

$\begin{array}{lr}\text { 3.4. Current biomarkers } & \text { S73 }\end{array}$

$\begin{array}{lr}\text { 3.4.1. Serum } & \text { S74 }\end{array}$

$\begin{array}{lr}\text { 3.4.2. } \text { Target organ } & \text { S74 }\end{array}$

Abbreviations: ACE, angiotensin converting enzyme; BMD, bone mineral density; BMI, body mass index; CHD, coronary heart disease; DXA, dual energy X-ray absorptiometry; GST, glutathione transferase; IL-6, interleukin-6; NAT2, $N$-acetyltransferase 2; NIDDM, non-insulin dependent diabetes mellitus; QCT, quantitative computed tomography.

* Corresponding author: Dr A. B. Hanley, Director of Research, C\&R Division, Leatherhead Food RA, Randalls Road, Leatherhead, Surrey, KT22 7RY UK, e.mail bhanley@1fra.co.uk

$\dagger$ Present address: Unilever Health Institute, Unilever Research Vlaardingen, PO Box 114, 3130 AC Vlaardingen, The Netherlands. 
3.5. Profile of effects of nutrient interventions $\quad$ S74

3.5.1. Antioxidant status
S75

3.5.2. Folate $\quad$ S75

3.5.3. Fat and lipids $\quad$ S75

3.5.4. Coronary heart disease and body mass index $\quad$ S76

3.5.5. Other interventions $\quad S 76$

3.6. Profile of disease damage $\quad$ S76

3.7. Conclusion S76

4. Osteoporosis (F. Branca) S76

4.1. Introduction $\quad$ S76

4.2. Preventative and causative factors $\quad \mathrm{S77}$

4.2.1. Genetic factors

4.2.2. Environnmental factors $\quad$ S77

4.3. Current biomarkers $\quad \mathrm{S78}$

4.3.1. Systemic S78

$\begin{array}{ll}\text { 4.3.2. Target organ } & \text { S78 }\end{array}$

4.4. Profile of effects of nutrient interventions $\quad$ S79

4.4.1. Calcium intake $\quad$ S79

4.4.2. Trace elements
S79

4.4.3. Dietary control of sex hormone metabolism $\quad$ S79

4.5. Study types $\quad \mathrm{S} 80$

5. Conclusion (B. Hanley) S80

Biomarkers have considerable potential in aiding the understanding of the relationship between diet and disease or health. However, to assess the role, relevance and importance of biomarkers on a case by case basis it is essential to understand and prioritise the principal diet and health issues. In the majority of cases, dietary compounds are only weakly biologically active in the short term, have multiple targets and can be both beneficial and deleterious. This poses particular problems in determining the net effect of types of foods on health. In principle, a biomarker should be able to contribute to this debate by allowing the measurement of exposure and by acting as an indicator either of a deleterious or of an enhanced health effect prior to the final outcome. In this review, the examples chosen - cancer (stomach, colon/rectal, breast); coronary heart disease and osteoporosis - reflect three major diet-related disease issues. In each case the onset of the disease has a genetic determinant which may be exacerbated or delayed by diet. Perhaps the most important factor is that in each case the disease, once manifest, is difficult to influence in a positive way by diet alone. This then suggests that the emphasis for biomarker studies should focus on predictive biomarkers which can be used to help in the development of dietary strategies which will minimise the risk and be of greater benefit.

Biomarkers: Health and disease: Stomach cancer: Colorectal cancer: Breast cancer: Coronary heart disease: Osteoporosis

\section{Introduction}

Biomarkers have considerable potential in aiding the understanding of the relationship between diet and disease or health since they can provide the link between the consumption of specific foods and biological outcome. It is essential, however, to first of all understand and prioritise the principal diet and health issues. The potential impact of the role, relevance and importance of biomarkers can then be made on a case by case basis. Such an understanding does not necessarily simply require an assessment of whole body response to specific compounds in foods. In many (if not most) cases, these compounds are only weakly biologically active in the short term, have multiple targets and can be both beneficial and deleterious. This poses particular problems in determining the net effect of types of foods on health. First of all, how much does a particular food or food component contribute to a specific health outcome compared with other dietary constituents and secondly how many of the parts of the totality of a disease or health outcome does a food impact upon. In principle, a biomarker should be able to contribute to this debate by allowing the measurement of exposure and by acting as an indicator either of a deleterious or of an enhanced health effect prior to the final outcome. This can be represented by an exposure-effect pathway culminating in a clinical endpoint in which biomarkers are measurements made on constituent parts of that pathway.

\subsection{Types of biomarkers}

Exposure to food chemicals can be measured in a variety of ways. Intake measurements based on food analysis and dietary intake tables have been proven to be a useful first 
step although the accuracy of food intake questionnaires is a source of potential error.

The measurement of specific excretion products either before or after metabolism reflects exposure. In some cases the presence of metabolites can be indicative of target organ exposure (e.g. metabolism by phase 1 and phase 2 enzymes in the liver). The presence of constituents in blood reflects systemic exposure and this in turn may be used to indicate the extent of target organ exposure based on animal and other model systems.

Once exposure has been established, the likely biological outcomes, which will result, can be estimated. These include diagnostic markers, which reflect a disease or health endpoint, and biological changes, which occur as a direct result of exposure to a specific dietary constituent. An example of the former would be the presence of nondividing trypomastigotes in the blood which would indicate systemic trypanosomiasis in an individual and occur together with a range of other clinical symptoms (e.g. low levels of certain hormones reflecting damage to endocrine glands and the presence of autoantibodies to heart and skeletal muscles). An example of the latter would be endocrine changes in premenopausal women, which occur as a consequence of ingestion of phytoestrogens (Cassidy et al. 1994, 1995).

Given the considerable difficulties in assessing the nature of the relationship between diet and health, it is important to try to develop an assessment framework. This framework is based upon:

- the strength of the relationship, i.e. is any link causal and mechanistically based or is it correlative;

- what are the most important human health issues in terms of morbidity, mortality and cost (social and economic).

In addition to these key questions, which provide the means to assess the importance and relevance of specific disease and health issues to food, there are a number of factors, which influence the nature of the link between diet and health and impact upon the use of biomarkers. These include:

- predisposition and susceptibility,

- predictivity,

- intervention/reversibility.

By consideration of these factors it will be possible to prioritise the specific diet/health issues and assess those biomarkers which are used to confirm the link between food and function.

Excretion can occur both pre- and postmetabolism. The effects measured may or may not be of relevance to a clinical endpoint. Biomarkers provide a link between exposure and effect.

\subsection{Diet and health}

Although the primary role of food is nutrition (including maintenance of well-being), other benefits including health effects have grown in importance. The non-nutritive benefits are in most cases, specific and have a basis in the activities of specific constituent chemicals. Much of the current interest in diet and health relates to longer-term consequences rather than pharmacological (overt) effects. Quantification of the proposed beneficial effects in these cases is much more difficult to carry out and a distinction must be made between causality and correlation.

A causal relationship between diet and health can be defined as one in which the chain of events, which link the ingestion of a given food with a defined biological endpoint, is established and the mechanism is known. A correlative relationship is one in which a health/disease endpoint appears to be related in some way to a given food, however the nature and extent of that relationship is unclear or not established.

There are various ways of validating a biomarker approach. These include population studies to demonstrate incidence ratio in distinct populations, mechanistic studies based on perceived modes of action and intervention trials to demonstrate efficacy.

Three major groups of diet-related diseases have been selected to illustrate the role(s) of biomarkers. These diseases are cancer, coronary heart disease and osteoporosis. It is not possible to determine, a priori, which of these is the most important in terms of the strength of the relationship between diet and health, however it is possible to make some estimate as to the cost of each of them in terms of morbidity, mortality and cost (social and economic). Each of the examples will consider predisposition and susceptibility, predictivity, intervention and reversibility as an integral part of the assessment of biomarker approaches.

\section{Cancer}

\subsection{Introduction}

2.1.1. Cancer background. Cancer is a multifactorial disease with a range of apparent causes (most significantly, perhaps, cumulative damage to DNA), a clear final endpoint (tumour formation) and several intermediate endpoints which relate, to differing extents of exposure and the disease. In general, as with most biomarker approaches, the closer the measured parameter is to a diagnostic assessment of the disease, the less firm the link is to dietary exposure and vice versa.

The mechanisms of cancer development commonly include the induction of alterations (mutations, amplification, and recombination) in proto-oncogenes, in tumour suppresser genes or in DNA repair genes. The accumulation of these alterations produces a clonal selection of cells with aggressive and invasive growth properties. Approximately $1 \%$ of all cancers is due to inheritance of these types of genetic alterations (Fearon, 1997a). Most other cancers carry multiple mutations, which are acquired in the respective somatic tissues during the lifetime. Some 20$60 \%$ of human tumours have been estimated to be diet related and are thus considered preventable either by removal of harmful factors or by incorporation of beneficial ones (Doll \& Peto, 1981; Doll, 1991, 1996). If biomarkers can be used to predict outcomes in response to dietary changes then they may be especially useful in the context of prevention of cancer. The term chemoprevention is used in pharmacology to describe the 'use of pharmacological or natural agents that inhibit the development of invasive 
cancer either by blocking the DNA damage that initiates carcinogenesis or by arresting or reversing the progression of premalignant cells in which such damage has already occurred' (Hong \& Sporn, 1997). Since this term encompasses the impact of dietary factors in the prevention of cancer; the modulation of diet can be considered to be a complex form of chemoprevention.

A recent report by the World Cancer Research Fund (WCRF, 1997) assessed the effects of diet on 10 major world cancers, ranked according to incidence. By far the most significant cancer in terms of incidence was lung cancer, however breast, colorectal, stomach and prostate cancers were also relatively common with incidences of 530 cases per 100000 . In terms of the significance of the effects of diet, the assessment suggested that up to $75 \%$ of cancers of the stomach and colon/rectum were preventable whereas the figure for breast cancer was $50 \%$ and that of lung cancer lower still at $33 \%$. Cancer of these organs are useful targets for consideration of a biomarker-based approach since they have a variable link to diet and can be monitored with different degrees of invasiveness.

2.1.2. Cancer and diet. Dietary intervention mainly aims at preventing cancer in healthy individuals (primary prevention). Chemoprevention is generally targeted towards active intervention either in already diseased individuals (secondary prevention) or in subjects who are of high risk due to specific disposition or exposure factors. The two approaches can be combined.

(1) In the intermediate stages of health and disease before tumour formation occurs, both dietary prevention and chemoprevention could be advantageous.

(2) A healthy diet can be advantageous for people already afflicted with the disease.

(3) Single agents may be of benefit for the general population and not only for afflicted patients or subjects at high risk.

In the case of dietary intervention, doses of individual compounds will be much lower, more repeated and will occur with a greater range of other protective and deleterious compounds than in chemoprevention. Dietary prevention is aimed at reducing exposure to known risk factors. Finally, the exposed group will include most if not all individuals, of a country, state, community, or city. This means in turn, that in order to assess efficacy of dietary intervention, a combination of biomarkers will be needed.

(1) Those which determine two types of effect:

- reduction of damage

- induction of protective processes,

(2) Those which determine two types of exposure:

- increase in protective factors

- decrease in risk factors

(3) Those which acknowledge several types of susceptibility:

- age

- $\operatorname{sex}$

- predisposing diseases
- immunological status

- predetermining and predisposing genetic alterations.

2.1.3. Biomarkers and cancer. Biomarkers for cancer may be specific for individual tumour types or may apply to most cancers, regardless of the target tissue. Self-evidently, these general or systemic biomarkers are of importance since the primary goal of research should be to prevent disease regardless of localisation. However, tissue-specific biomarkers may be chosen to learn more about the role of individual foods for cancers of certain organs (e.g. dietary fibre in the colon).

The most straightforward determination is to identify people already carrying the disease on the basis of having tumour cells in their body. These types of determination are of diagnostic value. In the context of diet and health, however, there is, as yet little persuasive evidence that dietary intervention may effectively alter aggressive tumour growth. Therefore, in this review, these types of determinations (also called tumour markers) will not be reviewed and attention will be directed to those parameters which may be measured before detectable manifestation of tumours, although it is obvious that a sharp line between non-transformed, altered, transformed, and malignant cells is not possible.

Since cancer is a multifactorial process that can be impacted by environmental factors at a number of points (Fig. 1), the opportunity to measure the impact of food and other environmental constituents occurs at a range of points in the process. Where precise mechanisms exist (for example activation or inhibition of phase 1 or phase 2 metabolic enzymes) then the role of individual constituents may be easier to ascertain. The challenge remains to provide plausible rationales whereby the parameter being measured is both indicative of the progression of the disease (or its precursor) and responsive to changes in exposure to the external factor.

\subsection{Diet and cancer}

Individual dietary factors may contribute to enhancing risks for certain cancers (Doll \& Peto, 1981). There are a large number of such factors and in many cases individual compounds have been suggested as being involved, but little definitive evidence is actually available in most cases.

In contrast, some foods are considered to be protective for several tissues. These include, most notably, vegetables and fruits. The numerous findings are exemplified by studies by Block et al. (1992) and Steinmetz \& Potter (1991) and in reviews by Hill (1994) and more recently by Potter \& Steinmetz (1996). Table 1 summarises some data presented for individual tissues. Additionally, Negri et al. (1991) have analysed the relative risk of consuming low, medium and high amounts of plant foods They found a reduced risk $(<0.5$ relative risk $)$ for high consumption of vegetable and fruit for several tissues. For seven of the 14 most frequent tumours, consumption of fruits and vegetables may decrease risk by varying levels of magnitude. Tissues, which seem to be most clearly protected are oesophagus, stomach, colon, lung, pancreas and bladder. The least clear-cut protection is 


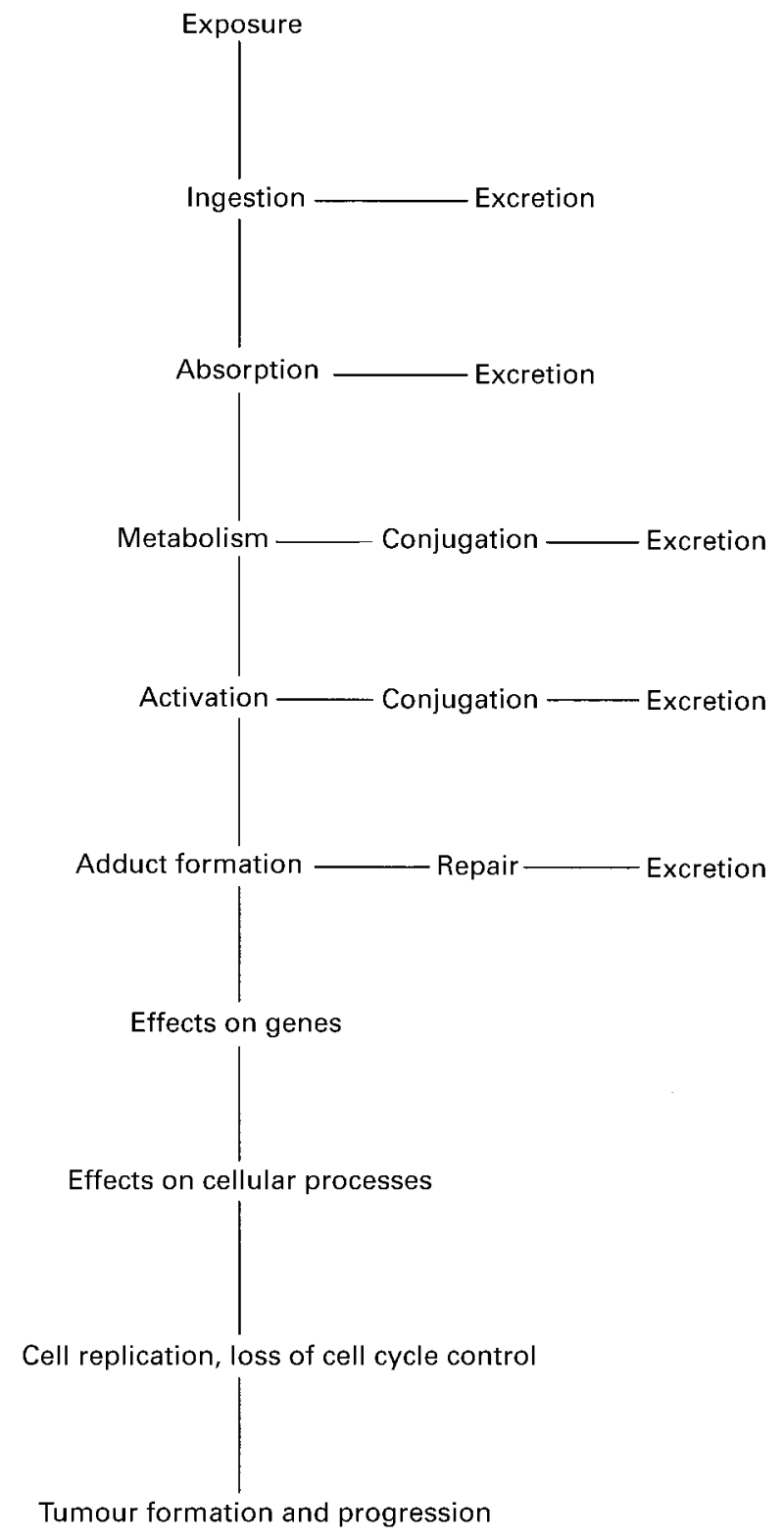

Fig. 1. The genotoxic approach to cancer.

achievable in the hormone-dependent tissues, prostate and breast, although a dietary component cannot be excluded for these tumours.

\subsection{Biomarkers and cancer}

Useful biomarkers for dietary chemoprevention may be divided into the following major categories.

(1) Susceptibility biomarkers, which are directly, predetermined: people at high risk, are those who carry genetic alterations (mutations, gene amplifications, or recombination) in cancer target genes (proto-oncogenes, tumour suppresser genes, and DNA repair genes). These may be divided into two categories, germ-line mutations and mutations in tumour target tissues (somatic genetic alterations).
Table 1. Summary of studies on the relative risk of cancer in relation to intake of fruit and vegetables reviewed by Steinmetz \& Potter (1991) (SP), Block et al. (1992) (B) and Potter \& Steinmetz (1996) (PS)

\begin{tabular}{|c|c|c|c|c|c|}
\hline Cancer site & Reviews & Total & Protection & No effect & Causal \\
\hline \multirow[t]{2}{*}{ Lung } & PS & 13 & 11 & 2 & 0 \\
\hline & $B$ & 25 & 24 & 1 & 0 \\
\hline \multirow[t]{2}{*}{ Colorectal } & SP & 14 & 11 & 2 & 1 \\
\hline & B & 27 & 20 & 4 & 3 \\
\hline Colon & PS & 19 & 15 & 4 & 0 \\
\hline Rectum & PS & 10 & 8 & 2 & 0 \\
\hline \multirow[t]{2}{*}{ Prostate } & PS & 5 & 0 & 5 & 0 \\
\hline & B & 14 & 4 & 8 & 2 \\
\hline \multirow[t]{2}{*}{ Breast } & PS & 13 & 9 & 4 & 0 \\
\hline & B & 14 & 8 & 6 & 0 \\
\hline \multirow[t]{2}{*}{ Pancreas } & PS & 9 & 7 & 2 & 0 \\
\hline & $B$ & 11 & 9 & 2 & 0 \\
\hline \multirow[t]{2}{*}{ Stomach } & PS & 31 & 28 & 2 & 1 \\
\hline & B & 19 & 17 & 1 & 1 \\
\hline \multirow[t]{2}{*}{ Oesophagus } & PS & 14 & 12 & 2 & 1 \\
\hline & B & 16 & 15 & 1 & 0 \\
\hline \multirow[t]{2}{*}{ Bladder } & PS & 5 & 4 & 1 & 0 \\
\hline & B & 5 & 3 & 2 & 0 \\
\hline
\end{tabular}

(2) Susceptibility biomarkers, which are predetermined: people who are potentially at higher risk carry frequent alterations in genes (genetic polymorphisms) which are indirectly related to the process of carcinogenesis. Increasing knowledge, about allelic variants or genetic defects in genes encoding carcinogen metabolising enzymes or receptors for pharmacologically active plant compounds has opened new possibilities for understanding susceptibility to cancer caused by environmental exposure. In addition, protective dietary factors could have different degrees of preventive impact in different individuals, depending on genetic composition. The SNP Consortium (www.snps.com) aims to map all human single nucleotide polymorphisms and to make the information available on the Internet. This may prove to have great significance in the determination of risk factors.

(3) Biomarkers of early effects in cells and tissues: genetic damage (DNA breaks, oxidative DNA damage, and genome instability) may result in an increased risk simply because increased DNA damage will enhance the likelihood of mutations occurring in critical target genes and cells. In addition to specific mutations, control of cell proliferation or apoptopic capability (intermediate endpoints) may provide measurable biomarkers. Their detection may indicate early steps of carcinogenesis and could be modulated unfavourably by risk factors or more positively by protective factors.

(4) Biomarkers of exposure (risk and protective factors): the detection of compounds associated with risk (e.g. carcinogens in food, reactive oxygen species, products of lipid peroxidation) or with cancer prevention (e.g. antioxidants, some fermentation products of the gut flora) are usually based on the causal associations derived from epidemiological data or on data from experimental systems (in vivo chronic animal bioassays, mutation assays with cultivated cells). Most of 
the evidence in this context is from whole food products or from dietary constituents (e.g. vegetables or fruits versus animal fats, meat or dietary fibre versus saturated animal fat) rather than for specific chemicals present in foods.

\subsubsection{Directly predetermined susceptibility biomar-} kers. These include the detection of genetic alterations such as mutations or amplifications, microsatellite instability in proto-oncogenes, tumour suppressor genes and DNA repair genes ( $K$-Ras2, Apc, p53, hMLH2 (colon), BrcAl and BrcA2 (breast), KRas2 (pancreas)). Studies have been carried out to map mutations from susceptible individuals from both target tissue (biopsy) and serum or plasma. One example is the immunological detection of normal and mutant forms of the step 53 protein (Sarhanis et al. 1996) or mutations in the p53 coding regions by two-dimensional gene scanning (Rines et al. 1998). These and other studies are referred to later (Tables 6 and 9).

2.3.2. Susceptibility biomarkers: predisposing alterations. These include the genetic polymorphisms for xenobiotic activating enzymes (usually oxidation reactions, phase 1 enzymes) and genetic polymorphisms for inactivating enzymes (which usually catalyse conjugation reactions, phase 2 enzymes). They will determine the extent of endogenous chemoprotection against genotoxic risk factors in humans. The development of techniques such as polymerase chain reaction partially coupled to restriction fragment length polymorphism methods enable precise identification of an individual's genotype. Specifically, genes coding for the activating super enzyme family, cytochrome $p 450$ isoenzymes, have been identified in several allelic variants (IARC, 1999). For nutritional toxicants (e.g. heterocyclic amines) slow and fast acetylating genotypes based on different allelic variants of $\mathrm{N}$-acetyltransferase 2 (NAT2) may be of specific importance (Smith et al. 1995; Bartsch \& Hietanen, 1996; d'Errico et al. 1996). These genetic variants may be associated with either enhanced or decreased metabolic conversion by the enzyme. Depending on the type of metabolic conversion (activation, deactivation), the result will be more or less organ exposure to activated genotoxins and thus variation in cancer risk. Studies aimed at finding an association between cancer risk and genetic polymorphisms have been carried out in patient groups afflicted with specific tumours (e.g. lung, breast, colon, bladder and stomach). A recent review of the literature presents a meta-analysis of the multiple available studies (d'Errico et al. 1996) and other reviews (Smith et al. 1995; Bartsch \& Hietanen, 1996) discuss specific aspects of individual cancers. Studies directed at assessing the impact of nutrition on differently susceptible individuals are increasingly beginning to appear and some examples are presented in Tables 2 and 3.

2.3.3. Biomarkers of early effect. The accumulation of DNA breaks, oxidative DNA damage, micronuclei and DNA adducts (e.g. in blood lymphocytes) may be indicative of an increased risk. Increased DNA damage will enhance the probability of mutations occurring in critical target genes and cells, and/or that increased DNA damage is the result of a higher load of genotoxic agents which will enhance the process of carcinogenesis (by inducing DNA damage as well as other molecular processes thought to be involved in carcinogenesis). The damage may be detected in peripheral blood lymphocytes or as excretion products in urine or plasma. In a few cases detection is also possible in tumour target tissues or in tissue-associated specific fluids (e.g. colon biopsies or faeces, exfoliated bladder cells or urine). All of these are on the border between biomarkers of exposure and biomarkers of effect since, although DNA damage has a biological consequence, the link between a certain type or level of damage and the disease outcome is tentative.

Numerous papers are available in which technique for measuring DNA damage and adduct formation is described. These include papers on ${ }^{32} \mathrm{P}$ postlabelling (Beach \& Gupta, 1992), DNA-adducts (Haseltine et al. 1983; Schut \& Shiverick, 1992), microsatellite alterations (Mao et al. 1994), mutagen hypersensitivity (Olden, 1994), micronuclei in lymphocytes (Fenech \& Rinaldi, 1995), chromosomal aberrations, blastogenesis and proliferative rate index (Anderson et al. 1988), human somatic mutations (Compton et al. 1991) and various types of oxidative damage in peripheral blood lymphocytes or in urine and sputum. The influence of diet on such markers has been studied sporadically. Reported examples include higher levels of 5-HO-methyl uracil in the urine of individuals on a high fat diet (Djuric et al. 1991), modulation of DNA adducts of malondialdehyde by diets with different fatty acid composition (Fang \& Vaca, 1997) and reduction of oxidative DNA damage by moderate wine consumption (Fenech et al. 1997a) and consumption of Brussels sprouts (Verhagen et al. 1995, 1997). Recently the adequate consumption of carotenoid-containing vegetable juices (Pool-Zobel et al. 1997) or intake of vitamins as dairy supplements (Duthie et al. 1996) have been shown to reduce oxidative damage of blood lymphocyte DNA. In contrast, the comparison of vegetarian with non-vegetarian life styles did not show differences in genetic damage in lymphocytes, detected as micronuclei (Fenech \& Rinaldi, 1995). Tables 2 and 3 summarise how some of these studies have been able to predict or confirm the epidemiological associations of diet and specific cancers.

Parameters associated with the impaired functions of somatic cells have been used as biomarkers. These events, such as enhanced cell proliferation or modulation of apoptosis, are also termed 'intermediate endpoints' (Lippman et al. 1990). Numerous methods may be applied, such as determination of mitotic crypt indices, proliferating nuclear antigen, uptake of bromodeoxyuridine or $\left[{ }^{3} \mathrm{H}\right]$ thymidine for proliferation (Richter et al. 1992) or DNA laddering, nucleic condensation, DNA breaks, or membrane changes for apoptosis (Corcoran et al. 1994). Reviews have appeared on possible alterations that could also be predictive as a result of in vitro studies or controlled chemopreventive and dietary prevention studies (Sharma et al. 1994; Kim \& Mason, 1996; Perera, 1996). Tables 2 and 3 show specific examples on how these alterations may relate to associations between cancer risks and diet in the human.

Finally, xenobiotics may exert an effect by the modulation of phase 1 and phase 2 enzymes in both predisposed and normal individuals. Thus, the dietary induction of glutathione transferases (GSTs) may be considered a protective mechanism whereas the induction 
of cytochrome $p 450$ enzymes is generally associated with increased risk, due to the greater metabolic activation of carcinogens (Goldin \& Gorbach, 1984; Kall et al. 1997; Stillwell et al. 1997). Induction or repression of these enzymes or changes in gene expression patterns, however, must occur within the cells of the tumour target tissue (Zhang et al. 1997) since that is the site of biological action. The use of a surrogate measure in a more readily accessible body constituent may provide evidence of tissue-specific effects, however the results from this approach are open to different interpretations. The detection of GSTs or other proteins in plasma may be indicative of toxicity and could result from enzyme leakage from remote, damaged cells (e.g. from the liver) with defective membranes (Fan et al. 1996). However, it is more generally recognised that a preferential induction of phase-2 enzymes, such as monitored from increased levels of GSTs in plasma, is indicative of protective rather than toxic effects (Bogaards et al. 1994; Nijhoff et al. 1995; Verhagen et al. 1997; van Iversen et al. 1999). Another possibility is to determine enzymes in peripheral lymphocytes or in fluids which are associated with specific tissues, as has been done for GST or alcohol dehydrogenase in saliva (Sreerama et al. 1995) and GST in lymphocytes (Nijhoff et al. 1995; Szarka et al. 1995; Duthie et al. 1996; Pool-Zobel et al. 1999). It should be noted, however, that metabolism of mutagens is relatively far removed from the final disease state (see Section 2.1) and modulation of phase 1 and phase 2 enzymes cannot generally be considered to be directly predictive of risk unless it can be demonstrated in a mechanistic way that modulation of xenobiotic metabolism is directly related to tumour formation (van Iversen et al. 1999).

2.3.4. Biomarkers of exposure (risk and protective factors). Individual dietary ingredients may have specific pharmacological effects. In contrast to clinical chemoprevention, dietary intervention will result in the ingestion of a large number of bioactive constituents - both harmful and protective. Biomarkers to determine exposure both to risk factor and to protective factors will be needed. The biological role of the dietary constituents must be determined and the biomarker should help to define this. The biomarker may be tissue specific or systemic. Some examples of non-tissue specific biomarkers are the detection of DNA reactive metabolites (Arif \& Gupta, 1997), mutagenicity of urine samples (Hayatsu et al. 1985; Perera \& Whyatt, 1994), excretion of nitroso compounds in the urine (Wu et al. 1993), malondialdehyde DNA-adducts (Fang et al. 1997) and malondialdehyde plasma levels (Nielsen et al. 1997). Several reviews on exposure monitoring have appeared (Ashby, 1988; Rosner et al. 1991; Schut \& Shiverick, 1992; Perera \& Whyatt, 1994). Tables 2 and 3 show some examples of their application in nutritional studies. Many of these are exposure rather than effect biomarkers and it can be difficult to correlate an exposure with a defined clinical endpoint even if information on bioavailability, metabolism, tissue levels and excretion profiles is available (Benford et al. 2000).

\subsection{Cancers of specific organs}

As noted previously, from the standpoint of mortality, the 
Table 3. Dietary factors which may decrease tumour risk (WCRF, 1997) in specific target organs

\begin{tabular}{|c|c|c|c|c|c|}
\hline Dietary factor & Target tissue & Risk component & Biomarker of exposure & Biomarker of effect & Biomarker of susceptibility \\
\hline Energy and related factor & $\begin{array}{l}\text { Colon } \\
\text { Lung } \\
\text { Breast }\end{array}$ & $\begin{array}{l}\text { Optimal regulation of } \\
\text { physiological function }\end{array}$ & $\begin{array}{l}\text { Activity associated with } \\
\text { antioxidant enzymes } \\
\text { (Ortenblad et al. 1997) }\end{array}$ & & \\
\hline \multirow[t]{5}{*}{ Carbohydrates } & $\begin{array}{l}\text { Colon } \\
\text { Rectum }\end{array}$ & Starch & $\begin{array}{l}\text { Resistant starch lowers faecal } \\
\text { concentrations of ammonia } \\
\text { and phenols (Birkett et al. 1996) }\end{array}$ & & \\
\hline & $\begin{array}{l}\text { Pancreas } \\
\text { Colon } \\
\text { Rectum } \\
\text { Breast }\end{array}$ & $\begin{array}{l}\text { Non-starch polysaccharide/ } \\
\text { fibre }\end{array}$ & $\begin{array}{l}\text { Lowered faecal bile salts } \\
\text { with increased consumption } \\
\text { of cereal/wheat bran } \\
\text { (Alberts et al. 1996) }\end{array}$ & $\begin{array}{l}\text { Reduction in rectal cell } \\
\text { proliferation with increased } \\
\text { cereal/wheat bran consumption } \\
\text { (Alberts et al. 1990) }\end{array}$ & $\begin{array}{l}\text { Reduced risk for neoplastic polyp } \\
\text { recurrence in women but not men } \\
\text { on a low fat/high fibre diet } \\
\text { (McKeown-Eyssen et al. 1994) }\end{array}$ \\
\hline & Stomach? & & $\begin{array}{l}\text { Low fat/high fibre diet modulates } \\
\text { fatty acid composition in breast } \\
\text { ductile fluid (Rodenhuis, 1997). }\end{array}$ & & \\
\hline & $\begin{array}{l}\text { Colon } \\
\text { Rectum }\end{array}$ & Resistant starch & $\begin{array}{l}\text { Increased faecal short-chain } \\
\text { fatty acids following intervention } \\
\text { (Van Munster et al. 1994) }\end{array}$ & $\begin{array}{l}\text { Protective fermentation profile } \\
\text { and reduced colon cell } \\
\text { proliferation following intervention } \\
\text { (Van Munster et al. 1994) }\end{array}$ & \\
\hline & $\begin{array}{l}\text { Lung } \\
\text { Oesophagus } \\
\text { Colon } \\
\text { Rectum } \\
\text { Stomach } \\
\text { Breast } \\
\text { Bladder? }\end{array}$ & Carotenoids & & $\begin{array}{l}\text { Reduction in DNA damage in } \\
\text { lymphocytes, GSTp and total } \\
\text { protein increased } \\
\text { (Pool-Zobel et al. 1997, 1998) }\end{array}$ & $\begin{array}{l}\text { Genetic enzyme polymorphisms } \\
\text { in subjects (GSTM1, GSTT1, } \\
\text { GSTP1-variants) (Pool-Zobel } \\
\text { et al. 1998) }\end{array}$ \\
\hline \multirow[t]{4}{*}{ Vitamins/minerals } & $\begin{array}{l}\text { Stomach } \\
\text { Oesophagus } \\
\text { Lung } \\
\text { Pancreas } \\
\text { Colon? } \\
\text { Rectum? } \\
\text { Breast? }\end{array}$ & Vitamin C & & & \\
\hline & $\begin{array}{l}\text { Lung } \\
\text { Colon? } \\
\text { Rectum? }\end{array}$ & Vitamin E & & $\begin{array}{l}\text { Intervention with vitamin E had } \\
\text { no effect on damage in human } \\
\text { lymphocytes (Fenech et al. 1997b) }\end{array}$ & \\
\hline & $\begin{array}{l}\text { Colon? } \\
\text { Rectum? }\end{array}$ & $\begin{array}{l}\text { Folate } \\
\text { Methionine }\end{array}$ & & $\begin{array}{l}\text { Micronuclei index is enhanced in } \\
\text { older men deficient in } \\
\text { homocysteine folate and vitamin } \\
\mathrm{B}_{12} \text { (Fenech et al. 1997a) }\end{array}$ & \\
\hline & $\begin{array}{l}\text { Colon? } \\
\text { Rectum? }\end{array}$ & Vitamin D & & & $\begin{array}{l}\text { Genetic polymorphisms for } \\
\text { vitamin D receptor linked to } \\
\text { prostate cancer risk (Ingles et al. } \\
\text { 1997; Feldman, 1997) }\end{array}$ \\
\hline
\end{tabular}


Bioactive constituents Stomach S-Alk(en)yl L-cysteine

sulphoxides from Allium

Breast? Isoflavonoids

Prostate? Lignans

Cereals (grains) Stomach Whole grain

Colon?

Oesophagus

Lung

Stomach

Pancreas

Breast

Bladder

Colon
Rectum

Prostate?

Vegetables

$\begin{array}{lll}\begin{array}{l}\text { Meat, poultry } \\ \text { fish and eggs }\end{array} & \text { Breast? } & \text { Fish } \\ \text { Others } & \text { Various } & \begin{array}{l}\alpha \text {-Tocopherol } \\ \beta \text {-Carotene } \\ \text { Retinol }\end{array} \\ & & \begin{array}{l}\text { Catechins } \\ \text { Pre/probiotics }\end{array} \\ \begin{array}{l}\text { Fermented milk } \\ \text { products } \\ \text { (not specified in }\end{array} & \text { Colon? } & \begin{array}{l}\text { Calcium } \\ \text { WRCF, 1997) }\end{array} \\ & & \begin{array}{l}\text { Mono-unsaturated } \\ \text { fatty acids }\end{array}\end{array}$

\section{Dietary fish oil exposure caused}

lower excretion of 4-cholesten-3-one

(Bartram et al. 1996)

Catechins found in plasma after ingestion of tea (Yang et al. 1998)

Heterocyclic amines excretion

lowered (Hayatsu \& Hayatsu, 1994;

Lidbeck et al. 1992) but no effect on

fermentation profile (Bartram et al. 1994)

after ingestion of yoghurts.

'positive' fermentation

profile claimed after investigation

(Ling et al. 1994)

selenium is associated with GST $\mu$

genotype (Cheng et al. 1995)

Genetic polymorphism for taste may affect consumption (Akella et al. 1997)

Metabolism to produce equol may be variable (Kelly et al. 1995)

No difference in lymphocytes between vegetarians (Fenech \& Rinaldi, 1995) Broccoli and Brussels sprouts affect metabolism of xenobiotics (McDanell

et al. 1989; Kall et al. 1997)

High urinary excretion of

8-oxoguanosine associated

with high vegetable consumption

(Hertog et al. 1997)

Excretion of oxidised DNA bases in

urine decreased after consumption

of Brussels sprouts (Verhagen et al.

1995) and increase of GSTp in

rectum cells and in lymphocytes

(Nijhoff et al. 1995)

Fish oil in normal and low-fat

diet (but not high fat) decreases

rectal cell proliferation (Bartram

et al. 1995)

$\beta$-carotene did not alter colonic cell

proliferation in patients with history

of colonic polyps or cancer

(Frommel et al. 1995)

High Ca intake associated with decreased risk of K-RAS mutation in tumours and high

monounsaturated fatty acids

appeared to be linked to lowered isk for wild type k-RAS tumours (Bautista et al. 1997) 
most important cancers in Europe are lung, breast, stomach and colon/rectum. Of these, the last three appear to have a strong link with diet (WCRF, 1997) and they will, therefore, be considered separately.

\subsubsection{Stomach cancer}

Incidence. The incidence of stomach cancer has declined recently but it remains significant, with deaths ranging from $41 \cdot 1 / 100000$ in the Russian Federation to $7 \cdot 1 / 100000$ (males) in Denmark and 3·3/100 000 (females) in France (Levi et al. 1995).

Genetic factors. There are a number of genetic factors that appear to predispose the individual to stomach cancer. These include over expression of human epidermal growth factor 2 (HER2) and abnormal expression of P-cadherin. In addition, mutations in $p 53, k$-Ras and $r b l$ appear either as late events or in low frequency (Hesketh, 1997). Both causative and protective factors have been identified in the diet with the former including high salt consumption, salted and smoked foods, alcohol and high levels of carbohydrates and starchy foods. The role of nitrosamines in the incidence of stomach cancer remains unproven although there is considerable information concerning the possibility of formation of nitrosamines in the stomach and their apparent carcinogenicity in animal models (Bartsch \& Hietanen, 1996; Bartsch, 1991).

Protective factors and risk factors. A range of dietary components has putative protective properties against stomach cancer. Most involve fruit and/or vegetable consumption and twenty-eight of these have been reviewed by Potter \& Steinmetz (1996). Green tea and diets high in whole grain, cereals and carotenoids have also been implicated (WCRF, 1997). In the case of compounds from the genus Allium, a range of S-containing products is formed after crushing (Fenwick \& Hanley, 1985) and these could scavenge reactive intermediates in the gastric lumen.

Both Helicobacter pylori infection and exposure to nitrosating agents may be risk factors for stomach cancer although further work is necessary to confirm the precise nature of their role (Bartsch, 1991; Munoz, 1994).

Available biomarkers. There are comparatively few biomarkers for exposure, effect or susceptibility for stomach cancer. There are, however a number of diagnostic markers which appear to reflect different stages of the disease process. Most of these require biopsy material and hence are both very invasive, and not predictive.

A number of cellular parameters have been found to correlate with the early stages of gastric cancer or with predisposition. These include the constitutional deletion of the short arm of chromosome 18 (Delavecchia et al. 1999), the presence of p53 antibodies in serum (Nakajima et al. 1999) and serum pepsinogen concentration (Kitahasu et al. 1999).

2.4.2. Colon/rectal cancer. As with stomach cancer, a high proportion of cancers of the colon and rectum are considered to be influenced (or able to be influenced) by diet (WCRF, 1997). There is considerably more information available regarding colorectal cancer than for many other types of cancer therefore this part of the review is divided into subsections dealing with current disease status and molecular mechanisms, dietary interactions, biomarkers and further research needs.
Mortality and incidence rates in Europe (Levi et al. 1995). Age-standardised death certification rates for cancers of the intestines (mainly colon and rectum) are highest in the Czech Republic with 37.7/100 000 for males and 20.6/100 000 for females. The lowest rates have been recorded in Greece with 8.6/100000 for males and in Krygizstan 7.2/100000 for females. The mean rates in Europe are 21.5/100000 for males and 14.3/100000 for females with mean incidence rates ( $\%$ of all tumours) of 11.9 (males) and 11.3 (females). Colon tumours rank in second place (behind lung) in terms of frequency and incidence for men and woman (WCRF, 1997).

Major types of diseases. Colorectal cancers are mainly adenomatosis-polyposis carcinoma, hereditary non-polyposis colon cancer, rectal adenocarcinoma and epidermoid carcinoma of the anal region (Kuroda et al. 1990).

Genetic mechanisms. Damage to a number of genes has been specifically linked to colorectal cancer. These include K-Ras2 (12p), Apc (5q), Mcc, Dcc (18q), p53 (17p), whereas abnormal expression of other genes may also occur. The alterations accumulate over a number of years and it may take decades for the development of a malignant carcinoma (Fearon \& Vogelstein, 1990) (Fig. 2). This increases the possibility that intervention mechanisms could prevent or delay the onset of such genetic alterations (Burnouf et al. 2000).

One of the two inherited cancer syndromes which afflict the colon is 'familial adenomatous polyposis' (FAP) and is caused by a germ-line mutation in APC (5q21) (Soravic et al. 1997). The second major group of inherited familial cancer syndromes of the colon is hereditary non-polyposis colon cancer (HNPCC) which involves mutations in MSH2 (2p16), MLH1 (3p21), PMS1 (2q32) and PMS2 (7p22). These mutations lead to microsatellite instability and deficiency in DNA mismatch repair (Whitehouse et al. 1998). In addition, mutations have been detected in APC and p53, following loss of functional MSH2 (Hesketh, 1997). These genetically inherited forms are roughly calculated to contribute to $5 \%$ of all colon cancer cases; in addition, there are familial cancers which have not been associated with a known mutation. Thus approximately $15-$ $20 \%$ of colon cancers are inherited.

Causative and protective dietary factors. Factors that increase risk and reduce risk for colorectal cancer have been identified. Even for people carrying predetermining genes, the onset of disease could be influenced by dietary factors, due to the long latency period between the first mutation and the development of a metastatic carcinoma.

Epidemiological evidence has suggested that high meat, high fat intake could increase the risk in cross-sectional comparisons. High meat, protein and fat consumption, as well as a low consumption of fibre and fibre-containing foods have been connected to a higher risk in case control studies (Levi et al. 1999). The role of high meat consumption is still controversial, however, since this association has only been found in studies from the USA but not from Europe (Ashwell, 1997; Parnaud \& Corpet, 1997). High triacylglycerol levels and alcohol consumption have been implicated in contributing to the aetiology of the disease (Manus et al. 1997). There is some experimental evidence which supports the role of meat and fats in 


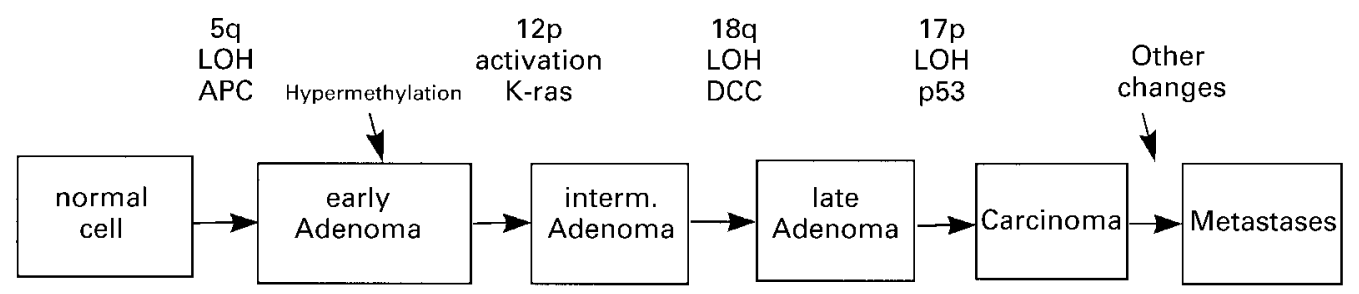

Fig. 2. Sequence of genetic alterations leading to colon cancer in humans (Fearon and Vogelstein, 1990).

epidemiological studies (Erhardt et al. 1998; Pence et al. 1998; Jansen et al. 1999). Nitrate and red meat intake can lead to enhanced formation of nitroso compounds which have been associated with increased risk of colorectal cancer (Knekt et al. 1999). Cooking, pan frying and grilling of meat also causes the formation of mutagens or carcinogens (heterocyclic amines, polycyclic aromatic hydrocarbons) (Augustsson et al. 1999). The presence of iron may lead to an increase in the production of reactive oxygen species from peroxides via the Fenton reaction and oxidative stress leads to cell damage including mutations (Reddy, 1995; Bingham, 1996, 1997; Johnson, 1997; Gooderham, 1997; Sawa et al. 1998). Some of these carcinogens and oxidants will be formed in the colon, they may arrive there directly with the ingested food, or after first pass metabolism by the liver via bladder or bile. They may be retained there for hours, depending on the stool transit time.

Epidemiological evidence is available for protective diets. In particular, vegetables (and physical activity) have been shown to reduce risk in cross-sectional comparisons. Vegetables are protective for colorectal cancers in retrospective case-control studies (11 of 14 and 20 of 27 studies in Table 1). When differentiating between colon cancer and rectal cancer, 11 of 15 (colon) and 8 of 13 (rectal) studies find inverse relationships between cancer and vegetable and fruit consumption (Potter \& Steinmetz, 1996). Cruciferous vegetables may be especially effective. Cohort studies are ongoing. Non-starch polysaccharides (fibre), starch and carotenoids possibly decrease risk, whereas the evidence for an effect by resistant starch is insufficient at present (WCRF, 1997; Wijnands et al. 1999).

The experimental evidence for protective properties of dietary factor in the colon includes intervention studies with calcium (Cats et al. 1995), antioxidant vitamins and fibre, mostly in patients with adenomatous polyps. In vivo supplementation or in vitro treatment with calcium has led to a decreased proliferation (Lipkin et al. 1996) however, these studies largely failed to result in a reduced recurrence of the disease (Faivre et al. 1996; Boutron et al. 1996). More basically, beneficial functions of specific bacterial strains of the gut flora, fermentation of fibre, starch and subsequently the protective effects of fermentation products (e.g. butyrate) support the assumption that ingredients or metabolites of plant foods may in some way prevent initiation, of cancer cell progression in the colon (Cats et al. 1995; Cummings et al. 1996).

Available biomarkers and performance criteria. There are a number of biomarkers for risk factors and protective factors. Assessment of a number of risk factors and protective factors is possible by collection and analysis of the faeces. Thus, the measurement of bile acids (Breuer et al. 1985), short-chain fatty acids (McIntyre et al. 1993; Cummings et al. 1996), gut flora composition (Gibson \& Roberfroid, 1995), dietary mutagens and oxidants (Johansson et al. 1992; Macfarlane et al. 1986), nitroso compounds (Rowland et al. 1991; Bingham et al. 1996), and the activities of bacterial enzymes (e.g. $\beta$-glucuronidase, $\beta$ glycosidase, azoreductase and nitroreductases) (Mallett \& Rowland, 1990) all give some indication of the situation directly prevailing in the colon. Two interesting newer approaches are the determination of faecal mutagenicity with colon cells instead of bacterial cells (Venturi et al. 1997), and the determination of oxidative stress in the faeces (Owen et al. 1996). A 'positive' fermentation profile is expected to reduce the exposure of colonocytes to carcinogenic compounds thereby lowering the risk of disease development.

Some biomakers are early markers of disease (effect). Colon biopsies can yield isolated macromolecules (DNA, proteins, lipids), single cell suspensions, individual colon crypts or whole tissue specimens for histological investigations. Proliferation can be determined in colon crypt cells (Lipkin, 1987). The analysis of crypts allows the localisation of cells with more or less proliferative activity, thus enabling not only tissue specific but also cell specific detection. Similarly, the immunhistological detection of altered DNA or other cellular parameters (Albaugh et al. 1992), GST (Nijhoff et al. 1995) or CYP1A2 activities (Sinha et al. 1994), rate of apoptosis, k-ras amplification or mutations (Burmer et al. 1991), p53 deletions (Nelson, 1997) or microsatellite instability in tissue sections (Loeb, 1994; Anker et al. 1997) may also be used. The use of exfoliated cells for determining parameters may have great potential for biomarker development in the future. One example is the detection of predetermining mutations in k-ras (Villa et al. 1996) or total DNA content (Loktionov et al. 1998) as parameters in these cells.

Despite the large range of parameters, which have been measured, there are no markers, which are completely predictive of future tumour formation. Further work is necessary to define the role of each of the criteria measured by the various markers in the mechanism of the disease process (Benford et al. 2000).

There are three special markers of susceptibility: genetic factors; genetic polymorphisms for xenobiotic metabolism and gender.

Predetermining germ-line alterations which may lead to colon cancer affect the genes $A p c, D c c, h M L H 2$ and $h M S H 1$. Additionally, somatically arising alterations occur 
in K-Ras2, p53 and others. K-Ras2 mutations and amplifications have been detected in biopsies of colon tissue and in faeces and serum (Table 4). It has been reported that high consumption of olive oil is associated with a decrease in the risk of cancer in wild-type K-Ras genotypes (Bautista et al. 1997). On the other hand, high calcium intake is associated with a decreased risk of K-Ras mutated tumours but not with a decrease of K-Ras wild-type tumours (Yarborough et al. 1996). This may indicate, that calcium and olive oil, respectively, protect against different type of colon cancer risk factors.

Several case-control studies have been performed to reveal associations between glutathione transferase (GST) polymorphisms and colon cancer risk. Some of these studies showed no significant associations, e.g. for GSTMI*0 (Lin et al. 1995), GSTT1*0 (Chenevix-Trench et al. 1995), or the trends that were observed were not significant, e.g. for GSTM1*0 (Katoh et al. 1996), other studies showed apparently significant associations, e.g. for $G S T T 1 * 0$ (Deakin et al. 1996), for CYP1A1-MSP1 mutation in exon 7 for Japanese (Sivaraman et al. 1994), for GSTMI*0 (Zhong et al. 1993), or for patients with ulcerative colitis (Duncan et al. 1995). The meta-analysis (d'Errico et al. 1996) of six further case-control studies in colorectal cancer patients, reported an odds ratio of 1.67 in Caucasians and 0.84 in Asians for rapid versus slow acetylators (the slow phenotype was associated with a protective effect). Carcinogenic heterocyclic amines from heavily cooked meats are metabolised by the enzymes $N$-acetyltransferase (NAT) and CYP1A2 giving activated products which bind to DNA. In slow acetylator genotypes, the lowered capacity to produce activated products may provide an explanation for the odds ratios indicated above. The methodology used for measurement of NAT phenotypes has recently been critically evaluated and found to be lacking in statistical power in many cases. This has led to a lack of proven association between acetylator genotype or phenotype and colorectal cancer (Brockton et al. 2000).

No differences between men and women have been found for associations of decreased colon cancer risk and increased vegetable and fruit consumption (reviewed in Potter \& Steinmetz, 1996). However, in one study, women on a low fat/high fibre diet had a reduced risk for neoplastic polyp recurrence and reduced concentrations of faecal bile acid concentrations, whereas men did not (McKeownEyssen et al. 1994). In cells isolated from colon biopsies, females had fewer DNA strand breaks than males and males had significantly more oxidised bases than females (PoolZobel et al. 1999)

Further research needs. Several intervention studies have been performed to investigate the ability of fat, red meat, fibre, alcohol, fruit and vegetables to modulate colorectal carcinogenesis. According to a review of recent, in part still ongoing, human studies, folate, selenium and $\omega$-3 fatty acids appeared to be important agents in nutrition chemoprevention, whereas antioxidant vitamins and calcium gave equivocal results (Kim \& Mason, 1996). In these studies, the endpoint was recurrence of adenoma or colorectal cancer. Adenoma as an endpoint is invasive and requires very large numbers of subjects (several hundreds or thousands) for statistical evaluation. Other intermediate biomarkers directed at earlier stages of carcinogenesis are needed. In addition new specific, but non-invasive, markers need to be developed. These must be underpinned by a mechanistic understanding of the carcinogenesis process.

2.4.3. Breast cancer. Although the popular perception of breast cancer is that it is a female disease, it also occurs in males. Much of the interest in diet and breast cancer relates to phytoestrogens but a number of other components have also been implicated.

Mortality and incidence rates in Europe (Levi et al. 1995). Age-standardised death certification rates for cancers of the breast have shown the highest rates to occur in Iceland: 29.0/100000 (females), whereas the lowest rates have been recorded in Krygizstan: 8.7/100 000 (females). Mean rates in Europe are 28.4/100 000 (females) and the mean incidence rates (\% of all tumours) in Europe are 22.5 (females).

Genetic mechanisms. The over-expression of epidermal growth factor genes (amphiregulin and cripto-1) and the family of genes for epidermal growth factor receptors (EGFR, HER2-4) have been detected in breast tumours (Panico et al. 1996; Kondapaka et al. 1997). Also amplification of the proto-oncogene MYC and abnormally high over-expression of cyclin D1 and/or cyclin D3 are risk factors and indicators of poor prognosis (Cuny et al. 2000). Over-expression of HSTF1, INT2, HRAS, p53, RB1 and YES1 also occur with low frequency in this disease (Hesketh, 1997). Inheritance of germ-line mutations is responsible for approximately $5-10 \%$ of all breast cancer cases. These include mutations in BRCA1 or BRCA2, p53 (Li Fraumeni-Syndrome), alterations of a gene on

Table 4. Experimental investigations aimed at detecting alterations of K-RAS2 as a diagnostic marker or as a biomarker for colon cancer

\begin{tabular}{|c|c|c|c|}
\hline Analysis of k-ras & Biological sample & Major result & Reference \\
\hline Mutations & Numerous colon tumours & $\begin{array}{l}4-100 \% \text { of samples } \\
\text { with alterations }\end{array}$ & Review in Nelson (1997) \\
\hline Mutations in codon 12 & $\begin{array}{l}\text { Aberrant crypt foci in largely } \\
\text { normal mucosa }\end{array}$ & $73 \%(11 / 15)$ with mutations & Pretlow et al. (1993) \\
\hline Mutations & $\begin{array}{l}\text { DNA isolated from stool of } \\
\text { cancer patients }\end{array}$ & $\begin{array}{l}89 \%(8 / 9) \text { samples with } \\
\text { mutations }\end{array}$ & $\begin{array}{l}\text { Mao et al. (1994); Sidransky et al. } \\
\text { (1992) }\end{array}$ \\
\hline $\begin{array}{l}\text { Amplification and } \\
\text { mutation }\end{array}$ & $\begin{array}{l}\text { DNA isolated from stool of } \\
\text { patients submitted for diagnostic } \\
\text { colonoscopy }\end{array}$ & $\begin{array}{l}44.8 \%(103 / 230) \text { with amplifications; } \\
\text { of these } 30 \%(30 / 103) \text { with mutations }\end{array}$ & Villa et al. (1996) \\
\hline Mutations & $\begin{array}{l}\text { Serum of carcinogen-exposed } \\
\text { workers ( } 25 \% \text { smokers) }\end{array}$ & $40 \%$ of samples with alterations & Review in Nelson (1997) \\
\hline
\end{tabular}


chromosome 11q (ataxia telangiectasia) and some other familial low penetrance genes (McKenzie, 1997).

Causative and protective dietary factors. Epidemiological studies report increases in relative risks of $2-2.5$ for women with body mass index (BMI) $\left(\mathrm{kg} / \mathrm{m}^{2}\right)>28-30$, for women in the fourth compared to the first quartile of measures versus control for adipositas and for women with weight gains from young adulthood to middle age of $>27 \mathrm{~kg}$. There is some controversy regarding the role of fat in this context (Wynder et al. 1997; Kohlmeier \& Mendez, 1997). Many data show high international correlations between fat intake and breast cancer rates; modest positive associations are found with high fat diets in case-control studies. In contrast, in cohort studies fat intake is unrelated to the risk of breast cancer. However, the weight of evidence does suggest that type and amount of fat in the diet is related to postmenopausal breast cancer, and that the inability to detect associations in cohort studies is because of measurement error and because of the relative homogeneity of diets measured (WCRF, 1997). Intervention studies employing new, sensitive and predictive biomarkers are needed to establish or refute the associations.

Recent case-control studies in Uruguay have studied the associations between meat intake and exposure to heterocyclic amines and risk for breast cancer. The odds ratio for the highest quartile for 2-amino-3-methylimidazo[4,5-f]quinoline exposure was 3.34 and strong effects were also found for red meat, beef and fried meat (DeStefani et al. 1997). Another study investigated the excretion of urinary oestrogen metabolites and breast cancer in a case-control study, indicating that 16 - $\alpha$-hydroxy oestrone excretion may be a strong risk factor (Kabat et al. 1997).

In animal models, dietary fat influences mammary cancer development. Postulated direct mechanisms include conversion of essential fatty acids into eicosanoids (Rose, 1997), reaction between reactive oxygen species (ROS) and polyunsaturated fatty acids (PUFA) leading to DNAdamaging agents (Nair et al. 1999) and inhibition of fatty acid synthase (Pizer et al. 1996). Additionally, indirect mechanisms may be involved including hormonal interference (Stoll, 1996; Liehr, 1997), interaction with membrane (lipid)-bound enzymes (Lanson et al. 1997), and changes of cell membrane functions and structures (Stoll, 1998).

Non-starch polysaccharides (fibre), regular physical activity and carotenoids possibly decrease the risk of breast cancer (WCRF, 1997). Overall dietary associations seem to be weaker than for digestive cancer (Potter \& Steinmetz, 1996). The intake of carrots, spinach and supplements containing vitamin A also showed only a modest protective effect in relation to breast cancer (Longnecker et al. 1997).

Phytoestrogens (isoflavonoids, lignans) have gained considerable attention as potential anticarcinogenic compounds in plant foods. In countries and regions with lower breast cancer incidence, dietary plant foods commonly consumed (soy products, grains) contain considerable amounts of these substances. In breast cancer tumour cells these compounds have been shown to react with oestrogen receptors, although with thousandfold lower affinity than endogenous hormones. However, their concentrations in blood may be a thousandfold higher than the physiological concentrations of the hormones (oestrogen and analogues) (Cassidy et al. 2000). The occurrence of at least two forms of the oestrogen receptor with different organ localisations and different binding affinities for endogenous and phytoestrogens may provide a mechanistic underpinning for the activity of phytoestrogens in different parts of the body (Paech et al. 1997; Cassidy et al. 2000). One of the phytoestrogens present in soya, genistein is a protein tyrosine kinase (PTK) inhibitor and, when conjugated to the epidermal growth factor (EGF), appears to trigger rapid apoptopic cell death in human breast cancer cells (Uckun et al. 1998).

Moreover, isoflavonoids have been shown additionally to prevent oxidative cell damage. However, no convincing associations have been reported for the increased consumption of phytoestrogens and reduced breast cancer risk (Adlercreutz, 1995; Gerber, 1996). An increase in the expression of cytochrome oxidase II, a putative risk factor for breast cancer (Sharp et al. 1992), has been observed in human primary cells derived from female keratinocytes exposed to the soya phytoestrogen genistein (McBride et al. 1998), but a direct link between diet and cancer risk remains unproven.

Indole compounds formed from indole glucosinolates particularly indole-3-carbinol - have an effect on steroid hormone metabolism and this may form the basis for their putative protective effects since this leads to lowering of circulating hormone levels (Baldwin \& Leblanc, 1992).

Available biomarkers and performance criteria. Excretion of oestrogen metabolites in the urine, altered oestrogen metabolism or detection of genotoxic activities of mammary lipids may be specific exposure markers, indicating breast cancer risk (Nebert, 1993; Kabat et al. 1997; Martin et al. 1997). Early markers of disease include K-ras mutations, however alterations of p53 (Nelson, 1997) and other biological markers of breast cancer have also been described (Porterjordan \& Lippman, 1994; Panico et al. 1996). These employ invasive techniques and are not suitable for screening purposes. Ductal carcinoma in situ, lobular carcinoma in situ, and genetic enzyme polymorphisms (d'Errico et al. 1996) and GSTM1 (Zhong et al. 1993) have been discussed as pointing to disease susceptibility. Individual differences in the degree of 4-hydroxylation of oestrogens (Liehr, 1997) and metabolism to produce equol may also influence risk (Kelly et al. 1995).

Further research needs. The link between diet and breast cancer remains to be established. Apart from the generic recommendations to increase fruit and vegetable consumption, the role of specific bioactive constituents (phytoestrogens) must be more closely defined. The discovery of alternative forms of the oestrogen receptor with different biological functions in terms of regulation of gene expression, different avidity for natural and environmental oestrogens and different levels of occurrence in different organs may help to explain the mechanistic basis for the activity of phytoestrogens on breast and other hormonally related cancers (Paech et al. 1997). It is difficult to unravel the relative effects of diet, environment, endogenous hormonal status and age in the occurrence of breast cancer and, as with a range of other cancers, the lack of availability of systemic biomarkers is a crucial problem. 
2.4.4. Conclusions. Cancer is a major disease in Europe. The levels of mortality and morbidity are high and the social, economic and personal cost is significant. Although there are significant differences in disease rates in different parts of Europe, it is by no means clear how much of this relates to diet, how much to environmental factors and how much is a result of genetic predisposition. The best estimates suggest that, for a combination of prevalence with the highest apparent association with diet, cancers of the stomach, colon/rectum and breast offer the best hope for dietary intervention. In virtually all cases, this intervention will have to be directed towards prevention of early stages in the disease (e.g. inhibition of DNA damage, enhancement of repair), however the further away the effect is from the final disease, the less certain we can be that the intervention is having the desired effects. The possibility of diet influencing the late onset biomarkers of cancer or of preventing recurrence are considerably less, however there are a few available markers including induction of apoptosis and effects on cell cycle whose variability in response to dietary challenge can be probed, at least in vitro.

There are currently no predictive, in vivo biomarkers for cancer although there are diagnostic markers. Given this and the incomplete understanding of the mechanism of the cancer process, it is difficult to see how the effect of diet can be determined outside of generalised epidemiological studies.

In general, diets high in energy, fats and meat appear to increase cancer incidence. The consumption of fruit and vegetables appears to be broadly protective in most cases of cancer where diet is thought to have influence.

There are some biomarkers (oxidative stress, mutagenicity of body fluids, DNA adducts) which appear to be relevant and these are summarised in Tables 5,6 and 7. They are divided into those that are detectable in blood lymphocytes, those that can be found in tissue-associated fluids, and those that can be measured in the target organ. A key requirement is the validation of biomarkers in the context of the disease and a better understanding of their potential predictivity and their responsiveness to diet.

Cancer provides a key challenge for researchers working in the area of diet and health. Despite the large amounts of time, money and effort that have been expended in the study of cancer, it remains in many cases, mechanistically ill defined. The potential for prevention and amelioration through diet appears to be significant (WCRF, 1997). In order to maximise the benefits, it is important to focus on those cancers for which there appears to be a clear link with diet and which are of the greatest significance in terms of morbidity and death. These would clearly include stomach, colon/rectum and breast (see above). By increasing our awareness and understanding of specific types of cancer and by then carrying out prospective intervention studies it will be possible to develop strategies for relating diet to cancer avoidance. Unfortunately cancer can take a large number of years to develop hence this 'observational' approach will not yield answers in a reasonable time scale. The role of biomarkers is as both a predictive aid and a research tool to help to define the key mechanistic steps in cancer processes and to reflect changes in status in these intermediate steps in response to specific dietary components. This is both a daunting challenge and a stimulating opportunity.

Table 5. Potential cancer biomarkers detectable in peripheral blood lymphocytes

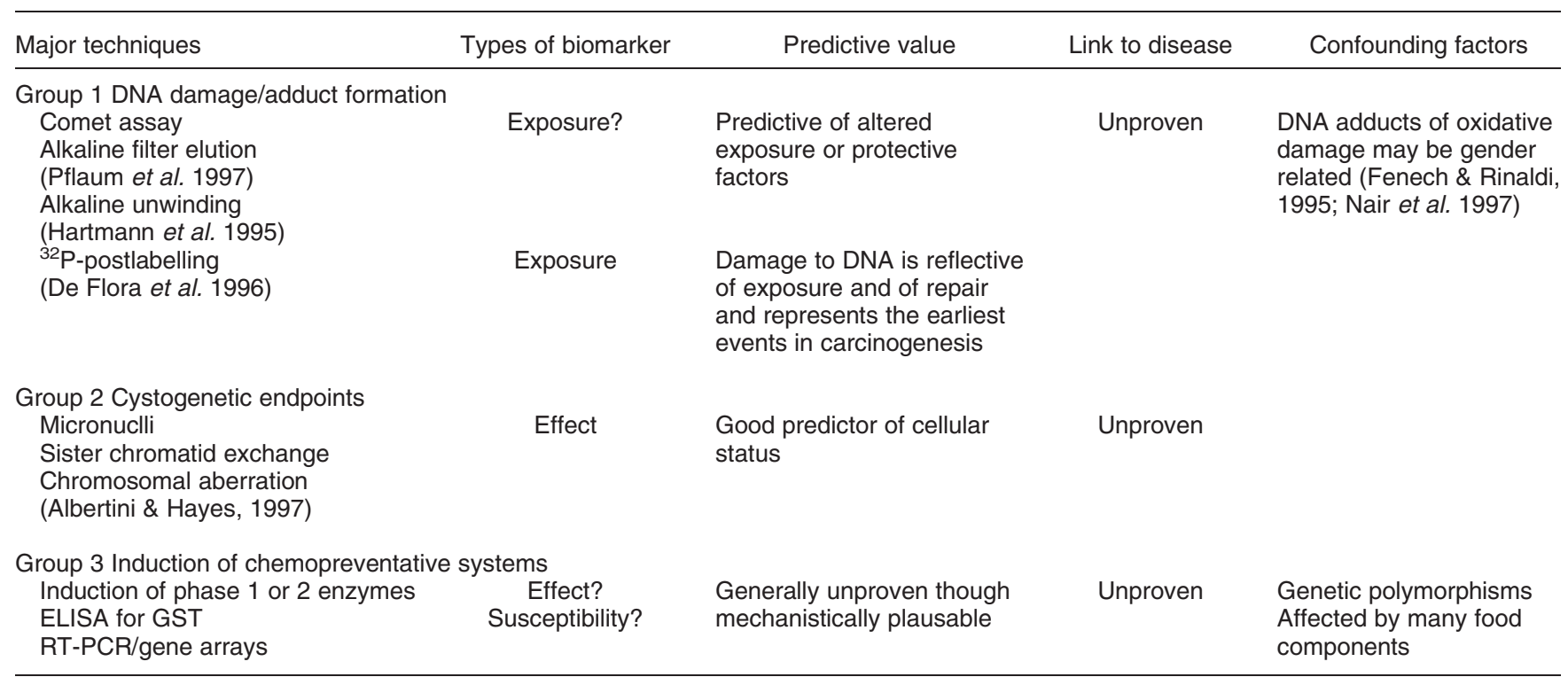

GST, glutathione transferase; RT-PCR, reverse transcription - polymerase chain reaction.

A range of techniques have been developed to measure DNA damage, adduct formation, induction of metabolising enzymes, induction of DNA repair enzymes and cytogenetic events in peripheral blood lymphocytes. The major confounding factors are proving the mechanistic link between the biomarker and the disease and demonstrating that a systemic marker has relevance to organ-specific events. Additional references include the following.

DNA damage/adducts: Duthie et al. (1996); Pool-Zobel et al. (1997, 1998); Fang et al. (1997); Wild \& Pisani (1997); Kensler et al. (1996); Fang \& Vaca (1997); Compton et al. (1991).

Cytogenetic changes: Fenech \& Rinaldi (1995); Tucker et al. (1997); Fenech et al. (1997a,b).

Induction of chemopreventive systems: Pool-Zobel et al. (1998); Garte et al. (1997); Ellis et al. (1996). 
Table 6. Biomarkers for cancer from target tissue - associated fluids

\begin{tabular}{|c|c|c|c|c|}
\hline Techniques & Types of biomarker & Predictive value & Link to disease & Confounding factors \\
\hline \multicolumn{5}{|l|}{ Genotoxicity of faecal water } \\
\hline $\begin{array}{l}\text { Comet assay after exposure of } \\
\text { colon cells } \\
\text { Ames test }\end{array}$ & Exposure? & $\begin{array}{l}\text { Limited but may indicate } \\
\text { mutagenic load }\end{array}$ & Not proven & \\
\hline \multicolumn{5}{|l|}{ Fermentation profile } \\
\hline $\begin{array}{l}\text { Measurement of a range of } \\
\text { parameters including } \mathrm{pH}, \\
\text { short-chain fatty acids, bile } \\
\text { acids etc. }\end{array}$ & $\begin{array}{l}\text { Exposure? } \\
\text { Susceptibility }\end{array}$ & $\begin{array}{l}\text { May indicate a positive profile } \\
\text { and dietary constituents } \\
\text { which affect it }\end{array}$ & $\begin{array}{l}\text { Unproven } \\
\text { mechanistically }\end{array}$ & \\
\hline Measurements in exfoliating cells & $\begin{array}{c}\text { Effect } \\
\text { Susceptibility? }\end{array}$ & $\begin{array}{l}\text { Potentially high since some } \\
\text { critical lesions are known, } \\
\text { e.g. for colorectal cancer }\end{array}$ & $\begin{array}{l}\text { Chain of events } \\
\text { on a genetic level is } \\
\text { in part established } \\
\text { hence good link }\end{array}$ & $\begin{array}{l}\text { Types of cells released. } \\
\text { Heterogeneity } \\
\text { of populations }\end{array}$ \\
\hline
\end{tabular}

Most of the work on target tissue-related fluids has focused on colorectal cancer since there are relatively simple, non-invasive materials available. The predictive value of the measurements is unproven in most cases. Additional information is provided in the following references. Genotoxicity of faecal water: Morishita \& Shiromizu (1990); Venturi et al. (1997); Hayatsu \& Hayatsu (1994); Hayatsu et al. (1985); Glinghammer et al. (1997).

Fermentation profile: Birkett et al. (1996); Alberts et al. (1996); Bartram et al. (1994, 1996); Geypens et al. (1997); Hayatsu \& Hayatsu (1994); Lidbeck et al. (1987); Erhardt et al. (1998); Homann et al. (1997): Stillwell et al. (1997); Bingham (1997); Bingham et al. (1996); Mallett \& Rowland (1990); Rowland (1993). Exfoliated cells: Levine et al. (1997); Loktionov et al. (1998).

\section{Coronary heart disease}

\subsection{Introduction}

Cardiovascular disease (CVD) or coronary heart disease is one of a series of circulatory disorders, which affect a large number of the population throughout Europe. Unlike cancer which has a relatively simple disease outcome (tumour formation in most cases) but a complex series of mechanisms, cardiovascular and other circulatory disorders have a more defined mechanism and a range of clinical endpoints.

Figures for mortality and morbidity due to circulatory disorders are available for a number of countries. The mortality due to cardiovascular disease is estimated to be $20 \%$ world-wide and amounts to some 14 million deaths per annum. Figures from the USA suggest that over 58 million Americans have one or more forms of cardiovascular disease and in 1995 cardiovascular disease caused $41.5 \%$ of all deaths (960592) compared with the total for all cancer deaths of 538455 . Figures for Europe are broadly in line with this although there are a number of significant "hotspots' including Scotland, Northern Ireland and parts of Scandinavia. In general, the levels are higher in 'developed, Western' cultures than in the middle and far East, although this trend appears to be becoming less pronounced as

Table 7. Biomarkers for cancer in target tissue cells

\begin{tabular}{|c|c|c|c|c|}
\hline Techniques & Types of biomarker & Predictive value & Link to disease & Confounding factors \\
\hline \multicolumn{5}{|l|}{ Group 1 proliferation } \\
\hline $\begin{array}{l}{ }^{3} \mathrm{H} \text {-Thymidine or BrdU } \\
\text { incorporation } \\
\text { Mitotic index } \\
\text { PCNA } \\
\text { Immunohistochemical staining }\end{array}$ & $\begin{array}{l}\text { Effect } \\
\text { Exposure }\end{array}$ & $\begin{array}{l}\text { Limited but may reflect } \\
\text { exposure changes }\end{array}$ & $\begin{array}{l}\text { Equivocal } \\
\text { (Hague et al. 1997) }\end{array}$ & $\begin{array}{l}\text { Folate can affect cell } \\
\text { proliferation in ulcerative } \\
\text { colitis patients } \\
\text { (Biasco et al. 1997) }\end{array}$ \\
\hline \multicolumn{5}{|l|}{ Group 2 K-Ras, p53 alterations } \\
\hline $\begin{array}{l}\text { Detection of specific amplifications, } \\
\text { deletions, mutations using } \\
\text { PCR and related techniques }\end{array}$ & $\begin{array}{l}\text { Effect } \\
\text { Susceptibility }\end{array}$ & $\begin{array}{l}\text { Varies with biopsy tissue } \\
\text { but generally a good } \\
\text { predictor although link to } \\
\text { specific exposure can be } \\
\text { difficult. Can be too late in } \\
\text { the tumour process to be } \\
\text { truly predictive }\end{array}$ & Variable & $\begin{array}{l}\text { Background mutations, } \\
\text { genetic polymorphisms. } \\
\text { (Watanabe et al. 1997) } \\
\text { Effects of specific dietary } \\
\text { factors (Bautista et al. } \\
\text { 1997) }\end{array}$ \\
\hline \multicolumn{5}{|l|}{ Group 3 DNA damage } \\
\hline $\begin{array}{l}\text { Comet assay } \\
{ }^{32} \mathrm{P} \text { postlabelling }\end{array}$ & $\begin{array}{l}\text { Exposure } \\
\text { Effect }\end{array}$ & $\begin{array}{l}\text { Partiality of specific gene } \\
\text { targets are detected }\end{array}$ & Variable & $\begin{array}{l}\text { Heterogeneity of cell } \\
\text { populations }\end{array}$ \\
\hline
\end{tabular}

PCNA, proliferating cell nuclear antigen; PCR, polymerase chain reaction.

Additional related literature:

Proliferation: Alberts et al. (1990, 1996, 1997) Bartram et al. (1993); Frommel et al. (1995).

DNA damage: Pool-Zobel et al. (1994, 1998); Pool-Zobel \& Leucht (1997). 
Western living standards are more commonly adopted world-wide (Musaiger \& Abuirmeileh, 1998). This has led a number of commentators to suggest that diet could be a major life-style factor, which could influence the occurrence of cardiovascular disease.

The strength of the relationship to diet seems to be variable, but several factors have been implicated including lipid intake, lipoprotein metabolism, cholesterol, oxidative stress, folic acid, type 2 diabetes and obesity. It is important, however, to evaluate such information carefully in order to draw sustainable conclusions.

\subsection{Causative and protective factors}

3.2.1. Environmental factors. In the Western world, circulatory disorders account for up to $40 \%$ of deaths (Egan \& Lackland, 1998). The economic and social cost of the disease is, therefore considerable. A plethora of studies have been carried out which have attempted to link the disease to diet and life-style, and a large number of candidate dietary constituents have been identified (Table 8).

Although there appears to be a correlation between cardiovascular disease and diet, and assays can be carried out more directly on the target organ through the circulatory system than is the case for cancer, determining the relationship between the disease and specific dietary components and assessing the extent to which genetic predisposition plays a part remain difficult.

3.2.2. Genetic predisposition. A number of factors have been found to predispose an individual to cardiovascular disease and a complete survey of these is outwith the scope of this review. In many cases, although there is a distinct genetic factor involved in predisposing the individual, the disease process is also strongly influenced by diet. Some of these risks are outlined below.

A major risk factor for cardiovascular disease is type 2 diabetes. Individuals with a genetic predisposition to insulin resistance are a major at risk group (Bloomgarden, 1998). The development of type 2 diabetes is associated with other risk factors for cardiovascular disease such as hypertension, hypertriglyceridaemia and decreased high density lipoproteins (Elliott \& Viberti, 1993). The complexity of response makes elucidation of the degree of association with individual genetic predispositions difficult to confirm. In addition, although there is a clearly defined link between the onset of type 2 diabetes and a genetic predisposition, the influence of diet on the eventual manifestation of the disease has been reported by several investigators and this presumably also affects the risk of coronary heart disease (Ravussin et al. 1994; Chisolm et al. 1998).

An increased affinity for sodium at an external site of the sodium-lithium counter transporter has been associated with a genetic predisposition to hypertension and to cardiovascular disease (Carr et al. 1997). An association between left ventricular hypertrophy and cardiovascular disease has been found and there appears to be some genetic component in this condition (Lauer, 1995). A further link between expression of angiotensinogen and angiotensinogen-converting enzyme (ACE) and left ventricular hypertrophy has been found. An increase in the expression of these two factors leads to elevated cardiac angiotensin II formation which in turn causes vasoconstriction of the coronary vasculature and subsequent hypertrophy. An insertion/deletion polymorphism of ACE has been associated with lower plasma activities of the enzyme compared with homozygous deletion/deletion individuals and this genotype appears to be associated with an elevated risk of left ventricular hypertrophy (Holmer \& Riegger, 1995).

A number of factors have been postulated to affect blood coagulation and, thence, predisposition to coronary heart disease (CHD). Coagulation factor VII has been considered to be a major biochemical determinant of CHD. Studies have suggested that, for example, the relatively low rate of CHD in westernised black Africans is due, amongst other things, to inherited lower levels of coagulation factor VII (Vermaak et al. 1991). In contrast, a Finnish study suggested that the specific coagulation factor VIIc was not associated with CHD (Tervahauta et al. 1993). However, it is, perhaps, inappropriate to attempt to make a direct comparison between elderly males who already suffer from CHD and predisease-onset, young males. This issue was further investigated in healthy men in the PROCAM study (Heinrich et al. 1994). Interestingly, although the mean factor VIIc activities in the CHD event and non-event groups did not differ significantly, there was a trend towards higher factor VIIc values when only fatal events were considered. A

Table 8. Dietary factors implicated in circulatory disorders

\begin{tabular}{ll}
\hline Dietary constituent & \multicolumn{1}{c}{ Reference } \\
\hline Fatty acids & Tavendale et al. (1992), Erkkila et al. (1998) \\
Saccharides & Saris et al. (1998) \\
Starch & Gordon et al. (1981) \\
Alcohol & Srivastava et al. (1994) \\
Dietary cholesterol & Keys (1965) \\
Fibre & Kromhout et al. (1996), Anderson (1995) \\
Phytosterols & Patel et al. (1998) \\
Thiamine & Brady et al. (1995) \\
Homocysteine, B vitamins, folate & Rimm et al. (1998), Brouwer et al. (1999a,b) \\
Vitamin D & Watson et al. (1997) \\
Taurine & Mizushima (1995) \\
Minerals & Singh et al. (1992) \\
Antioxidant vitamins & Mosca et al. (1997) \\
Flavonoids & Yochum et al. (1999) \\
\hline
\end{tabular}


similar study in Finland also suggested that factor VII was not a risk factor for CHD, but these authors suggested that prospective epidemiological studies are necessary to resolve the issue (Moor et al. 1995). Finally, two other studies have implicated factor VII and increased risk of CHD. In a followup study to the initial PROCAM work, it was found that factor VII was significantly higher in subjects with coronary events compared with those without (Junker et al. 1997). It appeared not to be an independent risk factor although it did act in concert with other risk factors and should be considered as part of an overall assessment. A direct link between factor VII and diet has been suggested (Miller, 1997) with consumption of diets rich in long-chain fatty acids leading to an increase in serum factor VII.

In addition to predictive epidemiological studies, there have been a small number of mechanistically based investigations. The variation among men in factor VIIc levels was associated with a genetic polymorphism. In a similar study in women at menopause, genotype appeared to be the major factor in determining factor VIIc levels. (Meclahn et al. 1995). The rate of increase of factor VIIc with age in women was found to be significantly greater than that in men (Scarabin et al. 1996). In both sexes, the authors concluded that levels of activated factor VIIc appeared to be associated with other risk factors for CHD and the cardioprotective effects of oestrogen in women may be mediated through factor VII. This putative link between oestrogens and the delayed occurrence of CHD in menopausal women may, in part, be due to this or similar effects (Venkov et al. 1996).

Other factors associated with coagulation have been implicated as predictors of CHD. These include antithrombin III (Koshkin et al. 1991); blood coagulation and fibrinolysis in healthy compared with CHD patients (Kovalenko et al. 1991); the platelet-vascular component of the haemostatic system (Brezitskaya \& Sedov, 1991), and the activation of factor XII in middle-aged men (Miller et al. 1997). In most cases the precise link between individual coagulation factors, diet and risk of CHD is difficult to prove and it seems most useful to consider a range of factors and their interrelationships.

Serum triacylglycerol levels have been proposed as valid predictive indicators (Austin et al. 1997) and pharmacological treatment of dyslipidaemia has been suggested as a useful intervention (Gotto, 1996). It has been demonstrated that serum triacylglycerols reflect dietary exposure (Vidgren et al. 1998), therefore the measurement of serum triacylglycerol levels may reflect dietary exposure and, if the status of the individual is known, may also act as a predictor or a risk.

A clear association between cardiovascular disease and hyperhomocysteinaemia has been observed and there is some mechanistic rationale for the effect. A genetic predisposition for this has been associated with deficiency in methylenetetrahydrofolate reductase (Rozen, 1997). This leads to elevated plasma levels of homocysteine, which are associated with increased risk of cardiovascular disease probably via a mechanism involving thiolation of free amino groups of LDL leading to aggregation and increased uptake by macrophages. Once again, dietary levels of folate (an important methyl donor) and/or deficiencies in the vitamin cofactors $\mathrm{B}_{6}$ or $\mathrm{B}_{12}$ may exacerbate the genetic situation.

The apparent association between apolipoprotein $\mathrm{E}$ and cardiovascular disease has been noted in a number of studies. There are three common alleles termed E2, E3 and $\mathrm{E} 4$ and the association between each of them and their response to fat intake has been studied.

Further work is needed to determine the magnitude of the genetic component of lipid metabolism and its contribution to cardiovascular disease. In general, lipid intake and metabolism has been found to correlate with cardiovascular disease risk. There is also, however, a genetic aspect to this part of the process. For example, Howard et al. (1994) found that lipoprotein (a) concentration in blood appeared to be largely genetically determined and this, together with its association with fibrinogen and LDL, suggest a mixed genetic/environmental effect. One physiological state, which is linked to a defined subgroup of the population, is the increased risk of cardiovascular disease in postmenopausal women (Razay et al. 1992; Maxwell, 1998).

In conclusion, cardiovascular disease has a series of specific genetic components. The effect of diet on individuals with various genetic susceptibilities will be discussed later.

\subsection{Preventative action possible}

Since cardiovascular disease has distinct genetic and dietrelated components (Sections 3.1 and 3.2), it is possible to consider markers in the context of those that could give an early warning of the possibility of the disease process beginning, those which indicate predisposition, those which reflect later stages and those which may help to prevent reoccurrence after initial disease.

3.3.1. Primary markers. Primary markers are those that relate to early stages in the disease process or to predisposition.

Direct markers. The area of primary prevention is closely linked to that of susceptibility, however there are a number of clinical markers that can be used as predictors of early damage and progression of the disease process.

Increased levels of serum creatinine kinase and the isoenzyme creatine kinase $\mathrm{MB}(\mathrm{CKMB})$ have traditionally been used to detect myocardical infarction. More recently cardiac troponin $\mathrm{T}$ has been proposed as a specific marker of myocardial injury (Solymoss et al. 1997) and as a predictor of even mild myocardial necrosis. The BB enzyme of glycogen phosphorylase has been proposed as a marker of cardiac damage and has undergone clinical trial (Boldt et al. 1996). In a study of young American adults, (ages 22-43), who died suddenly of atherosclerotic coronary artery disease, elevated levels of plasma cholesterol, triacylglycerols, LDL and apolipoprotein B appeared to be significant biomarkers for the developed disease (Hiserodt et al. 1995). However, the samples taken were, for obvious reasons, postmortem and may not reflect the utility of these as predictive markers. In an earlier study in Europe the offspring of fathers who suffered myocardical infarction before the age of 55 were examined (Rosseneau et al. 1994). The authors, in this case, focused on plasma cholesterol esters as biomarkers for the fatty acid composition of the diet but no 
significant correlation was found. Some regional differences were observed. Finnish students had the highest levels of plasma cholesteryl palmitate whereas cholesteryl linoleate and arachidonate levels were highest in Belgian and Southern European samples, respectively. This may reflect increased susceptibility. All of these factors, when combined with dietary changes and the adoption of a more sedentary life-style will increase the predisposition to circulatory disease.

The relationship of coronary heart disease to diabetes has been extensively studied and seems confirmed both for type 1 (Vaccaro et al. 1998) and type 2 (Lehto et al. 2000). The relative risk of CHD for people with diabetes against those without was 3.45 among women and 2.52 among men. Differences were observed between black and non-black populations and, although the risk of CHD with diabetes was somewhat lower in the former, this was outweighed by a greater prevalance of diabetes (Folsom et al. 1997). A final example of generic life-style relationships to circulatory disease was provided in a study in which the relationship between short stature and heart disease was investigated (Kee et al. 1997). The study based on data from throughout Europe concluded that, in men, height appeared to be an independent, inheritable risk factor for coronary heart disease.

Clearly, further studies are necessary to determine if the primary clinical markers of early cardiac damage predisposition are sufficiently predictive of long-term outcome. A number of less direct factors have been implicated as useful biomarkers to predict clinical outcome.

Indirect markers. The most commonly implicated indirect marker is clinical measurement of cholesterol and associated lipids. Lowering of the levels of LDL-cholesterol and VLDL-cholesterol and raising the levels of HDLcholesterol by clinical intervention has been demonstrated to lower the risk of coronary heart disease (Kashyap, 1997). The clinical significance of cholesterol has been further indicated by the success of inhibitors of hydroxymethylglutaryl (HMG)-CoA reductase (a key enzyme in cholesterol biosynthesis) in reducing incidence of coronary heart disease. A number of studies appear not to substantiate the claim that there is a causal relationship between even endogenous low serum cholesterol or drug interventions and an increased risk of non-cardiovascular mortality (Jones, 1994). However, in a follow-up to the Seven Countries study, the link between serum total cholesterol and longterm coronary heart disease in a number of countries was investigated (Verschuren et al. 1995). The relative increase in coronary heart disease mortality in populations with different cholesterol levels was similar within countries, but the absolute values for mortality varied considerably. This work suggested that cholesterol is linearly correlated with CHD mortality and the increase in CHD mortality with increased cholesterol was broadly similar in different cultures. An earlier study in developing countries arrived at broadly similar conclusions (Li et al. 1994). The authors postulated that the combination of several coronary heart disease risk factors could explain about $90 \%$ of the interpopulation variance in women. However, it was noteworthy that, when fasting or 2 hour post-food blood glucose was included in the model, total cholesterol was no longer significant in men but remained significant in women. The distinction between primary and secondary markers and between secondary markers and maintenance situations can be problematical in the case of cholesterol. In a study in Northern Ireland cholesterol screening of children from families with a history of cardiovascular disease was carried out. Only 63 of 190 individuals with hypercholesterolaemia were identified from their family history, suggesting that a strategy whereby only children from high risk families are screened for hypercholesterolaemia would be ineffective (Primrose et al. 1994). A range of other studies on cholesterol has been carried out with similarly confusing results.

Serum cholesterol is a relatively simple measurement to make and is routinely carried out in clinical chemistry laboratories. Importantly, the nature of the relationship between dietary cholesterol and serum total cholesterol remains problematical with linearity (Keys, 1966; Hegsted, 1983) being suggested. However, the nature of the relationship depends on a number of factors including cholesterol availability and storage (Dietschy, 1998) and genetic polymorphisms (Gylling et al. 1997). Studies reported by McNamara (1997) suggested a minimal link between dietary cholesterol and either blood cholesterol or CHD. Although lowering the levels of LDL-cholesterol and VLDL-cholesterol by clinical means has been shown to lower the risk of CHD (Kashyap, 1997), the effect of diet on these parameters remains hard to predict. It is difficult to conduct studies in which the risk of circulatory disease is measured without clinical intervention and, in most cases, the link is only established in patients who have already suffered a thrombotic incident and are hence on medication. For example, dietary intervention was proposed in a threeyear study of patients with CHD (Alessandri et al. 1994) together with extensive therapeutic intervention and cessation of cigarette smoking.

In several related studies, the predictive utility of serum triacylglycerol levels has been assessed. Treatment of dyslipidaemia has been suggested as a potential target (Gotto, 1996). Low density lipoprotein (LDL) particle size and plasma triacylglycerol have been proposed as predictors of CHD (Austin et al. 1997) and the fractional esterification rate of high density lipoprotein (HDL) has been used to predict the size distribution and physico-chemical characteristics of HDL in plasma (Ohta et al. 1997). Several studies have indicated that the size and density of LDL particles is of significance in predisposition to CHD. Small, dense LDL (LDL subclass phenotype B) is a common, genetically influenced risk factor for CHD (Austin, 1996).

Although quantification of risk factors due to circulating lipids is difficult, higher levels of non-HDL or LDL cholesterol have been associated with a 30-35\% higher CHD event rate in the elderly (Frost et al. 1996).

Lipoprotein (a) appears to be a risk factor for CHD in men and studies have also implicated it as a determinant in both pre-and postmenopausal women (Orth-Gomer et al. 1997). The role of lipoprotein (a) and apolipoprotein (a) in the increased risk of hypertensive individuals to CHD has been noted by Gazzaruso et al. (1997).

Lipoproteins may be particularly relevant predictors of coronary heart disease in individuals with type 2 or 
non-insulin dependent diabetes (NIDDM) and several studies have been carried out which appear to reflect this (e.g. Lehto et al. 1997). The correlation between blood pressure and blood lipid levels among vegetarians, nonvegetarian and semi-vegetarian native Africans was the subject of a recent study (Famodu et al. 1998). Although there was no statistically significant difference between the blood pressure of the three groups, the vegetarians did have significantly lower levels of serum total cholesterol and triglycerides and this may be reflected in the lower cardiovascular disease risk in this group compared to the others.

The absence of LDL has been demonstrated not to be a sole, valid predictor of risk of coronary heart disease. A small number of studies have indicated that low levels of HDL cholesterol without elevated levels of LDL or cholesterol can predict atherosclerosis (Wilt et al. 1997).

A range of other early predictors of damage have been suggested. These include the circulating adhesion molecules E-selection and intercellular adhesion molecule-1 (ICAM-1) (Hwang et al. 1997), and impairment of the fibrinolytic system leading to fibrin deposition (Juhan-Vague \& Alessi, 1997). Several haemostatic tests have been implicated in elevated risk of myocardial infarction (Wu, 1997), however further clinical trials are necessary to establish conclusively the relative importance of, for example, factor VIIIc, C-reactive protein, persistent positive spontaneous platelet aggregation and von Willebrand factor.

A range of studies have implicated a lack of folate and vitamin $B_{6}$ in increased risk of CHD (Rimm et al. 1998) and a plausible mechanism has been suggested which implicates homocysteine levels. There is reasonably compelling evidence (and some mechanistic support) for a link between plasma homocysteine levels and cardiovascular disease (Jacobsen, 1998). Based on this work it was estimated that some $10 \%$ of coronary artery disease risk may be attributable to homocysteine. However, even given this type of information, the precise nature of the link between cardiovascular disease and dietary levels of homocysteine or folic acid (via plasma homocysteine) remains imprecise (see Section 3.4).

3.3.2. Secondary effects. Secondary effects related to prevention of cardiovascular disease can be defined as those factors which are of benefit after cardiovascular damage has taken place. One of the principal secondary markers for the prevention of further instances of CHD is serum cholesterol levels. Several trials have suggested that cholesterol lowering is of benefit in secondary prevention and in producing regression of coronary lesions (Brown, 1997). The nature of the link between dietary cholesterol and serum levels remains unclear and, for the most part, unconfirmed (McNamara, 1997). In a three-year study of patients with CHD, a range of factors were considered to be important in the prevention of recurrence (Alessandri et al. 1994). The results suggested that extensive therapeutic intervention combined with a low cholesterol diet and ceasing of cigarette smoking could lower the incidence of secondary events. A putative link between dietary fat and CHD has been extensively reported and dietary intervention has been proposed for patients. The major problems associated with this type of approach are that it is important to establish the link both between diet and a clinical measurement and between the measurement and the disease outcome in terms of clinical events. One example of this is the apparent link between fatty food intake and serum levels of factor VII coagulant activity. Raised levels of factor VII coagulant activity have been implicated in increased risk of cardiovascular disease events and a link to self-reported fat intake was found (Connelly et al. 1993). The authors suggested that, because the effect was rapid, dietary intervention may be effective even in advanced cases.

Given that nutrients in the diet appear to be important in secondary health care for patients with circulatory disorders, a number of studies have attempted to identify more precisely the relative importance of different factors. In one extensive study, it was found that diagnosis of CHD resulted in changes in diet. In addition, by comparing different groups, low energy intake, high protein and moderate alcohol intakes are favourable with respect to CHD risk in men but only alcohol altered the risk in women (BoltonSmith et al. 1992). Somewhat surprisingly, dietary fat appeared not to be implicated.

A further factor, which relates to the role of serum lipids in secondary prevention of CHD is dietary antioxidant levels. A number of studies have implicated dietary antioxidants in the prevention of further disease events (Mosca et al. 1997), however a number of investigators have identified that randomised trials still need to be carried out (Hennekens et al. 1995; Iribarren et al. 1997).

In conclusion, a number of factors appear to be implicated in secondary health care in patients with circulatory disorders. Further work is necessary, particularly dietary intervention studies, in order to assess the relative importance of these. In general, the most effective strategies appear to be similar to those identified for primary care and prevention and these, coupled to appropriate therapeutic interventions seem to be of greatest significance. Although a number of serum-indices have been measured which appear to be correlated with future risk of disease, the strength of the correlation and the link to precise dietary components remains unclear.

3.3.3. Maintenance. The maintenance of health in patients with severe circulatory disease is closely linked with therapeutic strategies. The role of diet in health maintenance under these circumstances would appear to be marginal.

3.3.4. Other factors. The major complicating factors in the assessment of dietary strategies for prevention of circulatory disorders are genetic predisposition and noninsulin dependent diabetes. Coronary heart disease is linked to systolic and diastolic blood pressure (MacMahon et al. 1990). Although blood pressure can respond to dietary changes, it also has a distinct genetic component related to angiotensin I converting enzyme (ACE) gene polymorphisms (Chrostowska et al. 1998). Indeed, attempts are currently being made to identify the precise loci for essential hypertension (Morris \& Griffiths, 1998).

\subsection{Current biomarkers}

In the case of coronary heart disease, it could be argued that the whole cardiovascular system is the target organ hence 
systemic biomarkers and target organ biomarkers are intimately linked. For convenience, however, the level of analysis will be divided in two with measurements in serum considered separately from target organ-directed measurements. A number of the biomarkers outlined below have already been mentioned in preceding sections, however the examples used and the focus for the studies are different.

3.4.1. Serum. The majority of biomarkers are measured in serum. The major problem is in defining the link between the analyte or biochemical measure and the final clinical event. The simplest, non-invasive measure of a biomarker related to the likely onset of coronary heart disease is blood pressure. A number of studies have essentially demonstrated similar results - lowering of blood pressure is one of the major predictive biomarkers of lessened disease risk (e.g. Okayama et al. 1993).

Measurement of cholesterol is a convincing predictor of circulatory disease susceptibility (Cleeman, 1997), however the nature of the link between dietary cholesterol and serum cholesterol remains unproven. Clearly the nature of cholesterol esters is important and this is evidenced by the numbers of studies on HDL-cholesterol and LDLcholesterol (Ohta et al. 1997). It has been suggested that HDL-cholesterol can act in a positive fashion to inhibit endothelial cell adhesion molecule expression (Barter, 1997). This hypothesis would go some way towards explaining, on a molecular level, the effect of HDL. Many of the other studies that attempt to link serum lipids to coronary heart disease are descriptive and, essentially, nonpredictive in a mechanistic fashion. Further studies are needed to provide mechanistic insights, which can then be used to measure the effects of dietary intervention in terms of clinical outcome.

Reduction of risk for CHD requires an integrated and multifactorial approach to biomarker measurement (Parmley, 1997). It is important, in this context, to distinguish between effects on the heart and other systemic conditions (e.g. cerebrovascular disease). This has been recognised (e.g. Curb \& Marcus, 1991) with the major heart disease risk factors appearing to be serum cholesterol, hypertension and stress, whereas for stroke the principal factors were systolic blood pressure, cigarette smoking and alcohol intake. In the case of antioxidants, the putative mechanism involves a lessening of the susceptibility of LDL to oxidation (Mosca et al. 1997).

There are a range of clinical biomarkers associated with circulatory disorders which are at various stages of confirmation. These include serum levels of creatine kinase and, more recently, cardiac troponin $\mathrm{T}$ (Solymoss et al. 1997). These tend to predict existing myocardial necrosis rather than the risk of future events.

High levels of serum homocysteine appear to be correlated with increased risk of cardiovascular disease (Ballal et al. 1997) and plasma homocysteine has been proposed as a predictor of long-term mortality in patients with acute coronary ischaemia (Cohen, 1998). The magnitude of the risk associated with elevated plasma homocysteine levels was the subject of a recent EU project (Graham et al. 1997). Recent in vitro studies suggest that several mechanisms of homocysteine-induced cell damage are likely to contribute to the overall clinical effect
(Hultberg et al. 2000). A dose-response was noted between total homocysteine level and risk of cardiovascular disease and, furthermore, subjects taking vitamin supplements (including folate and B vitamins) had a substantially lower risk. In terms of genetic predisposition, one of the enzymes involved in the pathway is methylene tetrahydrofolate reductase (MTHFR). A thermolabile form of this enzyme is causally associated with high levels of plasma homocysteine thereby providing a means of providing a variation in susceptibility for subjects with different genetic predispositions.

3.4.2. Target organ. The target organ of cardiovascular disease is the heart. There are a number of clinical methods of varying degrees of invasiveness for directly measuring the effects on the heart. Disease incidence appears to be directly associated with greater coronary artery intramedia thickness (IMT) (Chambless et al. 1997). Although this is not a direct measure in the target organ, it is intermediate between a circulatory measure and a target organ biomarker.

\subsection{Profile of effects of nutrient interventions}

A number of studies have been carried out which relate dietary intervention to CHD. Quantification of potential benefits has proved difficult and drug trials have been found to be more effective than diet in reducing cholesterol (Holme, 1990). Dietary effects on factor VII have been noted (Connelly et al. 1993), but the link between factor VII as a sole risk factor for $\mathrm{CHD}$ remains unproven. Metaanalysis suggested that dietary intervention could reduce the incidence of CHD. However, the observed reduction in CHD did not affect overall death from all causes (Cucherat $\&$ Boissel, 1993). The combination of dietary intervention and exercise appeared to have a favourable effect on blood pressure (Anderssen et al. 1996).

The quality of fibrin networks has been suggested as having an effect on CHD and it has recently been reported that dietary pectin can influence fibrin network structure in hypercholesterolaemic individuals (Veldman et al. 1997). In addition, pectin appeared to decrease serum cholesterol, LDL-cholesterol, apolipoprotein (A and B) and lipoprotein (a).

Although a clear link between adiposity and food intake seems to be obvious a number of studies have indicated that some individuals can develop risk factors for CHD even though their eating behaviour is normal (Rolland-Cachera et al. 1990). It is important to consider a range of social and environmental issues when attempting to draw simple conclusions. An example of one such study is the adoption of a low lipid diet in the case of patients with CHD (Watts et al. 1992). This leads to lower serum lipids and thence to an unquantified reduction in heart disease. Other studies have advocated a combination of exercise and dietary intervention (Anderssen et al. 1996), dietary pectin (Veldman et al. 1997) and dietary cholesterol (Holme, 1990). In all of these cases, the extent of dietary intervention can be measured directly by measurement of serum levels (e.g. of lipids, cholesterol etc.) and, in a few cases, the clinical consequences can also be determined (e.g. changes in blood pressure and blood coagulation parameters). In 
comparatively few cases has it been possible to prove a reversibility in the condition.

3.5.1. Antioxidant status. The relationship between oxidative damage and CHD has been extensively researched. In general, studies can be divided into epidemiological investigations and mechanistic studies.

Epidemiology. A range of targets have been assessed for investigating the relationship between dietary antioxidants and CHD. The oxidation of LDL in the cell wall is postulated to play an important role in the development of atherosclerotic lesions. The hypothesis is that dietary antioxidants protect LDL against oxidation and hence prevent the onset of disease. The epidemiological evidence for this mechanism has recently been reviewed (Van de Vijver et al. 1997). The conclusion of this study of the literature was that general preventative measures based on antioxidant supplementation are not yet justifiable. A more direct link between antioxidants and HDL-cholesterol was suggested in a study related to the Coronary Artery Risk in Young Adults (CARDIA) investigation (Slattery et al. 1995). The authors attempted to correlate intake of antioxidant vitamin supplements (vitamins $A, C, E$ and $\beta$ carotene) with a range of plasma lipids. The only connection observed was for elevated levels of HDL-cholesterol when other life-style factors were considered to be of significance.

Although there is a tendency to suppose that individuals from regions with high vitamin $\mathrm{E}$ intake have a lower $\mathrm{CHD}$ rate, several studies have been contradictory. The balance of opinion seems to be that high doses of vitamin E may reduce the risk of $\mathrm{CHD}$ but that conclusive evidence is lacking (Stampfer \& Rimm, 1995). In an alternative approach, investigators in Sweden found that $\gamma$-but not $\alpha$-tocopherol levels were reduced in-patients with CHD (Ohrvall et al. 1996).

Mechanistic studies. Evidence to substantiate the possible mechanisms of action of dietary antioxidants is patchy. Flavonoids are known to be potent inhibitors of the oxidation of LDL as are oestrogenic isoflavones (Samman et al. 1996). Significant studies have been carried out on selenium supplementation as a means of preventing oxidative damage to plasma lipoproteins in animal models (e.g. Abou-Hozaifa, 1997), but further work is necessary to attempt to correlate the role of dietary micronutrients with specific biological indices of prevention of oxidation. To simply observe for example, that selenium is a key cofactor in the antioxidative enzyme gluthathione peroxidase, is insufficient to explain its potential mechanism of action.

The role of alcohol intake in CHD remains reasonably sure but unquantifiable. Both red and white wine appear to have a beneficial effect on clinical indices such as platelet aggregation and oxidation of serum lipoproteins (Struck et al. 1994). In one study, white wine was found to be more effective than red which runs somewhat counter to arguments suggesting the prime factor is the level of flavonoids present (Cook \& Samman, 1996).

A potential mechanism to explain the effects of phenolics in red wine has been suggested based on inhibition of eicosanoid synthesis (Pace-Asciak et al. 1995). This is in contrast to vitamin antioxidants, which have no such activity. Clearly further studies will be necessary to attempt to define the mechanistic relationship between specific dietary constituents such as the phenolics present in red wine and reduction in CHD prevalence.

The correlation between blood pressure and $\mathrm{CHD}$ has been extensively investigated. A number of studies have failed to find a link between exercise and blood pressure (e.g. Raitakari et al. 1997). However, older track athletes appear to have particularly low blood pressure (Mengelkoch et al. 1997) and this may relate directly to long-term exercise. A range of dietary and non-dietary factors have been reported as having an effect on blood pressure, however the precise relationship between blood pressure and CHD events remains unclear. In an extensive study of males of Japanese descent living in Hawaii, the results suggested that antihypertensive medication may be effective by reducing the variation in systemic blood pressure rather than by simply lowering it per se (Grove et al. 1997).

The role of oxidative stress has previously been discussed in the context of antioxidants. Overall, oxidative stress and the levels of stress have been correlated with a range of disease issues. Difficulties remain in attempting to quantify the extent of oxidative stress in individuals and mechanisms whereby it could correlate with specific disease states.

3.5.2. Folate. The use of folate supplementation to lower the risk to cardiovascular disease has been noted previously. The hypothesis remains that the reduced form of folate, N5-methyltetrahydrofolate is required for the remethylation of homocysteine to methionine and folate deficiency will result in elevated levels of homocysteine in the blood with the consequences noted above (Durand et al. 1998). In terms of intervention, low-dose folic acid supplementation has been found to decrease plasma homocysteine levels (Brouwer et al. 1999a,b). This opens the possibility of dietary modulation of plasma homocysteine levels and hence a potential effect on cardiovascular disease. It is unclear, however, if a positive effect would be observed in individuals with a genetic predisposition to hyperhomocysteinaemia.

3.5.3. Fat and lipids. The link between fat intake and cardiovascular disease in normal and hyperlipidaemic individuals has been extensively studied. A recent investigation, for example, showed that risk factors for cardiovascular disease in the United Arab Emirates (and instances of the disease itself) appeared to be following the increased 'Westernisation' of the diet (Musaiger \& alRoomi, 1997). Although there was a fall in the consumption of fresh fruit and vegetables and a concomitant rise in fat intake, other factors such as smoking should also be considered. The consumption of trans fatty acids has been suggested as a reason for elevated blood LDL and lowered HDL and also for raising lipoprotein concentration (Tinajas Ruiz, 1998). Once again, the extent to which a high fat diet will exacerbate the risk factors in normal as compared with genetically predisposed individuals in not completely clear, but significant information is already available.

There is some evidence for an age-related effect in cardiovascular disease risk with children and adolescents being susceptible to 'imprinting'. (Waterland \& Garza, 1999) and this has led some investigators to suggest that artherosclerosis can be described as a 'nutritional disease of childhood' (Berenson et al. 1998). This hypothesis suggests 
that the consumption of high fat foods by children and general overeating leads to obesity with corresponding increases in cardiovascular risk factors. However, it is important to emphasise that the effects of dietary fat will vary depending on the genetic predisposition and status of the individual. For example, African-American females with type 2 diabetes are at greater risk for cardiovascular morbidity and mortality than diabetic African-American males and Whites (Gacllard et al. 1998) and a number of measurable risk factors have been identified including fat intake. There are a number of serum and plasma-based markers which appear to correlate with fat intake. These include measures of LDL/HDL ratios, plasma triglyceride levels and pentadecanoic acid as a marker for intake of milk fat (Smedman et al. 1999).

3.5.4. Coronary heart disease and body mass index. A major purported influence on CHD is body mass index (BMI). Studies have indicated that the risk of cardiovascular disease events increases with the degree of regional, central or abdominal obesity (Kannel et al. 1991). There is also a clear link with NIDDM, which relates to obesity. In a study on mortality from all causes and from CHD in men over 15 years, mortality from all causes in older men tended to be higher in those with a low BMI but this was not the case for CHD mortality (Fitzgerald \& Jarrett, 1992). Studies have indicated that, in both men and women, triacylglycerols, BMI and alcohol intake contributed significantly to HDLcholesterol and apoA-1 variability (Schaefer et al. 1994). Although BMI appeared to be associated with several CHD risk factors in a study in Australia (Hodgson et al. 1994), BMI was not significantly associated with coronary artery disease as scored by coronary lesions or the extent of coronary atherosclerosis. Most studies indicate that BMI is associated with a range of CHD risk factors (e.g. Galanis et al. 1995). It is difficult to quantitatively assess the relative risk increase, which is directly attributable to increased BMI. Hsieh \& Yoshinaga (1995) suggested that normal BMI individuals should monitor their waist/height ratio because of increased CHD risk. An alternative interpretation has been suggested (De Pergola et al. 1997) in which BMI was found to correlate directly with plasma tissue plasminogen activator (an antithrombotic factor). Obesity in individuals correlated substantially with a range of positive CHD risk factors and this was considered to reflect the lower androgenicity of obese men. Finally, in an extensive study of over 3000 individuals, BMI was significantly and linearly associated with systolic blood pressure, fasting glucose levels, total cholesterol, VLDL cholesterol and LDL cholesterol levels. All the measured risk factors for CHD were associated with higher BMI in both men and women (Lamon-Fava et al. 1996).

In conclusion, the correlation between BMI and increased risk of CHD seems fairly certain. The degree of correlation and quantification of it has not been determined and, given the complexity of the interactions involved, delineation of a precise relationship may prove problematical.

3.5.5. Other interventions. A range of other dietary components have been implicated in altered risk to the onset or progression of cardiovascular disease. Significant effects have been claimed for the treatment of postmenopausal women with hormones, however it is unclear if a diet rich in phytoestrogens (e.g. soya isoflavones, lignans) could have a similar effect or if their effect is largely a result of their antioxidative capability (Cassidy et al. 2000).

\subsection{Profile of disease/damage}

A number of studies have attempted to link lipoprotein (a) to CHD. A correlation was observed between lipoprotein (a) and the rate of progression of atherosclerosis in individuals with familial hypercholesterolaemia (Tato et al. 1993). A study of sudden coronary death in China indicated that the coronary artery was narrowed in most cases and atherosclerotic plaques were serious and extensive (Chen \& Huang, 1992). Clearly this provides clear and direct evidence for the relationship between the coronary artery and CHD in terms of blood flow and other studies have demonstrated a similar relationship.

In terms of dietary links, the presence of natural antioxidants has been suggested as retarding the formation of atherosclerotic plaques thereby contributing to the benefits of the 'Mediterranean' type diet (Salami et al. 1995). This ties in with the theory that oxidatively modified LDL contributes towards the onset of atherosclerotic disease via plaque formation. Lipoprotein (a) has been shown to accumulate in areas of atherosclerotic plaque but the causal nature of this accumulation has not been confirmed (Suer et al. 1996; Zhou et al. 1996).

Many of the studies on the profile of CHD have been carried out on patients who have already developed the disease. In many cases it is not possible to correlate effects directly to diet.

\subsection{Conclusion}

The use of biomarkers in CHD and other circulatory disorders is, in some ways, fairly advanced. A number of clinical and diagnostic markers are known, but these tend to be non-predictive and reflect current status. In addition they rarely respond in a predictive way to dietary intervention. A number of risk factors have been identified which appear to correlate with eventual disease outcome, particularly in susceptible individuals, and some of these are directly affected by diet. Further work is needed to determine more precisely the nature of the link between the various factors which impact on cardiovascular disease outcome and the extent to which each of them can be altered by changes in diet.

\section{Osteoporosis}

\subsection{Introduction}

Osteoporosis is a disease of increased bone fragility leading to a higher risk of fracture in elderly people as a result of minimal trauma. The clearest clinical manifestation of the disease is hip fracture however osteoporosis is considered to affect half of women and a quarter of men over the age of 50 (Christensen, 1997). Bone fragility is mainly determined by bone mass, which explains $80 \%$ of the variance in compressive strength, but bone geometry, microarchitecture 
and the biochemical characteristics of the tissue are also considered to be important.

Disease progression occurs through a negative balance of bone mass - usually as a result of increased bone resorption. During development and growth bone is resorbed and deposited throughout the body. Once maturity has been reached the major process involves replacement of old bone with new at the same location. The process of resorption and rebuilding is carried out by osteoclasts and osteoblasts, respectively, both of which are derived from precursors originating in bone marrow. It is generally considered that the imbalance in bone formation and resorption is responsible for loss of bone and a number of factors (dietary and others) have been found to affect the process (Christensen, 1997).

\subsection{Preventative and causative factors}

The primary prevention of osteoporosis must begin in childhood. The growth and development of the skeleton is completed during the third decade of life and, after this resorption at specific sites without adequate rebuilding begins to take place. A number of factors can influence the occurrence and severity of osteoporosis and some of these are considered below.

4.2.1. Genetic factors. Bone metabolism is regulated by a complex interplay of a range of hormones and other factors. This means that genetic polymorphisms may play a role from a range of gene targets. Studies have been carried out with specific populations. For example, among Australians $75 \%$ of the variation in bone density is genetically determined (Simopoulos, 1996). One study carried out in the USA suggested that black women had both a higher peak bone mass and suffered less bone loss from selected sites (Aloia et al. 1996).

A number of conditions clearly contribute towards a predisposition to osteoporosis. These include, in particular, coeliac disease (although there are some doubts regarding this), hormone insensitivity syndromes, body mass and vitamin metabolism (Szathmari et al. 1997; Mora et al. 1999). In addition, recent developments in molecular genetics have led to the identification of specific genes associated directly with an increased risk of development of osteoporosis. Mutations in type 1 collagen appears to be associated with osteoporosis (Prockop \& Kivirikko, 1995). A key step in osteoblast formation and differentiation requires a specific transcription factor, CBFA1, since in its absence skeleton formation in mice is severely affected (Rodan \& Harada, 1997). In this case the mutant mice fail to survive. A range of genes have been found to be essential to normal limb formation in experimental animals but in many cases, the mechanism of the effect is unclear. A brief summary of some of these has been provided by Rodan (1998).

Indirect factors associated with genetic predisposition have been noted above. A major factor is the occurrence of coeliac disease. Measurement of bone mineral density in coeliac patients established an apparent link between persistent villous atrophy of the small bowel and lower bone mineral density (Valdimarsson et al. 1994). Other studies have supported this observation including a study in which historical data suggested the correlation between bone density and age of diagnosis of coeliac disease or time of adherence to a gluten-free diet in adults (Pistorius et al. 1995). The effects of a gluten-free diet in children were studied and appeared to cause a rapid increase in bone mineral density (Mora et al. 1998) but other workers found that a low gluten diet could not, on its own, lead to an increase in bone mineral density (Szathmari et al. 1997). Finally, one group of researchers found metabolic bone disease to be an early diagnostic marker for coeliac disease and they suggested that undiagnosed coeliac disease could be a risk factor for osteoporosis (Hernandez et al. 1997).

A second major genetic risk factor for the onset of osteoporosis is sex steroid deficiency. At menopause (or after castration in men) the rate of bone loss in the spine increases as much as tenfold (Manolagas, 1998). There appears to be a considerable association between osteoporosis and interleukin-6 (IL-6) lytokine function. Briefly, enhanced production of IL-6 is associated with loss of sex hormone brought about by a loss of gonadal function and this leads to increased bone resorption. In addition, IL-6 (and/or IL-6 receptor) also appears to be involved in a range of conditions associated with increased bone resorption including Paget's disease, rheumatoid arthritis and Gorhamstout or disappearing bone disease (Manolagas, 1998). Other cytokines (e.g. IL-1, tumour necrosis factor- $\alpha$ (TNFL) appear to stimulate the production and/or survival of osteoclasts thereby increasing bone resorption.

4.2.2. Environmental factors. Primary prevention of osteoporosis involves diet and physical activity at all life stages. Animal studies have shown that exercise can reduce the onset of loss of bone mineral density.

The principal dietary influences on bone density and risk of osteoporosis are considered to be calcium (and other mineral intake) and vitamin D. The possible influence of a range of factors on bone mineral density including weightbearing physical activity, daylight hours spent outdoors and dietary factors have been investigated (Gunnes \& Lehmann, 1995). In adolescents, bone mineral density was predicted by saturated fat, vitamin $\mathrm{C}$ and calcium but not by daylight hours spent outdoors or by physical activity. An eighteenyear prospective study which focused on dietary calcium in a single 24-h dietary recall obtained eighteen years previously suggested that the bone mineral density at hip sites increased significantly with the increasing tertile of calcium intake for women, however no effect was observed for men (Holbrook \& Barrett-Connor, 1995).

The role of vitamin $\mathrm{D}$ has also been extensively investigated. Vitamin $\mathrm{D}$ is converted into vitamin $\mathrm{D}_{3}$ in the skin upon exposure to sunlight and this intermediate is gradually transformed into 1,25-dihydroxy vitamin D, which acts to maintain serum calcium and phosphorus levels within the normal range. Numerous studies have been carried out in populations and in animal models which confirm the importance of vitamin D in the prevention of osteoporosis (Holick, 1996; Kaufman, 1995).

Other minerals which have been associated with preventions of bone loss and osteoporosis include magnesium (Rude et al. 1998), copper (Yee et al. 1995) and vitamins C (Leveille et al. 1997) and K (Feskanich et al. 1999). 
Other environmental and dietary factors which have been associated with osteoporosis and bone loss (either as causative or as protective agents) include phytoestrogens in postmenopausal women (Humfrey, 1998), fruit and vegetable intake (Tucker et al. 1999), antioxidants (Melhus et al. 1999), a range of dietary factors including iron and magnesium (Michaelsson et al. 1995), xylitol (Svanberg \& Knuuttila, 1994; Mattila et al. 1998) and alcohol intake (Fanti et al. 1997; Sampson \& Shipley, 1997). In many cases the potential mechanisms involved are unclear and conflicting data have been produced.

\subsection{Current biomarkers}

There are a range of potential biomarkers for measuring both the onset of osteoporosis, the likelihood of it taking place and the effects of dietary constituents.

4.3.1. Systemic. A range of bone turnover markers and hormones, which regulate skeletal metabolism, can be measured. In general, high levels of bone turnover occur during periods of rapid bone remodelling and growth but should diminish during adulthood. In the case of osteoporotic patients, high turnover and increased frequency of remodelling actuation sites occurs. A range of markers have been recently reviewed (Christenson, 1997) (Table 9). Although a number of these markers have been used, most of them lack specificity, but pyridinoline and deoxypyridinoline cross-links and the markers for bone formation would appear to be of greater value than, for example, the measurement of urinary calcium the level of which depends on a range of factors including diet and renal function (Nordin et al. 1999).

Bone turnover markers can provide information rapidly on the responsiveness of bone to intervention studies or therapy. They do, however, exhibit high levels of inter- and intra-individual variability and this limits their use particularly for epidemiological studies. A second problem which arises with bone turnover markers as indicators for osteoporosis is the half-life of bone response which is reflected in the slow response time and in the bone remodelling transient which is of the order of 2 years after an intervention.

There are a number of methods for measurement of bone biomarkers. Some of the more direct measures of bone density, bone geometry and bone strength are discussed below. The measurement of tartrate-resistant acid phosphatase (TRAP) using antibodies has been carried out by Janckia et al. (1998). Woitge et al. (1999) assessed a range of serum markers for bone resorption in different populations including pre- and postmenopausal women, patients with hepatic dysfunction, Paget's disease, multiple myeloma and breast cancer both with and without bone metastases. The chosen markers - serum measures of C-terminal and N-terminal telepeptides of type I collagen and bone scaloprotein - were compared with conventional markers including urinary total pyridinoline and total deoxypyridinoline and urinary total C-terminal and $\mathrm{N}$-terminal telepeptides of type I collagen. They concluded that serum markers reflected bone resorption to the same extent as urinary markers and may therefore be of value where urinary markers are inappropriate.
Table 9. Systemic markers for bone turnover (from Christiansen, 1997)

\begin{tabular}{ll}
\hline Marker & Pathophysiological change \\
\hline Alkaline phosphatase B & Bone formation \\
Procollagen/extension peptides & Bone formation \\
Osteocalcin & Bone formation/resorption \\
Urinary calcium & Bone resorption ? \\
$\begin{array}{l}\text { Acid phosphatase } \\
\text { (TRAP) }\end{array}$ & Bone resorption \\
Hydroxyproline & \\
$\begin{array}{l}\text { Telopeptides } \\
\text { Pyridinoline and deoxypyridinoline } \\
\text { cross-links }\end{array}$ & Bone resorption \\
\hline
\end{tabular}

4.3.2. Target organ. Target organ biomarkers are those that are local to a specific area of bone (e.g. a fracture) and are made on specific bone structures.

Bone density. The mineral content of the entire skeleton and of specific portions of the body can be measured in vivo by the use of several radiological techniques. Currently, dual energy X-ray absorptiometry (DXA) and quantitative computed tomography (QCT) are the most widely used, although the former is preferred for its low invasiveness. DXA measures the attenuation caused by bone and by soft tissues of a photon beam emitted from X-ray tubes. Appropriate algorithms permit the discrimination of different tissues and the measurement of the mineral content of the region identified as bone. DXA is able to quantitate the areas of the regions identified as bone (bone area, BA) and their average density (bone mineral density, BMD). BMD is given as 'aerial density' and is therefore expressed as $\mathrm{g} / \mathrm{cm}^{2}$.

Assuming a constant relationship between scanned area and bone thickness, bone mineral content (BMC, g) can be calculated. QCT provides a three-dimensional image of the skeleton and therefore allows BMD to be calculated based on the true anatomical dimensions of the bone. However, BMD measured by QCT includes marrow spaces and is therefore referred to as an 'apparent density'. It is expressed in $\mathrm{g} / \mathrm{cm}^{3}$. Both the aerial density and the apparent density are correlated to the 'true density' of the bone, i.e. the ratio of bone ash weight per $\mathrm{cm}^{3}$ of true bone volume, excluding marrow spaces and porosity. The assumptions inherent in each technique have to be considered in their application. Thus, aerial density cannot be used to compare bone density in individuals with changes in skeletal dimensions, such as children, and for comparing populations of different skeletal size, unless suitable correction procedures are applied.

BMD measurements can be carried out in the whole body or at the peripheral level, particularly the hip and the lumbar spine. In women, there is an age-related decline in BMD at all non-spine skeletal sites, although the largest decline is observed in the femoral neck; in men there are no significant changes at all non-spine sites (Krall et al. 1997). The measurement at the site of fracture is more predictive of the risk of fracture than at the other sites, at the proximal femur there is a 2.6-fold change in risk per each SD of BMD change, and this allows a good classification of individuals for decision on treatment. A cheap non-invasive alternative to peripheral DXA might be ultrasonography of the 
calcaneal region (quantitative ultrasound). This measures broadband ultrasonic attenuation and the velocity of sound to obtain BMD estimates. Repeated measurements of BMD can be used to evaluate changes in bone mass. The most precise apparatus has a $\mathrm{CV}$ of $1 \%$ and the average bone loss is $3 \%$ per year; thus, measurements at less than 1-year intervals are not useful. Comparisons of the observed BMD values with those of a reference population, measured with the same apparatus, allow classification of individuals according to their bone health. The WHO considers that an individual is normal when her/his BMD is above $-1 \mathrm{SD}$ of the population reference; osteopenic with BMD between -1 and $-2.5 \mathrm{SD}$ and osteoporotic with BMD below -2.5 SD.

Bone geometry and bone strength. The size and shape of the bones, as well as the trabecular architecture are also predictors of bone strength, which is the outcome indicator of interest in the study of osteoporosis (Peacock et al. 1995). Methods to evaluate bone geometry are currently being developed, using computer software attached to DXA and QCT machines. The important parameter appears to be the length of the femur neck. A hip axis length index has been calculated (Duboeuf et al. 1997) and evaluated in populations; each SD increase in hip axis length doubled fracture risk. A fall index has also been calculated, that combines the length of the femur neck and the BMD; this may possibly explain the lower fracture rate in the Japanese, despite lower BMD (Testi et al. 1999). Methods for predicting bone strength in vivo are also being developed. They also use DXA and QCT to look at the size of the bones and at the bone mineral distribution in a cross-section (Petersen et al. 1996; Cody et al. 1999; Sarin et al. 1999).

In addition, computer modelling of the cross-section modules, can produce an index of bending strength. The latest development of such techniques, called hip stress analysis, predicts the bending strength of excised femurs better than BMD alone.

\subsection{Profile of effects of nutrient interventions}

As noted previously a range of dietary constituents have been implicated in bone health and osteoporosis. The essence is that a beneficial factor should be one which maintains high turnover in the young and low turnover during adulthood.

4.4.1. Calcium intake. Calcium and vitamin D have been extensively studied as factors in osteoporosis and bone disease. (Holbrook et al. 1991; Kaufman, 1995; Holick, 1996). In the five years after menopause, a calcium intake above $800 \mathrm{mg} /$ day is not able to inhibit the rapid loss of skeletal mass, although a marginal protective effect in compact bone has been observed (Riis et al. 1987). In the following period, calcium intake has greater importance. A quicker skeletal loss has been observed for intake levels below $800 \mathrm{mg}$ (Dawson-Hughes et al. 1993a). With intakes of $1500-1700 \mathrm{mg} / \mathrm{day}$, in combination with moderate exercise, a delay in bone loss has been observed (Prince et al. 1991).

Lifetime calcium intake has been shown to correlate with adult BMD and greater calcium intake during infancy and adolescence leads to a higher BMD. On the other hand, populations with low calcium intakes, such as the Japanese, have lower fracture rates than the Europeans or the Americans (Stini, 1995). Poor vitamin D intake, in the absence of sufficient exposure to sunlight, is also thought to contribute to increased bone loss in the elderly. Recently, micronutrients, such as zinc and copper, and bioactive compounds, such as phytoestrogens (Eden, 1998), have been recognised as important determinants of bone mass. The effect of the early exposure to some of these compounds is thought to condition bone metabolism later in life (Soroko et al. 1994). The effect of dietary factors on other components of bone fragility, such as bone geometry and the microarchitecture of the bone tissue, has not been studied.

4.4.2. Trace elements. Minerals and trace elements other than calcium are involved in skeletal growth, some of them as matrix constituents, such as magnesium and fluoride, others as components of enzymatic systems involved in matrix turnover, such as zinc, copper and manganese. Insufficient dietary supply of these nutrients results in reduced bone growth or in the formation of defective bone (Saltman \& Strause, 1992). The relationship between trace element content and mechanical bone strength has been investigated (Jensen et al. 1997). The role of certain individual trace elements has also been studied including copper (Eaton-Evans et al. 1996) and zinc (Yamaguchi \& Kishi, 1993). Supplementation with both of these has a preventative effect in bone loss.

In addition to vitamin $\mathrm{D}$, vitamins $\mathrm{C}$ and $\mathrm{K}$ are also required for optimal bone metabolism. Vitamin $\mathrm{C}$ (ascorbic acid) is required for the synthesis of type I collagen, the main organic component of bone and for the vitamin-C dependent intracellular hydroxylations that allow the formation of collagen cross-links. Vitamin $\mathrm{K}$ is required for the synthesis of functional osteocalcin, an important structural protein of the bone matrix.

4.4.3. Dietary control of sex hormone metabolism. The effects of sex hormones on bone formation and resorption have been extensively studied (reviewed in Oursler, 1998) and recent studies have suggested that the mechanism whereby oestrogen can decrease bone formation does not require a prior reduction in bone resorption (Turner et al. 1999). The role of oestrogen receptors remains unclear, but the presence of both oestrogen receptor alpha and oestrogen receptor beta in bone (Arts et al. 1997) and the differential effect of binding ligands to each (Paech et al. 1997) suggest that further work could be of great value in this area. A recent investigation has linked oestrogen receptor beta polymorphisms with BMD and postmenopausal osteoporosis in Japanese women (Ogawa et al. 2000). The principal effects of oestrogens appear to be on resorption. There are a number of theories of how this could occur including direct effects on both osteoclasts and osteoblasts. Further work using model systems would clearly be of benefit and these may enable shorter-term intervention studies to be carried out.

The metabolism of sex hormones is influenced by the nutritional status of the individual and by the main dietary components, such as protein, fat, carbohydrates and fibre. High protein and fat and low complex carbohydrates and fibre intake lead to higher plasma levels of biologically 
active sex hormones and lower sex hormone binding globulin (SHBG) (Adlercreutz et al. 1992). In addition, several compounds with oestrogenic properties have been identified in plant foods of different kinds, such as fruits, vegetables, cereals and oils, both as natural constituents and as contaminants (Price \& Fenwick, 1985). Classes of compounds of interest are the isoflavones, lignans, coumestans, resorcylic acid lactones and indole, although only a restricted number of compounds has been shown to have oestrogenic properties. Clinical trials have also been performed mainly looking at the levels of oestrogens in premenopausal women ( $60 \mathrm{~g}$ of texturised soy protein was found to decrease follicle stimulating hormone and lutenising hormone and increase menstrual cycle length, due to changes of the follicular phase, Cassidy et al. 1994) or postmenopausal women (a soy-supplemented diet did not decrease these hormones, or increase SHBG, Baird et al. 1995).

The identification of high levels of phytoestrogens in the blood of children fed on soy milk (Setchell et al. 1997) has raised the question of the effect of these compounds in growing individuals and on future sensitivity to oestrogens. However, data on the effects of these compounds on bone mass and turnover are not available.

\subsection{Study types}

A number of studies have been carried out to determine if particular groups are at greater risk of developing osteoporosis. Both the formation and the subsequent maintenance of skeletal mass are under the control of environmental, hormonal and genetic factors. Studies in twins indicate that approximately $80 \%$ of the mass is genetically determined. Genetic polymorphism of the vitamin D receptor gene and defects of the collagen I gene, such as the one leading to osteogenesis imperfect, are associated to differences in bone mass and turnover. Different gene alleles have been found to be associated with different osteocalcin levels; the difference can explain $20 \%$ of the variation of bone density.

Other studies suggest that environmental factors such as physical activity and calcium intake can contribute $40 \%$ of the variance in bone density each, thus suggesting that there is a considerable overlap and interaction of the different factors (Ryan et al. 1998). However, the short-term effect of postmenopausal diet has been questioned (Earnshaw et al. 1997).

A number of studies have linked physical activity with prevention of bone loss particularly in post-menopausal women (Iwamoto et al. 1998; Kelly, 1998).

There is probably an interaction between genetic and environmental factors, as both the capacity to handle calcium balance and probably the response to exercise are mediated by genetic factors.

\section{Conclusion}

The role of biomarkers in diet and health provides a useful starting point for biomarker studies. The essential qualities of biomarkers - responsiveness, specificity, ease of use, applicability and relevance - apply particularly in this area.
The examples chosen reflect three major diet-related disease issues. In each case the onset of the disease has a genetic determinant which can be exacerbated or delayed by diet. The measurement of specific biomarkers can, to a greater or lesser extent, help in the development of the assessment of likelihood of disease onset or delay of clinical outcome. Perhaps the most important factor is that in each case the disease, once manifest, is difficult to influence in a positive way by diet alone. This then suggests that the emphasis for biomarker studies should focus on predictive biomarkers (Benford et al. 2000) which can be used to help in the development of dietary strategies which will minimise the risk and be of greater benefit.

The biomarker approach can be applied to diet and health however, as the examples given indicate, it is difficult to establish causality between health states and specific dietary constituents in the first place. It is necessary to take that process a step further by knowing something of the mechanism of the process if appropriate biomarkers are to be developed and used. It is possible, however, to treat the problem in an iterative way. Biomarkers may help to reveal some detail of the mechanism, which in turn may assist in the development of other biomarkers, which reveal more about the mechanisms and so on. In this way a more complete picture can be built up of a diet-health axis. In the case of cancer there are no true predictive biomarkers, however there are a number of dietary components which may have an effect (albeit unquantifiable) whose mechanisms of action are partially known and fit with a perceived risk profile. For example, dietary compounds which cause induction of phase 2 enzymes are likely to help to prevent DNA damage and, since this molecular event is recognised as the first step on the action of genotoxic carcinogens, such compounds will probably help to lower the risk of cancer developing by this route. The problem is that there is no scale, which indicates the extent of the lessening of risk when damage is measured in urine, blood or even in the target organ.

In coronary heart disease there are a greater number of potential measurements, which can be made, however, with the exception of dietary folate, the mechanistic basis is unclear and there is also, as for cancers, a significant genetic component. It is possible, however, to develop a 'score' of risk factors even if the weighting attached to each is not currently quantifiable. By further refining this scoring system to include factors such as lipoprotein levels in blood, cysteine and folate, cholesterol, lipids and BMI, it should be possible to advise on preventative action which can be mediated by diet and to test the effectiveness of this action. This holistic approach to biomarkers offers the greatest opportunity and potential at this time.

For osteoporosis, apart from a few distinct dietary constituents in specific groups (e.g. minerals, oestrogens in postmenopausal women), biomarkers of the type that have been discussed here are unlikely to be developed. Predictive, specific and sensitive biomarkers, which are directly linked to diet, are particularly scarce.

The accumulation of information on biomarkers continues to grow. Although this is to be welcomed, the key attributes of biomarkers - predictivity and responsiveness to changes in diet in a way which reflects a future health 
outcome - should be maintained and act as a testing procedure for research in this area. Ultimately the true test of a biomarker will be how much it is used and how its use affects diet and health. This requires that a profound knowledge of the link between diet and health is developed and biomarkers can contribute both to using the knowledge and to developing the strength of the link.

\section{References}

Abou-Hozaifa B (1997) Effect of selenium supplementation on plasma lipid and lipoprotein cholesterol levels in adult rats. Saudi Medical Journal 18, 294-298.

Adlercreutz H (1995) Phytoestrogens: epidemiology and a possible role in cancer protection. Environmental Health Perspectives 7, $103-112$.

Adlercreutz H, Mousavi Y, Clark J, Hockerstedt K, Hamalainen E, Wahala K, Makela T \& Hase T (1992) Dietary phytoestrogens and cancer: in vivo and in vivo studies. Journal of Steroid Biochemistry and Molecular Biology 41, 331-337.

Akella GD, Henerson SA \& Drewnowski A (1997) Sensory acceptance of Japanese green tea and soy products is linked to genetic sensitivity to 6-n-propylthiouracil. Nutrition and Cancer 29, 146-151.

Albaugh GP, Iyengar V, Lohani A, Malayeri M, Bala S \& Nair PR (1992) Isolation of exfoliated colonic epithelial cells. A novel non-invasive approach to the study of cellular markers. International Journal of Cancer 52, 347-350.

Albertini RJ \& Hayes RB (1997) Somatic cell mutations in cancer epidemiology. IARC Science Publications 142, 159-184.

Alberts DS, Einspahr J, Rees-McGee S, Ramanujam P, Buller MK, Clark L, Ritenbauch C, Atwood J, Penthigal P, Earnest D \& Villar H, Phelps J, Lipkin M, Wargrovich MJ \& Meyskens FL (1990) Effects of dietary wheat bran fiber on rectal epithelial cell proliferation in patients with resection for colorectal cancers. Journal of the National Cancer Institute 82, 1280-1285.

Alberts DS, Einspahr J, Ritenbaugh, Aickin C, Rees-McGee S, Atwood J, Emerson S, Mason-Liddil N, Bettinger L, Patel J, Bellapravalu S, Ramanujam PS, Phelps J \& Clark L (1997) The effect of wheat bran fiber and calcium supplementation on rectal mucosal proliferation rates in patients with resected adenomatous colorectal polyps. Cancer Epidemiology, Biomarkers and Prevention 6, 161-169.

Alberts DS, Ritenbaugh C, Story JA, Aickin M, Rees-McGee S, Buller MK, Atwood J, Phelps J, Ramanujam P, Bellapravalu S, Patel J, Bettinger L \& Clark L (1996) Randomized, doubleblinded, placebo-controlled study of effect of wheat bran fiber and calcium on fecal bile acids in patients with resected adenomatous colon polyps. Journal of the National Cancer Institute 88, 81-92.

Alessandri C, Basili S, Leonardo M, Pettirossi G, Paradiso M, Coppotelli L, Pergolini M \& Cordova C (1994) Multifactorial therapeutic approach to secondary prevention in coronary heart disease: preliminary report after 3-year follow-up. Current Therapeutic Research 55, 1201-1210.

Aloia JF, Vaswani A, Yeh JK \& Flaster E (1996) Risk for osteoporosis in black women. Calcification and Tissue International 59, 415-423.

Anderson D, Jenkinson PC, Dewdney RS, Francis AJ, Godbert P \& Butterworth KR (1988) Chromosome aberrations, mitogeninduced blastogenesis and proliferative rate index in peripheral lymphocytes from 106 control individuals of the UK population. Mutation Research 204, 407-420.

Anderson JW (1995) Dietary fibre, complex carbohydrate and coronary artery disease. Canadian Journal of Cardiology 11, $55-62$.
Anderssen N, Jacobs DR Jr, Sidney S, Bild DE, Sternfeld B, Slattery ML \& Hannan P (1996) Change and secular trends in physical activity patterns in young adults: a seven year longitudinal follow up in the Coronary Artery Risk Development in Young Adults Study (CARDIA). American Journal of Epidemiology 143, 351-362.

Anker P, Lefort F, Visioukhin V, Lyautey J, Lederrey C, Chen XQ, Stroun M, Mulcahy HE \& Farthing MJG (1997) K-ras mutations are found in DNA extracted from the plasma of patients with colorectal cancer. Gastroenterology 112, 1114-1120.

Arif JM \& Gupta RC (1997) Detection of DNA-reactive metabolites in serum and their tissue distribution in mice exposed to multiple doses of carcinogen mixtures: role in human biomonitoring. Carcinogenesis 17, 2213-2219.

Arts J, Kuiper GG, Janssen JM, Gustafsson JA, L"owik CW, Pols HA \& van Leeuwen JP (1997) Differential expression of estrogen receptors alpha and beta mRNA during differentiation of human osteoblast SV-HFO cells. Endocrinology 138, 5067-5070.

Ashby J (1988) Comparison of techniques for monitoring human exposure to genotoxic chemicals. Mutation Research 204, $543-551$.

Ashwell M (1997) Meat and colorectal cancer - the unanswered questions and the commitment of the Meat and Livestock Commission to finding the answers through strategic research. ECP-News 31, 4-7.

Augustsson K, Lindblad J, Overvik E \& Steineck G (1999) A population-based dietary inventory of cooked meat and assessment of the daily intake of food mutagens. Food Additives and Contaminants 16, 215-225.

Austin M (1996) Genetic epidemiology of dyslipidaemia and atherosclerosis. Annals of Medicine 28, 459-463.

Austin MA, Rodriguez BL, McKnight B, Curb JD \& Sharp DS (1997) Low-density lipoprotein (LDL) particle size and plasma triglyceride (TG) as predictors of coronary heart disease (CHD) in older Japanese American men. Circulation 70th Scientific Sessions of the American Heart Association 96, I337.

Baird DD, Umbach DM, Lansdell L, Hughes CL, Setchell KD, Weinberg CR, Hanley AF, Wilcox AJ \& Mclachlan JA (1995) Dietary intervention study to assess estrogenicity of dietary soy among postmenopausal women. Journal of Clinical Endocrinology and Metabolism 80, 1685-1690.

Baldwin WS \& LeBlanc GA (1992) The anti-carcinogenic plant compound indole-3-carbinol differentially modulates P450mediated steroid hydroxylase activities in mice. Chemical Biological Interactions 83, 155-169.

Ballal RS, Jacobsen DW \& Robinson K (1997) Homocysteine: update on a new risk factor. Cleveland Clinical Journal Medicine 64, 543-549.

Barter PJ (1997) Inhibitin of endothelial cell adhesion molecule expression by high density lipoproteins. Clinical and Experimental Pharmacology and Physiology 24, 286-287.

Bartram HP, Gostner A, Kelber E, Dusel G, Weimer W, Scheppach W \& Kasper H (1996) Effects of fish oil fecal bacterial enzymes and steroid excretion in healthy volunteers: implications for colon cancer prevention. Nutrition and Cancer 25, 71-78.

Bartram HP, Gostner A, Reddy BS, Rao CV, Scheppach W, Dusel G, Richter A, Richter F \& Kasper H (1995) Missing antiproliferative effect of fish oil on rectal epithelium in healthy volunteers consuming a high-fat diet: potential role of the n-3:n-6 fatty acid ratio. European Journal of Cancer Prevention 4, 231-237.

Bartram HP, Scheppach W, Gerlach S, Ruckdeschel G, Kelber E \& Kasper H (1994) Does yogurt enriched with Bifidobacterium longum affect colonic microbiology and fecal metabolites in healty subjects. American Journal of Clinical Nutrition $\mathbf{5 9}$, $428-432$. 
Bartram HP, Scheppach W, Schmid H, Hofmann A, Dusel G, Richter F, Richter A \& Kasper H (1993) Proliferation of human colonic mucosa as an intermediate biomarker of carcinogenis: effect of butyrate, desoxycholate, calcium, ammonia, and $\mathrm{pH}$. Cancer Research 53, 3283-3288.

Bartsch H (1991) N-nitroso compounds and human cancer: where do we stand? IARC Scientific Publication 105, 1-10.

Bartsch H \& Hietanen E (1996) The role of individual susceptibility in cancer burden related to environmental exposure. Environmental Health Perspectives 104, 569-577.

Bautista D, Obrador A, Moreno V, Vabeza E, Canet R, Benito E, Bosch X \& Costa J (1997) Ki-ras mutation modifies the protective effect of dietary monounstaurated fat and calcium on sporadic colorectal cancer. Cancer Epidemiology, Biomarkers and Prevention 6, 57-61.

Beach AC \& Gupta RC (1992) Human biomonitoring and the ${ }^{32}$ P-postlabeling assay. Carcinogenesis 13, 1053-1074.

Benford DJ, Hanley AB, Bottrill K, Oehlschlager S, Balls M, Branca F, Castegnaro JJ, Descotes J, Hemminiki K, Lindsay D \& Schilter B (2000) Biomarkers as predictive tools in toxicity testing. ATLA 28, 119-131.

Berenson GS, Srinivasam SR \& Nicklas TA (1998) Atherosclerosis: a nutritional disease of childhood. American Journal of Cardiology 82, 22T-29T.

Biasco G, Zannoni U, Paganelli GM, Santucci R, Gionchetti P, Rivolta G, Miniero R, Pironi L, Calabrese C, Diefebo G \& Migliolo M (1997) Folic acid supplementation and cell kinetics of rectal mucosa in patients with ulcerative colitis. Cancer Epidemiology, Biomarkers and Prevention 6, 469-471.

Bingham SA (1996) Epidemiology and mechanisms relating diet to risk of colorectal cancer. Nutrition Research Reviews 9 , 197-239.

Bingham SA (1997) The potential role of endogenously formed $\mathrm{N}$-nitroso compounds in colorectal cancer. ECP-News 31, 12-15.

Bingham SA, Pignatelli B, Pollock JRA, Ellul A, Malaveille C, Gross G, Runswick S, Cummings JH \& O'Neill IKO (1996) Does increased endogenous formation of N-nitroso compounds in the human colon explain the association between red meat and colon cancer? Carcinogenesis 17, 515-523.

Birkett A, Muir J, Phillips J, Jones G \& O’dea K (1996) Resistant starch lowers fecal concentrations of ammonia and phenols in humans. American Journal of Clinical Nutrition 63, 766-772.

Block G, Patterson B \& Subar A (1992) Fruit vegetables, and cancer prevention: a review of the epidemiological evidence. Nutrition and Cancer 18, 1-29.

Bloomgarden ZT (1998) Insulin resistance - current concepts. Clinical Therapeutics 20, 216-231.

Bogaards JJ, Verhagen H, Willems MI, van Poppel G \& van Bladeren PJ (1994) Consumption of Brussels sprouts results in elevated alpha-class glutathione S-transferase in human blood. Carcinogenesis 15, 1073-1075.

Boldt J, Rothe G, Schindler E, Doel C, Goerlach G \& Hempelmann $\mathrm{G}$ (1996) Can clonidine, enoximone, and enalaprilat help to protect the myocardium against ischaemia in cardiac surgery. Heart (London) 76, 207-213.

Bolton-Smith C, Woodward M \& Tunstall-Pedoe H (1992) The Scottish heart health study dietary intake by food frequency questionnaire and odds ratios for coronary heart disease risk 1. The Macronutrients. European Journal of Clinical Nutrition 46, $75-84$.

Boutron MC, Faivre J, Marteau P, Couillault C, Senesse P \& Quipourt V (1996) Calcium, phosphorus, vitamin D, dairy products and colorectal carcinogenesis: a French case-control study. British Journal of Cancer 74, 145-151.

Brady JA, Rock CL \& Horneffer MR (1995) Thiamin status, diuretic medications, and the management of congestive heart failure. Journal of the American Dietetic Association 95, 541-544.

Breuer NF, Dommes P, Jaekel S \& Goebell H (1985) Fecal bile acid excretion pattern in colonic cancer patients. Digestive Diseases and Sciences 30, 852-859.

Brezitskaya ON \& Sedov KR (1991) The platelet-vascular component of the hemostatic system in residents of the far North. Vestnik Akademii Meditsinskikh Nauk SSSR 10, 42-45.

Brockton N, Little J, Sharp L \& Cotton SC (2000) N-acetyltransferase polymorphisms and colorectal cancer: a HuGE review. American Journal of Epidemiology 151, 846-861.

Brouwer IA, van Dusseldorp M, West CE, Meyboom S, Thomas CM, Duran M, van het Hof KH, Eskes TK, Hautvast JG \& Steegers-Theunissen RP (1999a) Dietary folate from vegetables and citrus fruit decreases plasma homocysteine concentrations in humans in a dietary controlled trial. Journal of Nutrition 129, $1135-1139$.

Brouwer IA, van Dusseldorp M, Thomas CM, Duran M, Hautvast JG, Eskes TK \& Steegers-Theunissen RP (1999b) Low-dose folic acid supplementation decreases plasmahomocysteine concentrations - a randomized trial. American Journal of Clinical Nutrition 69, 99-104.

Brown WV (1997) Hypercholesterolemia in the United States: how far have we come? American Journal of Medicine 102, 3-6.

Burmer GC, Rabinovitch PS \& Loeb LA (1991) Frequency and spectrum of c-Ki-ras mutations in human sporadic colon carcinomas arising in ulcerative colitis and pancreatic adenocarcinoma. Environmental Health Perspectives 93, 27-31.

Burnouf D, Miturski R, Nagao M, Nakagama H, Nothisen M \& Wagner (2000) Molecular approach in cancer epidemiology: early detection of carcinogens mutations in a whole genome (Review). International Journal of Molecular Medicine 5, 15-20.

Carr SJ, Moore D, Sikand K \& Norman RI (1997) Raised affinity for extracellular sodium of the sodium-lithium countertransporter is associated with a family history of hypertension and uraemia in patients with renal disease. Clinical Science $\mathbf{9 2}$, 497-503.

Cassidy A, Bingham S \& Setchell KDR (1994) Biological effect of isoflavones present in soy in premenopausal women: implications for the prevention of breast cancer. American Journal of Clinical Nutrition 60, 333-334.

Cassidy A, Bingham S \& Setchell KDR (1995) Biological effects of isoflavones in young women - importance of the chemical composition of soya products. British Journal of Nutrition 74, 557-560.

Cassidy A, Hanley B \& Lamuela-Raventos RM (2000) Isoflavones, lignans and stilbenes - origins, metabolism and potential importance to human health. Journal Science Food and Agriculture 80, 1044-1062.

Cats A, Kleinbeuker JH, Van Der Meer R, Kuipers F, Sluiter WJ, Hardonk MJ, Oremus EThHGJ, Mulder NH \& DeVrues EGE (1995) Randomized, double-blinded placebo-controlled intervention study with supplemental calcium in families with hereditary nonpolyposis colorectal cancer. Journal of the National Cancer Institute 87, 598-603.

Chambless LE, Heiss G, Folsom AR, Rosamond W, Szklo M, Sharrett AR \& Clegg L (1997) Association of coronary heart disease incidence with carotid arterial wall thickness and major risk factors: The Atherosclerosis Risk in Communities (ARIC) Study, 1987-1993. American Journal of Epidemiology 146, 483-494.

Chen X \& Huang G (1992) A pathological study of sudden coronary death in China Report of 89 Autopsy Cases. Forensic Science International 57, 129-137.

Chenevix-Trench G, Young J, Coggan M \& Board P (1995) 
Glutathione S-transferase M1 and T1 polymorphisms: susceptibility to colon cancer and age of onset. Carcinogenesis 16, 1655-1657.

Cheng TJ, Christiani DC, Xu X, Wain JC, Wiencke JK \& Kelsey KT (1995) Gluthathione S-transferase u genotype, diet, and smoking as determinants of fister chromid exchange frequency in lymphocytes. Cancer Epidemiology, Biomarkers and Prevention 4, 535-542.

Chisolm DJ, Samaras K, Markovic T, Carey D, Lapsys N \& Campbell LV (1998) Obesity: genes, glands or gluttony. Reproduction, Fertility and Development 10, 49-53.

Christensen RH (1997) Biochemical marker of bone metabolism: an overview. Clinical Biochemistry 30, 573-593.

Chrostowska M, Narkiewicz K, Bigda J, Winnicki M, Pawlowski R, Rossi GP \& Krupa-Wojciechowska B (1998) Ambulatory systolic blood pressure is related to the deletion allele of the angiotensin I converting enzyme gene in young normotensives with parental history of hypertension. Clinical Experimental Hypertension 20, 283-294.

Cleeman JI (1997) Adults aged 20 and older should have their cholesterol measured. American Journal of Medicine 102, $31-36$.

Cody DD, Gross GJ, Hou FJ, Spencer HJ, Goldstein SA \& Fyhrie DP (1999) Femoral strength is better predicted by finite element models models than QCT and DXA. Journal of Biomechanics 32, $1013-1020$.

Cohen A (1998) Atheroma of the aortic arch and embolic risk. Annales de Cardiologie et d'Angeiologie (Paris) 47, 683-689.

Compton PJE, Hooper K \& Smith MT (1991) Human somatic mutation assays as biomarkers of carcinogenesis. Environmental Health Perspectives 94, 135-141.

Connelly JB, Roderick PJ, Cooper JA, Meade TW \& Miller GJ (1993) Positive association between self-reported fatty food consumption and factor VII coagulant activity a risk factor for coronary heart disease in 4246 middle-aged mean. Thrombosis and Haemostasis 70, 250-252.

Cook NC \& Samman S (1996) Flavonoids - chemistry, metabolism, cardioprotective effects, and dietary sources. Journal of Nutritional Biochemistry 7, 66-76.

Corcoran GB, Fix L, Jones DP, Moslen MT, Nicotera P, Oberhammer FA \& Buttyan R (1994) Apoptosis: molecular control point in toxicity. Toxicity and Applied Pharmacology 128, 169-181.

Cucherat M \& Boissel JP (1993) A mathematical model for the determination of the optimum value of the treatment threshold for a continuous risk factor. European Journal of Epidemiology 14, 23-29.

Cummings JH, Beatty ER, Kingman SM, Bingham SA \& Englyst HN (1996) Digestion and physiological properties of resistant starch in the human large bowel. British Journal of Nutrition $\mathbf{7 5}$, $733-747$.

Cuny M, Kramar A, Courjal F, Johannsdottir V, Iacopetta B, Fontaine H, Greiner J, Culine S \& Theillet C (2000) Relating genotype and phenotype in breast cancer: an analysis of the prognostic significance of amplification at eight different genes or loci and of p53 mutations. Cancer Research 60, 1077-1083.

Curb JD \& Marcus EB (1991) Body fat, coronary heart disease, and stroke in Japanese men. American Journal of Clinical Nutrition 53, 1612S-1615S.

Dawson-Hughes B, Krall EA \& Harris S (1993b) Risk factors for bone loss in healthy postmenopausal women. Osteoporosis International 3, 27-31.

Dawson-Hughes B, Harris S, Kramich C, Dallal G \& Rasmussen HM (1993a) Calcium retention and hormone levels in black and white women on high- and low- calcium diets. Journal of Bone Mineralogy Research 8, 779-787.

Deakin M, Elder J, Hendrickse C, Peckham D, Baldwin D, Pantin
C, Wild N, Leopard P, Bell DA, Jones P, Duncan H, Brannigan K, Aldersea J, Fryer AA \& Strange RC (1996) Glutathione S-transferase GSTT1 genotypes and susceptibility to cancer: studies of interactions with GSTM1 in lung, oral, gastric and colorectal cancers. Carcinogenesis 17, 881-884.

Deflora S, Izzotti A, Randerath K, Randerath E, Bartsch H, Nair J, Balansky R, Van Schooten F, Degan P, Fronza G, Walsh D \& Lewtas J (1996) DNA adducts and chronic degenerative disease. Pathogenetic relevance and implications in preventive medicine. Mutation Research 366, 197-238.

Delavecchia C, Guala A, Oliviem C, Haitink O, Cadaro F, Luinetti O, Fiocca R, Minelli A, Danesino C \& Bona G (1999) Early on set of gastric carcinoma and constitutional deletion of $18 \mathrm{p}$. Cancer Genetics and Cytogenetics 113, 96-99.

De Pergola G, De Mitrio V, Sciaraffia M, Pannacciulli N, Minenna A, Giorgino F, Petronelli M, Laudadio E \& Giorgino R (1997) Lower androgenicity is associated with higher plasma levels of prothrombotic factors irrespective of age, obesity, body fat distribution, and related metabolic parameters in men. Metabolism Clinical and Experimental 46, 1287-1293.

D’Errico A, Taiolo E, Chen X \& Vineis P (1996) Genetic metabolic polymorphisms and the risk of cancer: a review of the literature. Biomarkers 1, 149-173.

DeStefani E, Ronco A, Mendilahasu M, Guidobobo M \& DeneoPellegrini H (1997) Meat intake, heterocyclic amines, and risk of breast cancer: a case-control study in Uruguay. Cancer Epidemiology, Biomarkers and Prevention 6, 573-581.

Dietschy JM (1998) Dietary fatty acids and the regulation of plasma low density lipoprotein cholesterol concentrations. Journal of Nutrition 128, 444S-448S.

Djuric Z, Heilbrun LK, Reading BA, Boomer A, Valerliote FA \& Martino S (1991) Effects of a low-fat diet on levels of oxidative damage to DNA in human peripheral nucleated blood cells. Journal of the National Cancer Institute 83, 766-769.

Doll R (1991) The lessons of life: keynote address to the Nutrition and Cancer Conference. Cancer Research 52, Suppl, 2024s-2029s.

Doll R (1996) Nature and nurture: possibilities for cancer control. Carcinogenesis 17, 177-184.

Doll R \& Peto R (1981) The causes of cancer: quantitative estimates of avoidable risks of cancer in the United States today. Journal of the National Cancer Institute 66, 1191-1308.

Duboeuf F, Hans D, Schott AM, Kotzki PO, Favier F, Marcelli C, Meunier PJ \& Delmas PD (1997) Different morphometric and densitometric parameters predict cervical and trochanteric hip fracture: the EPIDOS Study. Journal of Bone Mineralogy Research 12, 1895-1902.

Duncan H, Swan C, Green J, Jones P, Brannigan K, Aldersea J, Fryer AA \& Strange RC (1995) Susecptibility to ulcerative colitis and Crohn's disease: interactions between glutathione S-transferase GSTM1 and GSTT1 genotypes. Clinica Chimica Acta 240, 53-61.

Durand P, Prost M \& Blache D (1998) Folate deficcencies and cardiovascular pathologies. Clinical Chemistry and Laboratory Medicine 36, 419-429.

Duthie SJ, Ma A, Ross MA \& Collins AR (1996) Antioxidant supplementation decreases oxidative DNA damage in human lymphocytes. Cancer Research 56, 1291-1295.

Earnshaw SA, Worley A \& Hosling DJ (1997) Current diet does not relate to bone mineral density after the menopause. British Journal of Nutrition 78, 65-72.

Eaton-Evans J, McIIrath EM, Jackson WE, MsCartney H \& Strain JJ (1996) Copper supplementation and the maintenance of bone mineral density in middle-aged women. Journal of Trace Elements in Experimental Medicine 9, 87-94.

Eden J (1998) Phytoestrogens and the menopause. Baillieres Clinical Endocrinology and Metabolism 12, 581-587. 
Egan BM \& Lackland DT (1998) Strategies for cardiovascular disease prevention: importance of public and community health programs. Ethnicity and Disease 8, 228-239.

Elliott TG \& Viberti G (1993) Relationship between insulin resistance and coronary heart disease in diabetes mellitus and the general population: a critical appraisal. Baillieres Clinical Endocrinology and Metabolism 7, 1079-1103.

Ellis EM, Judah DJ, Neal GE, O’Connor T \& Hayes JD (1996) Regulation of carbonyl-reducing enzymes in rat liver by chemoprotectors. Cancer Research 56, 2758-2766.

Erhardt JG, Lim SS, Bode JC \& Bode C (1998) A diet rich in fat and poor in dietary fiber increases the in vitro formation of reactive oxygen species in human feces. Journal of Nutrition 127, 706-709.

Erkkila AT, Sarkkinen ES, Koukkumen H, Kempparen A, Lehto S, Pyorala K \& Uutsiputa MIJ (1998) Concordance of diet with the recommended cholesterol lowering diet in patents with coronary heart disease. European Journal of Clinical Nutrition 52, $279-285$.

Famodu AA, Osilesi O, Makinde YO \& Osonuga OA (1998) Blood pressure and blood lipid levels among vegetarian, semivegetarian, and non-vegetarian native Africans. Clinical Biochemistry 31, 545-549.

Fan KC, Huang YC \& Li CH (1996) Radioimmunoassay for plasma glutathione S-transferase-pi and its clinical application in gastrointestinal cancer. Cancer 76, 1363-1367.

Fang JL \& Vaca CE (1997) Detection of DNA adducts of acetaldehyde in peripheral white blood cells of alcohol abusers. Carcinogenesis 18, 632.

Fang JL, Vaca CE, Valsta LM \& Mutanen M (1997) Determination of DNA adducts of malonaldehyde in humans: effects of dietary fatty acid composition. Carcinogenesis 17, 1033-1040.

Fanti P, Monier-Faugere MC, Geng Z, Cohen D \& Malluche HH (1997) Moderately high consumption of ethanol suppresses bone resorption in ovariectomized but not in sexually intact adult female rats. Clinical Experimental Research 21, 1150-1154.

Faivre J, Couillault C \& Belghiti C (1996) Intervention trials on colorectal cancer prevention. IARC Scientific Publication 139, $115-124$.

Fearon ER (1997) Human cancer syndromes: clues to the origin and nature of cancer. Science 278, 1043-1050.

Fearon ER \& Vogelstein B (1990) A genetic model for colorectal tumorigenesis. Cell 61, 759-767.

Feldman D (1997) Androgen and vitamin D receptor gene polymorphisms: the long and short of prostate cancer risk. Journal of the National Cancer Institute 89, 109-111.

Fenech M \& Rinaldi J (1995) A comparison of lymphocyte micronuclei and plasma micronutrients in vegetarians and nonvegetarians. Carcinogenesis 16, 223-230.

Fenech M, Stockley C \& Aitken C (1997a) Moderate wine consumption protects against hydrogen peroxide-induced DNA damage. Mutagenesis 12, 289-296.

Fenech MF, Dreosti I \& Aitken C (1997b) Vitamin-E supplements and their effect on vitamin-E status in blood and genetic damage rate in peripheral blood lymphocytes. Carcinogenesis $\mathbf{1 8}$, $359-364$.

Fenwick GR \& Hanley AB (1985) The genus Allium. CRC Critical Reviews in Food Science and Nutrition 22, 273.

Feskanich D, Weber P, Willett WC, Rockett H, Booth SL \& Colditz G (1999) Vitamin K intake and hip fractures in women: a prospective study. American Journal of Clinical Nutrition 69, $74-79$.

Fizgerald AP \& Jarrett RJ (1992) Body weight and coronary heart disease mortality an analysis in relation to age and smoking habit 15 years follow-up data from the Whitehall study. International Journal of Obesity 16, 119-123.

Folsom AR, Szklo M, Stevens J, Liao F, Smith R \& Eckfeldt JH
(1997) A prospective study of coronary heart disease in relation to fasting insulin, glucose, and diabetes. The Atherosclerosis Risk in Communities (ARIC) Study. Diabetes Care 20, 935-942.

Frommel TO, Mobarhan S, Doria M, Halline AG, Luk GD, Bowen PE, Candel A \& Liao Y (1995) Effect of $\beta$-carotene supplementation on indices of colonic cell proliferation. Journal of the National Cancer Institute 87, 1781-1787.

Frost PH, Davis BR, Burlando AJ, Curb JD, Guthrie GP Jr, Isaacsohn JL, Wassertheil-Smoller S, Wilson AC \& Stamler J (1996) Serum lipids and incidence of coronary heart disease: findings from the Systolic Hypertension in the Elderly Program (SHEP). Circulation 94, 2381-2388.

Gacllard TR, Schuster DP \& Osei K (1998) Gender differences in cardiovascular risk factors in obese, nondiabetic first degree relatives of African Americans with type 2 diabetes mellitus. Ethnicity and Disease 8, 319-330.

Galanis DJ, McGarvey ST, Sobal J, Bausserman L \& Levinson PD (1995) Relations of body fat and fat distribution to the serum lipid, apolipoprotein and insulin concentrations of Samoan men and women. International Journal of Obesity 19, 731-732.

Garte S, Zocchetti C \& Taioli E (1997) Gene-environment interactions in the application of biomarkers of susceptibility in epidemiology. IARC Science Publications 142, 251-264.

Gazzaruso C, Buscaglia P, Garzaniti A, Falcone C, Mariotti S, Savino S, Boneti G, Finardi G \& Geroldi D (1997) Association of lipoprotein (a) levels and apolipoprotein (a) phenotypes with coronary heart disease in patients with essential hypertension. Journal of Hypertension 16, 227-235.

Gerber M (1996) Fiber and breast cancer: another piece of the puzzle - but still an incomplete picture. Journal of the National Cancer Institute 88, 857-858.

Geypens B, Claus D, Evenepoel P, Hiele M, Maes B, Peeters M, Rutgeerts P \& Ghoos Y (1997) Influence of dietary protein supplements on the formation of bacterial metabolites in the colon. Gut 41, 70-76.

Gibson GR \& Roberfroid MB (1995) Dietary modulation of the human colonic microbiota: introducing the concept of prebiotics. Journal of Nutrition 125, 1401-1412.

Glinghammer B, Venturi M, Rowland IR \& Rafter J (1997) Shift from a dairy product-rich to a dairy product-free diet: influence on cytotoxicity and genotoxicity of fecal water - potential risk factors for colon cancer. American Journal of Clinical Nutrition 66, 1277-1282.

Goldin BR \& Gorbach SL (1984) The effect of milk and lactobacillus feeding on human intestinal bacterial enzymes activity. American Journal of Clinical Nutrition 39, 756-761.

Gooderham NJ (1997) The metabolism of heterocyclic amines. ECP-News 31, 24-26.

Gordon T, Kagan A, Garcia-Palmieri M, Kannel WB, Zukel WJ, Tillotsen J, Sorlie P \& Hjorteand M (1981) Diet and its relation to coronary heart disease and death in three populations. Circulation 63, 500-515.

Gotto AM Jr (1996) Lipid-regulating and antiatherosclerotic therapy: current options and future approaches. Cleveland Clinic Journal of Medicine 63, 31-41.

Graham IM, Daly LE, Refsum HM, Robinson K, Battstrom LE, Ueland PM, Palma-Reis RJ, Boers GH, Sheahan RG, Israelsson B, Uiterwaal CS, Meleadr R, McMaster D, Verhoef P, Witteman J, Rubba P, Bellet H, Wautrecht JC, de Valk HW, Sales Luis AC, Parrot-Rouland FM, Tan KS, Higgins I, Garcon D \& Andria G (1997) Plasma homocysteine as a risk factor for vascular disease. The European Concerted Action Project. Journal of the American Medical Association 277, 1775-1781.

Grove JS, Reed DM, Yano K \& Hwang L-J (1997) Variability in systolic blood pressure. A risk factor for coronary heart disease? American Journal of Epidemiology 145, 771-776. 
Gunnes M \& Lehmann EH (1995) Dietary calcium, saturated fat, fiber and vitamin $\mathrm{C}$ as predictors of forearm cortical and trabecular bone mineral density in healthy children and adolescents. Acta Paediatrica 84, 388-392.

Gylling H, Kontula K, Koivisto UM, Miettinen HE \& Miettinen TA (1997) Polymorphisms of the genes encoding apoproteins A-I, B, C-III and E and LDL receptor, and cholesterol and LDL metabolism during increased cholesterol intake. Common alleles of the apoprotein $\mathrm{E}$ gene show the greatest regulatory impact. Arteriosclerosis Thrombosis and Vascular Biology 17, $38-44$.

Hague A, Singh B \& Paraskeva C (1997) Butyrate acts as a survival factor for colonic epithelial cells: further fuel for the in vivo versus in vitro debate. Gastroenterology 112, 1036-1040.

Hartmann A, Nie AM, Grunert-Fuchs M, Poch B \& Speit G (1995) Vitamin E prevents exercise-induced DNA damage. Mutation Research 364, 195-202.

Haseltine WA, Franklin W \& Lippke JA (1983) New methods for detection of low levels of DNA damage in human populations. Environmental Health Perspectives 48, 29-41.

Hayatsu H \& Hayatsu T (1994) Suppressing effect of Lactobacillus casei administration on the urinary mutagenicity arising from ingestion of fried ground beef in the human. Cancer Letters 73, $2-3$.

Hayatsu H, Hayatsu T \& Ohara Y (1985) Mutagenicity of human urine cause by ingestion of fried ground beef. Japanese Journal of Cancer Research 76, 445-448.

Hegsted DM (1983) Diet, nutrition and cancer. Preventive Medicine 12, 470-474.

Heinrich J, Balleisen L, Schulte H, Assmann G \& Van de Loo J (1994) Fibrinogen and factor VII in the prediction of coronary risk: results from the PROCAM study in healthy men. Arteriosclerosis and Thrombosis 14, 54-59.

Hennekens CH, Gaziano JM, Manson JE \& Buring JE (1995) Antioxidant vitamin-cardiovascular disease hypothesis is still promising, but still unproven: the need for randomised trials. American Journal of Clinical Nutrition 62, 1377S-1380S.

Hernandez ML, Martinez MJ, Lopez de Heredia M \& Ochoa B (1997) Protein phosphatase 1 and 2A inhibitors activate acylCoA: cholesterol transferase and cholesterol ester formation in isolated rat hepatocytes. Biochimica Biophysica Acta 1349, 233-241.

Hertog MGL, Devries A, Ocke MC, Schouten A, Buenodemesquita HB \& Verhagen H (1997) Oxidative DNA damage in humans - comparison between high and low habitual fruit and vegetable consumption. Biomarkers 2, 259-262.

Hesketh R (1997) The Oncogene and Tumour Suppressor Gene Facts Book. New York: Academic Press.

Hill MJ (1994) Fruit and vegetable consumption and cancer risk. ECP-News 26, 3-5.

Hiserodt JC, Perper JA, Koehler SA \& Orchard TJA (1995) comparison of blood lipid and lipoprotein values in young adults who die suddenly and unexpectedly from atherosclerotic coronary artery disease with other noncardiac deaths. American Journal of Forensic Medicine and Pathology 16, 101-106.

Hodgson JM, Wahlqvist ML, Balazs NDH \& Boxall JA (1994) Coronary atherosclerosis in relation to body fatness and its distribution. International Journal of Obesity 18, 41-46.

Holbrook TL \& Barrett-Connor E (1991) Calcium intake: covariates and confounders. American Journal of Clinical Nutrition 53, 741-744.

Holbrook TL \& Barrett-Connor E (1995) An 18-year prospective study of dietary calcium and bone mineral density in the hip. Calcification and Tissue International 56, 364-367.

Holick MF (1996) Vitamin D and bone health. Journal of Nutrition 4, 1159-1164.

Holme I (1990) An analysis of randomized trials evaluating the effect of cholesterol reduction on total mortality and coronary heart disease incidence. Circulation 82, 1916-1924.

Holmer SR \& Riegger GAJ (1995) Role of the cardiac reninangiotensin system in hypertensive heart disease. Herz, 20 $322-329$.

Homann N, Jousimies-Somer H, Jokelainen K, Heine R \& Salaspuro M (1997) High acetaldehyde levels in saliva ater ethanol conuption: methodological aspects and pathogenetic implications. Carcinogenesis 18, 1739-1743.

Hong WK \& Sporn MB (1997) Recent advances in chemoprevention of cancer. Science 278, 1073-1078.

Howard BA, Le N-A, Belcher JD, Flack JM, Jacobs DR Jr, Lewis CE, Marcovina SM \& Perkins LL (1994) Concentrations of Lp (a) in black and white young adults: relations to risk factors for cardiovascular disease. Annals of Epidemiology 4, 341-350.

Hsieh SD \& Yoshinaga H (1995) Is there any difference in coronary heart disease risk factors and prevalence of fatty liver in subjects with normal body mass index having different physiques? Tohoku Journal of Experimental Medicine 177, $223-231$.

Hultberg B, Andersson A \& Isaksson A (2000) Hypomethylation as a cause of homocysteine-induced cell damage in human cell lines. Toxicology 147, 69-75.

Humfrey CD (1998) Phytoestrogens and human health effect: weighing up the current evidence. Natural Toxins 6, 51-59.

Hwang S-J, Ballantyne CM, Sharrett AR, Smith LC, Davis CE, Gotto AM Jr \& Boerwinkle E (1997) Circulating adhesion molecules VCAM-1, ICAM-1, and E-selection in carotid atherosclerosis and incident coronary heart diseases cases: The Atherosclerosis Risk in Communities (ARIC) Study. Circulation 96, 4219-4225.

IARC Publication No 150 (1999) Exocyclic DNA adducts in Mutagenesis and Carcinogenesis. [L Singer and H Bartsch, editors] Lyon: IARC Press.

Ingles SA, Ross RK, Yu MC, Irvine RA, Lapera G, Haile RW \& Coetzee GA (1997) Association of prostate cancer risk with genetic polymorphisms in vitamin $\mathrm{D}$ receptor and androgen receptor. Journal of the National Cancer Institute 89, 166-170.

Iribarren C, Folsom AR, Jacobs DR Jr, Gross MD, Belcher JD \& Eckfeldt JH (1997) Association of serum vitamin levels, LDL susceptibility to oxidation and autoantibodies against MDALDL with carotid atherosclerosis: a case-control study. Arteriosclerosis Thrombosis and Vascular Biology 17, $1171-1177$.

Iwamoto J, Takeda T, Otani T \& Yabe Y (1998) Effect of increased physical activity on bone mineral density in postmenopausal osteoporotic women. Keio Journal of Medicine 47, 157-161.

Jacobsen DW (1998) Homocysteine and vitamins in cardiovascular disease. Clinical Chemistry 44, 1833-1843.

Janckia AJ, Walton SP \& Yam LT (1998) Species specificity of monoclonal antibodies to human tartrate-resistant acid phosphatase. Biotechnic and Histochemistry 73, 316-324.

Jansen MC, Bueno-de-Mesquita HB, Buzina R, Fidanza F, Menotti A, Blackburn H, Nissinen AM, Kok FJ \& Kromhout D (1999) Dietary fiber and plant foods in relation to colorectal cancer mortality: the Seven Countries Study. International Journal of Cancer 81, 174-179.

Jensen JB, Stang H, Kringsholm B, Pritzl G \& Sorensen OH (1997) Relationship between trace element content and mechanical bone strength. Bone (New York) 20, 104S.

Johansson G, Holmen A, Persson L, Bogstedt B, Wassen C, Ottova L \& Gustafsson J-A (1992) The effect of a shift from a mixed diet to a lacto-vegetarian diet on human urinary and fecal mutagenic activity. Carcinogenesis 13, 153-157.

Johnson I (1997) The potential role of iron in colorectal cancer. ECP-News 31, 18-20.

Jones PH (1994) Low serum cholesterol increases in the risk of 
noncardiovascular events: an antagonist viewpoint. Cardiovascular Drugs and Therapy 8, 871-874.

Juhan-Vague I \& Alessi MC (1997) Variables of the fibrinolytic system: risk indicators for CHD. Fibrinolysis and Proteolysis 11, 47-49.

Junker R, Heinrich J, Schulte H, Van De Loo J \& Assmann G (1997) Coagulation factor VII and the risk of coronary heart disease in healthy men. Arteriosclerosis Thrombosis and Vascular Biology 17, 1539-1544.

Kabat GC, Chang CJ, Sparano JA, Sepkovic DW, Hu X-P, Khalil A, Rosenblatt R \& Bradlow HL (1997) Urinary estrogen metabolites and breast cancer: a case-controls study. Cancer Epidemiology, Biomarkers and Prevention 6, 505-509.

Kall MA, Vang O \& Clausen J (1997) Effect of dietary broccoli on human in vivo drug metabolizing enzymes: evaluation of caffeine, oestrone and chlorzoxazone metabolism. Carcinogenesis 17, 793-799.

Kannel WB, Cupples LA, Ramaswami R, Stokes J III, Kreger BE \& Higgins M (1991) Regional obesity and risk of cardiovascular disease the Framingham Study. Journal of Clinical Epidemiology 44, 183-190.

Kashyap ML (1997) Cholesterol and atherosclerosis: a contemporary perspective. Annals of the Academy of Medicine of Singapore 26, 517-523.

Katoh T, Nagata N, Kuroda Y, Itoh H, Kawahara A, Kuroki N, Ookuma R \& Bell DA (1996) Glutathione S-transferase M1 (GSTM1) and T1 (GSTT1) genetic polymorphism and susceptibility to gastric and colorectal adenocarcinoma. Carcinogenesis 17, 1855-1859.

Kaufman JM (1995) Role of calcium and vitamin D in the prevention and the treatment of postmenopausal osteoporosis: an overview. Clinical Rheumatology 14, 9-13.

Kee F, Nicaud V, Tiret L, Evans A, O'Reilly D \& De Backer G (1997) Short stature and heart disease: nature or nurture? The EARS Group. International Journal of Epidemiology 26, 748-756.

Kelly GA (1998) Aerobic exercise and bone density at the hip in postmenopausal women: a meta-analysis. Preventive Medicine 27, 798-807.

Kelly GE, Joannou GE, Reeder AY, Nelson C \& Waring MA (1995) The variable metabolic response to dietary isoflavones in humans. Proceedings of the Society for Experimental Biology and Medicine 208, 40-43.

Kensler TW, Groopman JD \& Wogan GN (1996) Use of carcinogen-DNA and carcinogen-protein adduct biomarkers for cohort selection and as modifiable end points in chemoprevention trials. IARC Science Publications 139, 237-248.

Keys A (1966) Arteriosclerotic heart disease in a favoured community. Journal of Chronic Disease 19, 245-254.

Kim YI \& Mason JB (1996) Nutrition chemoprevention of gastrointestinal cancers: a critical review. Nutrition Reviews 54, 259-279.

Kitahasu F, Kobayashi K, Sato T, Araki T \& Fujino MA (1999) Accuracy of screening for gastric cancer using serum pepsinogen concentrations. Gut 44, 693-697.

Knekt P, Jarvinen R, Dich J \& Hakulinen T (1999) Risk of colorectal and other gastro-intestinal cancers after exposure to nitrate, nitrite and N-nitroso compounds: a follow-up study. International Journal of Cancer 80, 852-856.

Kohlmeier L \& Mendez M (1997) Controversies surrounding diet and breast cancer. Proceedings of the Nutrition Society 56, 369-382.

Kondapaka SB, Fridman R \& Reddy KB (1997) Epidermal growth factor and amphiregulin up-regulate matrix metalloproteinase-9 (MMP-9) in human breast cancer cells. International Journal of Cancer 70, 722-726.

Koshkin Yu P, Khalfen ESH \& Koshechkin VA (1991) Blood coagulation system as a component for hereditary predisposition to coronary heart disease. Kardiologiya 31, 39-42.

Kovalenko VM, Shunkova EI, Gol'Dberg GA, Karagaeva LG, Shlafer ID \& Epifansteva NN (1991) Platelet aggregation in healthy persons and patients with coronary heart disease during exercise and at rest. Terapevticheskü Arkhiv 63, 69-71.

Krall EA, Dawson-Hughes B, Hirst K, Gallagher JC, Sherman SS \& Dalsky G (1997) Bone mineral density and biochemical markers of bone turnover in healthy elderly men and women. Journal of Gerontology 52, M61-M67.

Kromhout D, Bloemberg BP, Feskens EJ, Hertog MG, Menotti A \& Blackburn H (1996) Alcohol, fish, fibre and antioxidant vitamins intake do not explain population differences in coronary heart disease mortality. International Journal of Epidemiology 25, 753-759.

Kuroda Y, Shankel DM \& Waters MD (1990) Antimutagens and Anticarcinogens Mechanisms II, New York, London: Plenum Press.

Lamon-Fava S, Wilson PWF \& Schaefer EJ (1996) Impact of body mass index on coronary heart disease risk factors in men and women: The Framingham Offspring Study. Arteriosclerosis Thrombosis and Vascular Biology 16, 1509-1515.

Lanson M, Besson P \& Bougnoux P (1997) Supplementation of MCF-7 cells with essential fatty acids induces the activation of protein kinase $\mathrm{C}$ in response to IGF-1. Journal of Lipid Mediated Cell Signalling 16, 189-197.

Lauer MS (1996) Left ventricular hypertrophy and cardiovascular prognosis. Cleveland Clinical Journal of Medicine 62 , $169-175$

Lehto S, Ronnemaa T, Haffner SM, Pyorala K, Kallio V \& Laakso M (1997) Dyslipidemia and hyperglycemia predict coronary heart disease events in middle-aged patients with NIDDM. Diabetes 46, 1354-1359.

Lehto S, Ronnemma T, Pyorala K \& Laakso M (2000) Cardiovascular risk factors clustering with endogenous hyperinsulinaemia predict death from coronary heart disease in patients with Type II diabetes. Diabetologia 43, 148-155.

Leveille SG, LaCroix AZ, Koepsell TD, Beresford SA, Van Belle G \& Buchner DM (1997) Dietary vitamin C and bone mineral density in postmenopausal women in Washington State, USA. Journal of Epidemiology and Community Health 51, 479-485.

Levi F, Lavecchia C, Lucchini F \& Negri E (1995) Cancer mortality in Europe. European Journal of Cancer Prevention 4, 389-417.

Levi F, Pasche C, La Vecchia C, Lucchini F \& Franceschi S (1999) Food groups and colorectal cancer risk. British Journal of Cancer 79, 1283-1287.

Levine EA, Holzmayer T, Bacus S, Mechetner E, Mera R, Bolliger C, Robinson IB \& DasGupta TK (1997) Evaluation of newer prognostic markers for adult soft tissue sarcomas. Journal of Clinical Oncology 15, 3249-3257.

Li N, Tuomilehto J, Dowse G, Virtala E \& Zimmet P (1994) Prevalence of coronary heart disease indicated by electrocardiogram abnormalities and risk factors in developing countries. Journal of Clinical Epidemiology 47, 599-611.

Lidbeck A, Gustafsson JA \& Nord CE (1987) Impact of Lactobacillus acidophilus on the normal intestinal flora after administration of two antibiotic agents. Infection 16, 329-336.

Lidbeck A, Overvik E, Rafter J, Nord CE \& Gustafsson JA (1992) Effect of Lactobacillus acidophilus supplements on mutagen excretion faeces and urine in humans. Microbial Ecology in Health and Disease 5, 59-67.

Liehr JG (1997) Dual role of oestrogens as hormones and procarcinogens: tumour initiation by metabolic activation of oestrogens. European Journal of Cancer Prevention 6, 3-10.

Lin HJ, Probst-Hensch NM, Ingles SA, Han CY, Lin BK, Lee DB, Frankl HD, Lee ER, Longnecker MP \& Haile RW (1995) 
Glutathione transferase (GSTM1) null genotype, smoking and prevalence of colorectal adenomas. Cancer Research 55, 1224-1226.

Ling WH, Korpela R, Mykkanen H, Salminen S \& Hanninen O (1994) Lactobacillus strain Gg supplementation decreases colonic hydrolytic and reductive enzyme activities in healthy female adults. Journal of Nutrition 124, 18-23.

Lipkin M (1987) Biomarkers of increased susceptibility to gastrointestinal cancer. Gastroenterology 92, 1083-1086.

Lipkin M, Yang K, Edelmann W, Newmark H, Fan KH, Risio M \& Kucherlapati R (1996) Inherited and acquired risk factors in colonic neoplasia and modulation by chemopreventive intervention. Journal of Cell Biochemistry Suppl 25, 136-141.

Lippman SM, Lee JS, Lotan R, Hittelman W, Wargovich MJ \& Hong WK (1990) Biomarkers as intermediate end points in chemoprevention trials. Journal of the National Cancer Institute 82, 555.

Loeb LA (1994) Microsatellite instability: marker of mutator phenotype in cancer. Cancer Research 54, 5059-5063.

Loktionov A, O’Neill IK, Silvester KR, Cummings JH, Middleton SJ \& Miller R (1998) Quantitation of DNA from exfoliated colonocytes isolated from human stool surface as a novel noninvasive screening test for colorectal cancer. Clinical Cancer Research 4, 337-342.

Longnecker MP, Newcomb PA, Mittendorf R, Greenberg ER \& Willett WC (1997) Intake of carrots, spinach and supplements containing vitamin A in relation to risk of breast cancer. Cancer Epidemiology, Biomarkers and Prevention 6, 887-892.

McBride J, Popping B, Oehlschlager S, Hanley A \& Fewtrell M (1998) Identification of differentially expressed genes after phytoestrogen exposure. Proceedings of the COST Phytoestrogen Workshop, Netherlands, pp. 47-52.

McDanell R, McLean AE, Hanley AB, Heaney RK \& Fenwick GR (1989) The effect of feeding Brassica vegetables and intact glucosinolates on Mixed Function Oxidase activity in the liver and intestines of rats. Food and Chemical Toxicology 27, 289293.

Macfarlane FT, Cummings JH \& Allison C (1986) Protein degration by human intestinal bacteria. Journal of General Microbiology 132, 1647.

McIntyre A, Gibson PR \& Young GP (1993) Butyrate production from dietary fibre and protection against bowel cancer in a rat model. Gut 34, 386-391.

McKenzie KE (1997) Breast cancer: molecular epidemiology. Encyclopedia of Cancer 1, 173-183.

McKeown-Eyssen GE, Bight-See E, Bruce WR \& Jazmaji V \& The Toronto Polyp Prevention Group (1994) A randomized trial of a low fat high fibre diet in the recurrence of colorectal polyps. Journal of Clinical Epidemiology 47, 525-536.

MacMahon S, Peto R, Cutler R, Sorlie P, Neaton J, Abbott R, Godwin J, Dyer A \& Stamler J (1990) Blood pressure, stroke, and coronary heart disease. Part 1, prolonged differences in blood pressure: prospective observational studies corrected for the regression dilution bias [see comments]. Lancet 355, $765-774$.

McNamara DJ (1997) Cholesterol intake and plasma cholesterol: an update. Journal of the American College of Nutrition 16, 530-534.

Mallett AK \& Rowland IR (1990) Bacterial enzymes: their role in the formation of mutagens and carcinogens in the intestine. Drug Disposition 8, 71-79.

Manolagas SC (1998) Cellular and molecular mechanisms of osteoporosis. Aging Clinical Experimental Research 10, $182-190$.

Manus B, Adang RP, Ambergen AW, Bragelmann R, Armbrecht U \& Stockbrugger RW (1997) The risk factor profile of rectosigmoid adenomas: a prospective screening study of 665 patients in a clinical rehabilitation centre. European Journal of Cancer Prevention 6, 38-43.

Mao L, Lee DJ, Tockman MS, Erozan YS, Askin FB \& Sidransky D (1994) Microsatellite alterations as clonal markers for the detection of human cancer. Proceedings of the National Academy of Sciences USA 91, 9871-9875.

Martin FL, Venitt S, Carmichael PL, Crofton-Sleigh C, Stone EM, Cole KJ, Gusterson BA, Grover PL \& Phillips DH (1997) DNA damage in breast epithelial cells: detection by the single-cell (comet) assay and induction by human mammary lipid extracts. Carcinogenesis 18, 2299-2305.

Mattila PT, Svanberg MJ, P"okk"a P \& Knuuttila ML (1998) Dietary xylitol protects against weakening of bone biomechanical properties in ovariectomized rats. Journal of Nutrition $\mathbf{1 2 8}$ $1811-1814$.

Maxwell SR (1998) Women and heart disease. Basic Research in Cardiology 93, 79-84.

Meclahn E, Ferrell R, Kiss J, Temple A, Green F, Humphries S \& Kuller L (1995) Genetic determination of coagulation factor VIIc levels among healthy middle-aged women. Thrombosis and Haemostasis 73, 623-625.

Melhus H, Michaelsson K, Holmberg L, Wolf A \& Ljunghall S (1999) Smoking, antioxidant vitamins, and the risk of hip fracture. Journal of Bone Mineral Research 14, 129-135.

Mengelkoch LJ, Pollock ML, Limacher MC, Graves JE, Shireman RB, Riley WJ, Lowenthal DT \& Leon AS (1997) Effects of age, physical training, and physical fitness on coronary heart disease risk factors in older track athletes at twenty-year follow-up. Journal of the American Geriatrics Society 45, 1446-1453.

Michaelsson K, Holmberg L, Mallmin H, Sorensen S, Wolk A, Bergstrom R \& Ljunghall S (1995) Diet and hip fracture risk: a case-control study. Study Group of the Multiple Risk Survey on Swedish Women for Eating Assessment. International Journal Epidemiology 24, 771-782.

Miller GJ (1997) Dietary fatty acids and blood coagulation. Prostaglandins Leukotrienes and Essential Fatty Acids 57, 389-394.

Miller GJ, Esnouf MP, Burgess AI, Cooper JA \& Mitchell JP (1997) Risk of coronary heart disease and activation of factor XII in middle-aged men. Arteriosclerosis Thrombosis and Vascular Biology 17, 2103-2106.

Mizushima S (1995) Roles of seafood and magnesium intake on prevention of cardiovascular disease: findings from the International Nutritional Epidemiological Study. Yokohama Medical Bulletin 46, 45-57.

Moor E, Silveira A, Van't Hooft F, Suontaka AM, Eriksson P, Blomback M \& Hamsten A (1995) Coagulation factor VII mass and activity in young men with myocardial infarction at a young age: role of plasma lipoproteins and factor VII genotype. Arteriosclerosis Thrombosis and Vascular Biology 15, 655-664.

Mora S, Barera G, Beccio S, Proverbio MC, Weber G, Bianchi C \& Chiumello G (1999) Bone density and the bone metabolism are normal after long-term gluten-free diet in young celiac patients. American Journal of Gastroenterology 94, 398-403.

Mora S, Barera G, Ricotti A, Weber G, Bianchi C \& Chiumello G (1998) Reversal of low bone density with a gluten-free diet in children and adolescents with celiac disease. American Journal of Clinical Nutrition 67, 477-481.

Morishita Y \& Shiromizu K (1990) Suppressive effect of feeding yogurt or lactose on $N$-methyl- $N^{\prime}$-nitrosoguanidine-induced gastric tumorigenesis in rats. Bifidobacteria Microflora 9, $135-138$.

Morris BJ \& Griffiths LR (1998) Scanning the genome for essential hypertension loci. Clinical Experimental Pharmacology and Physiology Supplement 25, S72-S78.

Morton MS, Matos-Ferreira A, Abrances-Monteiro L, Correia R, 
Blacklock N, Chan PSF, Cheng C, Lloyd S, Chien-ping W \& Griffiths K (1997) Measurement and metabolism of isoflavonoids and lignans in the human male. Cancer Letters 114, $145-151$

Mosca L, Rubenfire M, Mandel C, Rock C, Tarshis T, Tsai A \& Pearson T (1997) Antioxidant nutrient supplementation reduces the susceptibility of low density lipoprotein to oxidation in patients with coronary artery disease. Journal of the American College of Cardiology 30, 392-399.

Munoz N (1994) Is Helicobacter pylori a cause of gastric cancer? An appraisal of the seroepidemiological evidence. Cancer Epidemiology Biomarkers and Prevention 3, 445-451.

Musaiger AO \& Abuirmeileh NM (1998) Food consumption patterns of adults in the United Arab Emirates. Journal Royal Society for Health 118, 146-150.

Musaiger AO \& al-Roomi KA (1997) Prevalence of risk factors for cardiovascular disorders among men and women in an Arab Gulf community. Nutrition Health 11, 149-157.

Nair J, Barbin A, Velic I \& Bartsch H (1999) Etheno DNA-base adducts from endogenous reactive species. Mutation Research 424, 59-69.

Nair J, Vaca CE, Velic I, Mutanen M, Valsta LM \& Bartsch H (1997) High dietary ù-6 polyunsaturated fatty acids drastically increase the formation of etheno-DNA base adducts in white blood cells of female subjects. Cancer Epidemiology, Biomarkers and Prevention 6, 597-601.

Nakajima K, Suzuki T, Shimada H, Hayashi H, Takeda A \& Ochiai $\mathrm{T}$ (1999) Detection of pre operative serum anti-p53 antibodies in gastric cancer. Tumor Biology 20, 147-152.

Nebert DW (1993) Elevated estrogen 16 $\alpha$-hydroxylase activity: is this a genotoxic or nongenotoxic biomarker in human breast cancer risk. Journal of the National Cancer Institute $\mathbf{8 5}$, $1888-1891$.

Negri E, La Vecchia C, Francheschi S, D’avanzo B \& Parazzini F (1991) Vegetable and fruit consumption and cancer risk. International Journal of Cancer 48, 350-354.

Nelson E (1997) Laboratory probing of oncogens from human liquid and solid specimens as markers of exposure to toxicants. Critical Reviews in Toxicology 26, 483-549.

Nielsen F, Mikkelsen BB, Nielsen JB, Anderson HR \& Grandjean $P$ (1997) Plasma malondialdehyde as biomarker for oxidative stress: reference interval and effects of life-style factors. Clinical Chemistry 43, 1209-1214.

Nijhoff WA, Mulder TPJ, Verhagen H, Van Poppel G \& Peters WHM (1995) Effect of consumption of Brussels sprouts on plasma and urinary glutathione S-transferase class- $\alpha$ and $-\beta$ in humans. Carcinogenesis 16, 955-957.

Nordin BE, Need AG, Morris HA \& Horowitz M (1999) Biochemical variables in pre and post menopausal women: reconciling the calcium and estrogen hypothesis. Osteoporosis International 9, 351-357.

Ogawa S, Hosoi T, Shiraki M, Orimo H, Emi M, Muramatsu M, Ouchi Y \& Inoue S (2000) Association of estrogen receptor beta gene polymorphism with bone mineral density. Biochemical and Biophysical Research Communications 269, 537-541.

Ohrvall M, Sundlof G \& Vessby B (1996) Gamma, but not alpha, tocopherol levels in serum are reduced in coronary heart disease patients. Journal of Internal Medicine 239, 111-117.

Ohta T, Saku K, Takata K, Nagata N, Maung KK \& Matsuda I (1997) Fractional esterification rate of cholesterol in high density lipoprotein (HDL) can predict the particle size of low density lipoproptein and HDL in patients with coronary heart disease. Atherosclerosis 135, 205-212.

Okayama A, Ueshima H, Marmot MG, Nakamura M, Kita Y \& Yamakawa M (1993) Changes in total serum cholesterol and other risk factors for cardiovascular disease in Japan, 19801989. International Journal of Epidemiology 22, 1038-1047.
Olden K (1994) Mutagen hypersensitivity as a biomarker of genetic predisposition to carcinogenesis. Journal of the National Cancer Institute 86, 1660-1661.

Ortenblad N, Madsen K \& Djurhuus MS (1997) Antioxidant status and lipid peroxidation after short term maximal exercise in trained and untrained humans. American Journal of Physiology 272, 1258-1263.

Orth-Gomer K, Mittleman MA, Schenck-Gustafsson K, Wamala SP, Eriksson M, Belkic K, Kirkeeide R, Svane B \& Ryden L (1997) Lipoprotein (a) as a determinant of coronary heart disease in young women. Circulation 95, 329-334.

Oursler MJ (1998) Estrogen regulation of gene expression in osteoblasts and osteoclasts. Critical Reviews Expression 8, 125-140.

Owen RW, Wimonwatwatee T, Spiegelhalder B \& Bartsch H (1996) A high performance liquid chromatography system for quantification of hydroxyl radical formation by determination of dihydroxy benzoic acids. European Journal of Clinical Prevention 5, 233-240.

Pace-Asciak CR, Hahn S, Diamandis EP, Soleas G \& Goldberg DM (1995) The red wine phenolics trans-resveratrol and quercetin block human platelet aggregation and eicosanoid synthesis: implications for protection against coronary heart disease. Clinica Chimica Acta 235, 207-219.

Paech K, Webb JP, Kuiper GGJM, Nilsson S, Gustatsson J, Kushner PJ \& Scanlan TS (1997) Differential ligand activation of estrogen receptors ERL and Erâ at AP1 sites. Science 277, 1508-1510.

Panico L, D’Antonio A, Salvatore G, Mezza E, Tortora G, De Laurentiis M, De Placido S, Giordano T, Merino M, Salomon DS, Mullick WJ, Pettinato G, Schnitt SJ, Bianco AR \& Ciardello F (1996) Differential immunohistochemical detection of transforming growth factor alpha, amphiregulin and CRIPTO in human normal and malignant breast tissues. International Journal of Cancer 65, 51-56.

Parmley WW (1997) Nonlipoprotein risk factors for coronary heart disease: evaluation and management. American Journal of Medicine 102, 7-14.

Parnaud G \& Corpet DE (1997) [Colorectal cancer: controversial role of meat consumption]. Bulletin Cancer 84, 899-911.

Patel SB, Salen G, Hidaka H, Kwiterovich PO, Stalenhoef AF, Miettinen TA, Grundy SM, Lee MH, Rubenstein JS, Polymeropoulos MH \& Brownstein MJ (1998) Mapping a gene involved in regulating cholesterol absorption. The cholesterolemia locus os found at chromosome $2 \mathrm{p} 21$. Journal of Clinical Investigation 102, 1041-1044.

Peacock M, Turner CH, Liu G, Manatunga AK, Timmerman L \& Johnston CC Jr (1995) Better discrimination of hip fracture using bone density, geometry and architecture. Osteoporosis International 5, 167-173.

Pence BC, Landers M, Dunn DM, Shen CL \& Miller MF (1998) Feeding of a well-cooked beef diet containing a high heterocyclic amine content enhances colon and stomach carcinogenesis in 1,2-dimethylhydrazine-treated rats. Nutrition and Cancer 30, 220-226.

Perera FP (1996) Molecular epidemiology: insights into cancer susceptibility, risk assessment, and prevention. Journal of the National Cancer Institute 88, 509.

Perera FP \& Whyatt RM (1994) Biomarkers and molecular epidemiology in mutation/cancer research. Mutation Research 313, 117-129.

Petersen MM, Jensen NC, Gehrchen PM, Nielsen PK \& Nielsen PT (1996) The relationship between trabecular bone strength and bone mineral density assessed by dual photon and dual energy $\mathrm{X}$-ray absorptiometry in the proximal tibia. Calcification and Tissue International 59, 311-314.

Pflaum M, Will O \& Epe B (1997) Determination of steady-state 
levels of oxidative DNA base modifications in mammalian cells by means of repair endonucleases. Carcinogenesis $\mathbf{1 8}$, 2225-2231.

Pistorius LR, Sweidan WH, Purdie DW, Steel SA, Howey S, Benett JR \& Sutton DR (1995) Coeliac disease and bone mineral density in adult female patients. Gut 37, 639-642.

Pizer ES, Jackisch C, Wood FD, Pasternack GR, Davidson NE \& Kuhajda FP (1996) Inhibition of fatty acid synthesis induces programmed cell death in human breast cancer cells. Cancer Research 56, 2745-2747.

Pool-Zobel BL, Abrahamse SL, Collins A, Kark U, Oberreuther D, Siegel X, Treptow-van Lishaut S \& Rechkemmer G (1999) Endogenous DNA damage and oxidised DNA bases in human colon cells from biopsies and HT29 cells. Cancer Epidemiology Biomarkers and Prevention 8, 609-614.

Pool-Zobel BL, Bub A, Liegibel UM, Treptow-van Lishaut S \& Rechkemmer G (1997) Consumption of vegetables reduces genetic damage in humans: first results of an intervention trial with carotenoid-rich foods. Carcinogenesis 18, 1827-1830.

Pool-Zobel BL, Bub A, Liegibel UM, van-Trepow Lishaut S \& Rechkemmer G (1998) Mechanisms by which vegetable consumption reduces genetic damage in humans. Cancer Epidemiology Biomarkers and Prevention 7, 891-899.

Pool-Zobel BL \& Leucht U (1997) Induction of DNA damage in human colon cells derived from biopies by suggested risk factors of colon cancer. Mutation Research 375, 105-116.

Pool-Zobel BL, Lotzmann N, Knoll M, Kuchenmeister F, Lambertz R, Leucht U, Schroder HG \& Schmezer P (1994) Detection of genotoxic effects in human gastric and nasal mucosa cells isolated from biopsy samples. Environmental and Molecular Mutagenesis 24, 23-45.

PorterJordan K \& Lippman ME (1994) Overview of the biologic markers of breast cancer. Hematology-Oncology Clinics of North America 8, 73-100.

Potter JD \& Steinmetz KA (1996) Vegetables, fruit and phytoestrogens as preventive agents. In Principles of Chemoprevention, pp. 61-90 [BW Stewart, DB McGregor and $\mathrm{P}$ Kleihues, editors]. Lyons: International Agency for Research on Cancer.

Pretlow TP, Brasitus TA, Fulton NC, Cheyer C \& Kaplan EL (1993) K-ras mutations in putative preneoplastic lesions in human colon. Journal of the National Cancer Institute 85, 2004-2007.

Price KR \& Fenwick GR (1985) Naturally occurring oestrogens in foods-a review. Food Addititives and Contaminants 2, 73-106.

Primrose ED, Savage JM, Boreham CA, Cran GW \& Strain JJ (1994) Cholesterol screening and family history of vascular disease. Archives of Disease in Childhood 71, 239-242.

Prince RI, Dick IM, Lemmon J \& Randell D (1997) The pathogenesis of age-related osteoporotic fracture: Effects of dietary calcium deprivation. Journal of Clinical Endocrinology and Metabolism 82, 260-264.

Prince RL, Smith M, Dick IM, Price RI, Webb PG, Henderson NK \& Harris MM (1991) Prevention of postmenopausal osteoporosis. A comparative study of exercise, calcium supplementation, and hormone-replacement therapy. New England Journal of Medicine 325, 1189-1195.

Prockop DJ \& Kivirikko KI (1995) Collagen: molecules biology, diseases, and potentials for therapy. Annual Review Biochemistry 64, 403-434.

Raitakari OT, Taimela S, Porkka KVK, Telama R, Valimaki I, Akerblom HK \& Viikari JSA (1997) Associations between physical activity and risk factors for coronary heart disease: The Cardiovascular Risk in Young Finns Study. Medicine and Science in Sports and Exercise 29, 1055-1061.

Ravussin E, Bennett PH, Valencia ME, Schultz LO \& Esparza J
(1994) Effects of a traditional lifestyle on obesity in Pima Indians. Diabetes Care 17, 1067-1074.

Razay G, Heaton KW \& Bolton CH (1992) Coronary heart disease risk factors in relation to the menopause. Quarterly Journal Medicine 85, 889-896.

Reddy BS (1995) Nutritional factors and colon cancer. Critical Reviews in Food Science and Nutrition 33, 175-190.

Richter F, Richter A, Yang K \& Lipkin M (1992) Cell proliferation in rat colon measured with bromodeoxyuridine, proliferating cell nuclear antigen, and $\left[{ }^{3} \mathrm{H}\right]$ thymidine. Cancer Epidemiology Biomarkers and Prevention 1, 561-566.

Riis B, Thomsen K \& Christiansen C (1987) Does calcium supplementation prevent postmenopausal bone loss? A doubleblind, controlled clinical study. New England Journal of Medicine 316, 173-177.

Rimm EB, Willett WC, Hu FB, Sampson L, Colditz GA, Manson JE, Hennekens C \& Stampfer MJ (1998) Folate and vitamin B6 from diet and supplements in relation to risk of coronary heart disease among women. Journal of the American Medical Association 279, 359-364.

Rines RD, van Orsouw NJ, Sigalas I, Li FP, Eng C \& Vijg J (1998) Comprehensive mutational scanning of the $\mathrm{p} 53$ coding region by two-dimensional gene scanning. Carcinogenesis 19, 979-984.

Rodan GA (1998) Bone mass homeostasis and bisphosphonate action. Bone 20, 1-4.

Rodan GA \& Harada S (1997) The missing bone. Cell 89, 677680.

Rodenhuis (1997) Ras gene alterations in human lung cancer. Encyclopedia of Cancer 1, 1481-1489.

Rolland-Cachera MF, Bellisle F, Tichet J, Chantrel AM, GuilloudBataille M, Vol S \& Pequignot G (1990) Relationship between adiposity and food intake: an example of pseudo-contradictory results obtained in case-control versus between populations studies. International Journal Epidemiology 19, 571-577.

Rose DP (1997) Effects of dietary fatty acids on breast and prostate cancers: evidence from in vitro experiments and animal studies. American Journal of Clinical Nutrition 66, 1513S-1522S.

Rosner MH, Grassman JA \& Haas RA (1991) Immunochemical techniques in biological monitoring. Environmental Health Perspectives 94, 131-134.

Rosseneau M, Cambien F, Vinaimont N, Nicaud V \& De Backer G (1994) Biomarkers of dietary fat composition in young adults with a parental history of premature coronary heart disease compared with controls. The EARS study. Atherosclerosis 106, $127-136$.

Rowland IR (1993) Diet, gut microflora and carcinogenesis. In Food, Nutrition and Chemical Toxicity, pp. 337-341 [DV Parke and R Walker, editors]. Great Britain: Smith-Gordon.

Rowland IR, Granli T, Bockman OC, Key PE \& Massey RC (1991) Endogenous N-nitrosation in man assessed by measurement of apparent total $\mathrm{N}$-nitroso compounds in feces. Carcinogenesis $\mathbf{1 2}$, 1395-1401.

Rozen R (1997) Genetic predisposition to hyperhomocysteinemia: deficiency of methylenetetrahydrofolate reductase (MTHFR). Thrombosis and Haemostasis 78, 523-526.

Rude RK, Kirchen ME, Gruber HE, Stasky AA \& Meyer MH (1998) Magnesium deficiency induces bone loss in the rat. Mineral Electrolyte Metabolism 24, 314-320.

Ryan AS, Treuth MS, Hunter GR \& Elahi D (1998) Resistive training maintains bone material density in postmenopausal women. Calcification Tissue International 62, 295-299.

Salami M, Galli C, De Angelis L \& Visioli F (1995) Formation of F-2-isoprostanes in oxidized low density lipoprotein: inhibitory effects of hydroxytyrosol. Pharmacological Research 31, $275-279$.

Saltman P \& Strause L (1992) The role of trace minerals in 
osteoporosis. Journal of the American College of Nutrition 11, 599.

Samman S, Lyons-Wall PM, Cook NC \& Nahii MR (1996) Minor dietary factors in relation to coronary heart disease: flavonoids, isoflavones and boron. Journal of Clinical Biochemistry and Nutrition 20, 173-180.

Sampson HW \& Shipley (1997) Moderate alcohol consumption does not augment bone density in ovariectomized rats. Alcohol Clinical Experimental Research 21, 1165-1168.

Sarhanis P, Redman C, Perrett C, Brannigan K, Clayton RN, Hand P, Musgrove C, Suarez V, Jones P, Fryer AA, Farrell WE \& Strange RC (1996) Epithelial ovarian cancer: influence of polymorphism at the glutathione S-transferase GSTM1 and GSTT1 loci on p53 expression. British Journal of Cancer 74, $1757-1761$

Sarin VK, Loboa Polefka EG, Beaupr'e GS, Kiratli BJ, Carter DR \& van der Meulen MC (1999) DXA-derived section modules and bone mineral content predict long-bone torsional strength. Acta Orthopedica Scandinavica 70, 71-76.

Saris WH, Asp NG, Bjorck I, Blaak E, Bornet F, Brouns F, Frayn KN, Furst P, Riccardi G, Roberfroid M \& Vogel M (1998) Functional food science and substrate metabolism. British Journal of Nutrition 80, Suppl 1, S47-S75.

Sawa T, Akaike T, Kida K, Fukushima Y, Takagi K \& Maeda H (1998) Lipid peroxyl radicals from oxidized oils and heme-iron: implication of a high-fat diet in colon carcinogenesis. Epidemiology, Biomarkers and Prevention 7, 1007-1012.

Scarabin PY, Vissac AM, Kirzin JM, Bourgeat P, Amiral J, Agher R \& Guize L (1996) Population correlates of coagulation factor VII: importance of age, sex, and menopausal status as determinants of activated factor VII. Arteriosclerosis Thrombosis and Vascular Biology 16, 1170-1176.

Schaefer EJ, Lamon-Fava S, Ordovas JM, Cohn SD, Schaefer MM, Castelli WP \& Wilson PWF (1994) Factors associated with low and elevated plasma high density lipoprotein cholesterol and apolipoprotein A-I levels in the Framingham Offspring Study. Journal of Lipid Research 35, 871-882.

Schut HAJ \& Shiverick KT (1992) DNA adducts in humans as dosimeters of exposure to environmental, occupational, or dietary genotoxins. FASEB Journal 6, 2942-2951.

Setchell KD, Zimmer-Nechemias L, Cai J \& Heubi JE (1997) Exposure of infants to phyto-oestrogens from soy-based infant formula. Lancet 350, 23-27.

Sharma S, Stutzman JD, Kelloff GJ \& Steele VE (1994) Screening of potential chemopreventive agents using biochemical markers of carcinogenesis. Cancer Research 54, 5848-5855.

Sharp MG, Adams SM, Walker RA, Brammar WJ \& Varley JM (1992) Differential expression of the mitochondrial gene cytochrome oxidase II in benign and malignant breast tissue. Journal of Pathology 168, 163-168.

Sidransky D, Tokino T, Hamilton SR, Kinzler KW, Levin B, Frost P \& Vogelstein B (1992) Identification of ras oncogene mutations in the stool of patients with curable colorectal tumours. Science 256, 102-105.

Simopoulos AP (1996) Genetic variationa and nutrition. Biomedical Environmental Science 9, 124-129.

Singh RB, Mori H \& Kummerow FA (1992) Macro and trace mineral metabolism in coronary heart disease. Trace Elements and Medicine 9, 144-156.

Sinha R, Rothman N, Brown ED, Mark SD, Hoover RN, Caporaso NE, Levander OA, Knize MG, Lang NP \& Kadlubar FF (1994) Pan-fried meat containing high levels of heterocyclic aromatic amines but low levels of polycyclic aromatic hydrocarbons induces cytochrome P4501A2 activity in humans. Cancer Research 54, 6154-6159.

Sithisarankul P, Vines P, Kang D, Rothman N, Caporaso N \& Strickland P (1997) Association of l-hydroxypyrene-glucuronide in human urine with cigarette smoking and broiled or roasted meat consumption. Biomarkers 2, 217-221.

Sivaraman L, Leatham MP, Yee J, Wilkens LR, Lau AF \& Marchand LL (1994) CYP1A1 genetic polymorphisms and in situ colorectal cancer. Cancer Research 54, 5692-5695.

Slattery ML, Jacobs DR Jr, Dyer A, Benson J, Hilner JE \& Caan BJ (1995) Dietary antioxidants and plasma lipids: The Cardia Study. Journal of the American College of Nutrition 14, 635-642.

Smedman AEM, Gustafssen I-B, Berglund LG \& Vessby BOH (1999) Pentadecanoic acid in serum as a marker for intake of milk fat. American Journal of Clinical Nutrition 69, 22-29.

Smith G, Stanley LA, Sim E, Strange RC \& Wolf CR (1995) Metabolic polymorphisms and cancer susceptibility. In Genetics and Cancer, a Second Look, pp. 27-65 [H Ponder and AJ Bruce, editors]. New York: Cold Spring Harbor Laboratory Press.

Solymoss BA, Bourassa MG, Wesolowska E, Dryda I, Theroux L, Perrault D \& Gilfix BM (1997) The role of cardiac troponin T and other new biochemical markers in evaluation and risk stratification of patients with acture chest pain syndromes. Clinical Cardiology 12, 934.

Soravic C, Bapat B \& Cohen Z (1997) Familial adenomatous polyposis (FAP) and hereditary nonpolyposis colorectal cancer (HNPCC): a review of clinical, genetic and therapeutic aspects. Schweizerische Medizinische Wochenschrift 127, 682-690.

Soroko S, Holbrook TL, Edelstein S \& Barrett Connor E (1994) Lifetime milk consumption and bone mineral density in older women. American Journal of Public Health 84, 1319-1322.

Sreerama L, Hedge MW \& Sladek NE (1995) Identification of a class 3 aldehyde dehydrogenase in human saliva and increased levels of this enzyme, glutathione S-transferase, and DTdiaphorase in the saliva of subjects who continually ingest large quantities of coffee or broccoli. Clinical Cancer Research 1, $1153-1163$.

Srivastava LM, Vasisht S, Agarwal DP \& Goedde HW (1994) Relation between alcohol intake, lipoproteins and coronary heart disease: the interest continues. Alcohol 29, 11-24.

Stampfer MJ \& Rimm EB (1995) Epidemiologic evidence for vitamin $\mathrm{E}$ in prevention of cardiovascular disease. American Journal of Clinical Nutrition 62, 1365S-1369S.

Steinmetz KA \& Potter JD (1991) Vegetables, fruit, and cancer. I. Epidemiology. Cancer Causes and Control 2, 325-357.

Stillwell WG, Kidd LCR, Wishnok JS, Tannenbaum SR \& Singa R (1997) Urinary excretion of unmetabolized and phase II conjugates of 2-amino-1-methyl-6-phenylimidazo[4,5- $b$ ]pyridine and 2-amino-3,8-dimethylimidazo[4,5- $f$ ]quinoxaline in humans: relationship to cytochrome p4501A2 and $\mathrm{N}$-acetyltransferase activity. Cancer Research 57, 3457-3464.

Stini WA (1998) Calcium homeostasis and human evolution. Coll Anthropology 22, 411-425.

Stoll BA (1996) Nutrition and breast cancer risk: can an effect via insulin resistance be demonstrated. Breast Cancer Research and Treatment 38, 239-246.

Stoll BA (1998) Breast cancer and the western diet: role of fatty acids and antioxidant vitamins. European Journal of Cancer 34, $1852-1856$.

Struck M, Watkins T, Tomeo A, Halley J \& Bierenbaum M (1994) Effect of red and white wine on serum lipids, platelet aggregation, oxidation products and antioxidants: a preliminary report. Nutrition Research 14, 1811-1819.

Suer S, Ulutin T, Sonmez H, Kokoglu E, Ucisik N, Bayram C \& Sultuybek G (1996) Plasma Lp (a) and t-PA-PAI-1 complex levels in coronary heart disease. Thrombosis Research 83, $77-85$.

Svanberg M \& Knuuttila M (1994) Dietary xylitol retards bone resorption in rats. Mineral and Electrolyte Metabolism 20, $153-157$. 
Szarka CE, Pfeiffer GR, Hum ST, Everly LC, Balshem AM, Moore DF, Litwin S, Goosenberg EB, Frucht H, Engstrom PF \& Clapper ML (1995) Glutathione S-transferase activity and glutathione S-transferase activity and glutathione S-transferase $\mu$ expression in subjects with risk for colorectal cancer. Cancer Research 55, 2789-2793.

Szathmari M, Tulassay T, Arato A, Bodanszky H, Szabo A \& Tulassay Z (1997) [Mineral content in bones of chicken with symptomless celiac disease and gluten-free diet]. Orvosi Hetilap 138, 3233-3238.

Taioli E, Garbers S, Bradlow HL, Carmella SG, Akerkar S \& Hecht S (1997) Effects of indole-3-carbinol on the metabolism of 4-(methylnitrosamino)-1(3-pyridyl)-1-butanone in smokers. Cancer Epidemiology, Biomarkers and Prevention 6, 517-522.

Tato F, Keller C, Schuster H, Spengel F, Wolfram G \& Zoellner N (1993) Relation of lipoprotein A to coronary heart disease and duplex sonographic findings of the carotid arteries in heterozygous familial hypercholesterolemia. Atherosclerosis 101, 69-77.

Tavendale R, Lee AJ, Smith WCS \& Tunstall-Pedee H (1992) Adipose tissue fatty acids in Scottish men and women. Atherosclerois 94, 161-169.

Tervahauta M, Pekkanen J, Kivinen P, Stengard J, Jauhiainen M, Ehnholm C \& Nissinen A (1993) Prevalence of coronary heart disease and associated risk factors among elderly Finnish men in the Seven Countries study. Atherosclerosis 104, 47-59.

Testi D, Viceconti M, Baruffaldi F \& Cappello A (1999) Risk of fracture in elderly patients: a new predictive index based on bone mineral density and finite element analysis. Computational Methods Programs in Biomedicine 60, 23-33.

Tinajas Ruiz A (1998) Cardiovascular health and trans fatty acid consumption. Alimentaria 35, 75-80.

Tucker JD, Eastmond DA \& Littlefield LG (1997) Cytogenetic end-points as biological dosimeters and predictors of risk in epidemiological studies. IARC Science Publications 142, 185200.

Tucker KL, Hannan MT, Chen H, Cupples LA, Wilson PW \& Kiel DP (1999) Potassium, magnesium, and fruit and vegetable intakes are associated with greater bone mineral density in elderly men and women. American Journal of Clinical Nutrition 69, 727-736.

Turner RT, Kidder LS, Zhang M, Harris SA, Westerlind KC, Maran A \& Wronski TJ (1999) Estrogen has rapid tissue-specific effects on rat bone. Journal of Applied Physiology 86, 1950-1958.

Uckun FM, Narla RK, Zeren T, Yanishevski Y, Myers DE, Waurzyniak B, Ek O, Schneider E, Messinger Y, Chelstrom LM, Gunther R \& Evans W (1998) In vivo toxicity, pharmacokinetics, and anticancer activity of genistein linked to recombinant human epidermal growth factor. Clinical Cancer Research 4, 1125-1134.

Urban T, Ricci S, Grange JD, Lacave R, Boudghene F, Breittmayer F, Languille O, Roland J \& Bernaudin JF (1993) Detection of c-Ki-ras mutation by PCR/RFLP analysis and diagnosis of pancreatic adenocarcinomas. Journal of the National Cancer Institute 85, 2008-2012.

Vaccaro O, Stamler J \& Neaton JD (1998) Sixteen-year coronary mortality in black and white men with diabetes screened for the Multiple Risk Factor Intervention Trial (MRFIT). International Journal of Epidemiology 27, 636-641.

Valdimarsson T, Toss G, Ross I, L"ofman O \& Str"om M (1994) Bone mineral density in coeliac disease. Scandinavian Journal of Gastroenterology 29, 457-461.

Van De Vijver LPL, Kardinaal AFM, Grobbee DE, Princen HMG \& Van Poppel G (1997) Lipoprotein oxidation, antioxidants and cardiovascular risk: epidemiologic evidence. Prostaglandins Leukotrienes and Essential Fatty Acids 57, 479-487.
Van Iversen MLPS, Verhagen H \& van Bladeren PJ (1999) The role of biotransformation in dietary (anti) carcinogenesis. Mutation Research 443, 259-270.

Van Munster IP, Tangerman A \& Nagengast FM (1994) Effect of resistant starch on colonic fermentation, bile acid metabolism, and mucosal proliferation. Digestive Disease and Sciences 39, 834-842.

Veldman FJ, Nair CH, Vorster HH, Vermaak WJ, Jerling JC, Oosthuizen W \& Venter CS (1997) Dietary pectin influences fibrin network structure in hypercholesterolaemic subjects. Thrombosis Research 86, 183-196.

Venkov CD, Rankin AB \& Vaughan DE (1996) Identification of authentic estrogen receptor in cultured endothelial cells: A potential mechanism for steroid hormone regulation of endothelial function. Circulation 94, 727-733.

Venturi M, Hambly RJ, Glinghammer B, Rafter JJ \& Rowland IR (1997) Genotoxic activity in human faecal water and the role of bile acids: a study using the alkaline comet assay. Carcinogenesis 18, 2353-2359.

Verhagen H, Poulson HE, Loft S, Van Poppel G, Willems MI \& Van Bladeren PJ (1995) Reduction of oxidative DNA-damage in humans by Brussels sprouts. Carcinogenesis 16, 969-970.

Verhagen H, Rompelberg CJM, Strube M, van Poppel G \& van Bladeren PJ (1997) Cancer prevention by dietary constituents in toxicological perspective. Journal of Environmental Pathology Toxicology and Oncology 16, 343-360.

Vermaak WJH, Ubbink JB, Delport R, Becker PJ, Bissbort SH \& Ungerer JPJ (1991) Ethnic immunity to coronary heart disease. Atherosclerosis 89, 155-162.

Verschuren WMM, Jacobs DR, Bloemberg BPM, Kromhout D, Menotti A, Aravanis C, Blackburn H, Buzina R, Dontas AS, Fidanza F, Karvonene MJ, Nedeljkovic S, Nissinen A \& Toshima H (1995) Serum total cholesterol and long-term coronary heart disease mortality in different cultures: twentyfive year follow-up of the Seven Countries Study. Journal of the American Medical Association 274, 131-136.

Vidgren HM, Louheranta AM, Agren JJ, Scheab US \& Uusitupa MI (1998) Divergent incorporation of dietary trans fatty acids in different serum lipid fractions. Lipids 33, 955-962.

Villa E, Dugani A, Rebecchi AM, Vignoli A, Grottola A, Buttafoco P, Losi L, Perni M, Trande P, Merighi A, Lerose R \& Manenti F (1996) Identification of subjects at risk for colorectal carcinoma through a test based on K-ras determination in the stool. Gastroenterology 110, 1346-1353.

Watanabe M, Fukutome K, Shiraishi T, Murata M, Kawamura J, Shimazaki J, Kotake T \& Yatani R (1997) Differences in the p53 gene mutational spectra of prostate cancers between Japan and western countries. Carcinogenesis 18, 1355-1358.

Waterland RA \& Garza C (1999) Potential mechanisms of metabolic imprinting that lead to chronic disease. American Journal of Clinical Nutrition 69, 175-197.

Watson KE, Abrolat ML, Malone LL, Hoeg JM, Doherty T, Detrano R \& Demer LL (1997) Active serum vitamin D levels are inversely correlated with coronary calcification. Circulation 96, 1755-1760.

Watts GF, Lewis B, Brunt JN, Lewis ES, Coltart DJ, Smith LD, Mann JI \& Swan AV (1992) Effects on coronary artery disease of lipid-lowering diet, or diet plus cholestyramine, in the $\mathrm{St}$ Thomas' Atherosclerosis Regression Study. Lancet 339, 563-569.

Whitehouse A, Meredith DM \& Markham AF (1998) DNA mismatch repair genes and their association with colorectal cancer (Review). International Journal of Molecular Medicine 1, 469-474.

Wijnands MV, Appel MJ, Hollanders VM \& Woutersen RA (1999) A comparison of the effects of dietary cellulose and fermentable galacto oligosaccharide, in a rat model of colorectal 
carcinogenesis: fermentab confers greater protection than nonfermentable fibre in both high and backgrounds. Carcinogenesis 20, 651-656.

Wild CP \& Pisani P (1997) Carcinogen-DNA and carcinogenprotein adducts in molecular epidemiology. IARC Science Publications 142, 143-158.

Wilt TJ, Rubins HB, Robins SJ, Riley WA, Collins D, Elam M, Rutan G \& Anderson JW (1997) Carotid atherosclerosis in men with low levels of HDL cholesterol. Stroke 28, 1919-1925.

Woitge HW, Pecherstorfer M, Martin Li, Yuming K, Andrea V, Horn E, Ziegler R \& Seibel MJ (1999) Novel serum markers of bone resorption: clinical assessment and comparison with established urinary indices. Journal of Bone and Mineral Research 14, 792-801.

World Cancer Research Fund \& American Institute for Cancer Research (1997) Food, Nutrition and the Prevention of Cancer: a Global Perspective, Washington DC: American Institute for Cancer Research.

Wu KK (1997) Hemostatic tests in the prediction of atherothrombotic disease. International Journal of Clinical and Laboratory Research 27, 145-152.

Wu Y, Chen J, Ohshima H, Pignatelli B, Boreham J, Li J, Campbell TC, Peto R \& Bartsch H (1993) Geographic association between urinary excretion of $\mathrm{N}$-nitroso compounds and oesophageal cancer mortality in China. International Journal of Cancer 54, $713-719$.

Wynder EL, Cohen AL, Muscat JE, Winters B, Dwyer JT \& Blackburn G (1997) Breast cancer: weighing the evidence for a promotion role of dietary fat. Journal of the National Cancer Institute 89, 766-775.
Yamaguchi M \& Kishi S (1993) Prolonged aministration of betaalanyl-L-histidinato zinc prevents bone loss in ovariectomized rats. Japanese Journal of Pharmacology 63, 203-207.

Yang CS, Chen L, Lee MJ, Balentine D, Kuo MC \& Schantz SP (1998) Blood and urine levels of tea catechins after ingestion of different amounts of green tea by volunteers. Cancer Epidemiology Biomarkers and Prevention 7, 351-354.

Yarborough A, Zhang YJ, Hsu TM \& Santella RM (1996) Immunoperoxidase detection of 8-hydroxydeoxyguanosine in aflatoxin B1-treated rat liver and human oral mucosal cells. Cancer Research 56, 683-688.

Yee CD, Kubena KS, Walker M, Champney TH \& Sampson HW (1995) The relationship of nutritional copper to the development of postmenopausal osteoporosis in rats. Biological Trace Element Research 48, 1-11.

Yochum L, Kushi LM, Meger K \& Folsom AR (1999) Dietary flavonoid intake and the risk of cardiovascular disease. American Journal of Epidemiology 149, 943-948.

Zhang L, Zhou W, Velculescu VE, Kern SE, Hruban RH, Hamilton SR, Vogelstein B \& Kinzler KW (1997) Gene expression profiles in normal and cancer cells. Science 276, 1268-1272.

Zhong S, Wyllie AH, Barnes D, Wolf CR \& Spurr NK (1993) Relationship between the GSTM1 genetic polymorphism and susceptibility to bladder, breast and colon cancer. Carcinogenesis 14, 1821-1824.

Zhou Y, Song C \& Chao S (1996) The level of plasma lipoprotein (a) and its correlation with other lipids in patients with hypertension and CHD. Acta Academiae Medicinae Hubei 17, 336-339. 